\title{
A mountain of millipedes I: An endemic species-group of the genus Chaleponcus Attems, 1914, from the Udzungwa Mountains, Tanzania (Diplopoda, Spirostreptida, Odontopygidae)
}

\author{
Henrik ENGHOFF \\ Natural History Museum of Denmark, University of Copenhagen, Universitetsparken 15, DK-2100 \\ København Ø, Denmark, email: henghoff@snm.ku.dk \\ urn:1sid:zoobank.org:author:FB09A817-000D-43C3-BCC4-2BC1E5373635
}

\begin{abstract}
Twenty new species of the millipede genus Chaleponcus Attems, 1914, are described from the Udzungwa Mountains: C. netus sp. nov., C. quasimodo sp. nov., C. malleolus sp. nov., C. scopus sp. nov., $C$. nikolajscharffi sp. nov., $C$. mwanihanensis sp. nov., $C$. basiliscus sp. nov., $C$. krai sp. nov., $C$. nectarinia sp. nov., C. circumvallatus sp. nov., C. ibis sp. nov., C. vandenspiegeli sp. nov., $C$. vilici $\mathrm{sp}$. nov., $C$. teres sp. nov., C. hamerae sp. nov., C. termini sp. nov., C. gracilior sp. nov., C. mwabvui sp. nov., $C$. howelli sp. nov. and $C$. tintin sp. nov. Together with $C$. dabagaensis Kraus, 1958, they constitute the Chaleponcus dabagaensis-group, well characterized by apparently apomorphic gonopodal characters, presumably monophyletic, and the first example of a major radiation within the Udzungwas. All species are restricted to altitudes $>1390 \mathrm{~m}$, all but one were found in only one, rarely two forest reserves, and the vast majority of specimens were collected in montane forest. Chaleponcus gracilior sp. nov. was collected in four forest reserves, often in secondary habitats where other species were only exceptionally found. Co-occurrence of multiple species, inter-specific differences in body size and unusual tarsal setation of a few species tentatively suggest adaptive radiation.
\end{abstract}

Keywords. Eastern Arc, species swarm, taxonomy, new species

Enghoff H. 2014. A mountain of millipedes I: An endemic species-group of the genus Chaleponcus Attems, 1914, from the Udzungwa Mountains, Tanzania (Diplopoda, Spirostreptida, Odontopygidae). European Journal of Taxonomy 100: 1-75. http://dx.doi.org/10.5852/ejt.2014.100

\section{Contents}

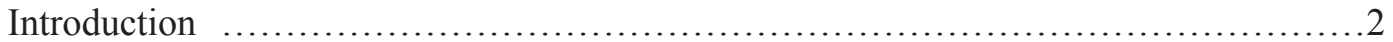

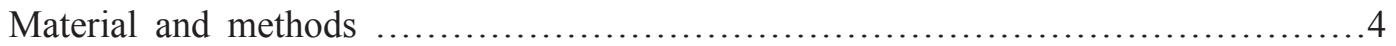

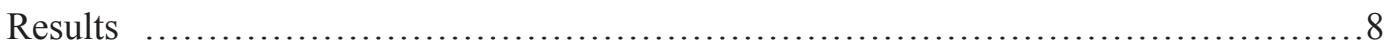

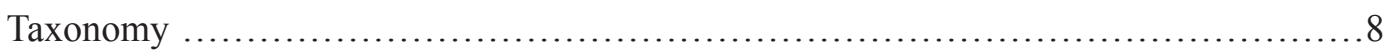

General description of the Chaleponcus dabagaensis group .......................... 10

Species in which the gonopod coxa has an obvious lateral process ................... 17

Chaleponcus netus sp. nov. ........................................................ 17

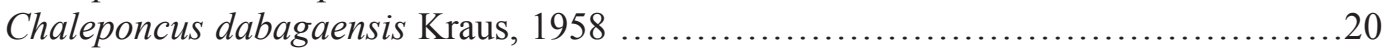

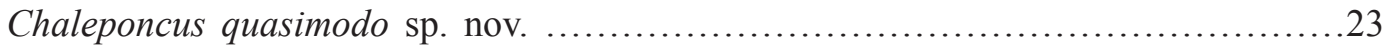




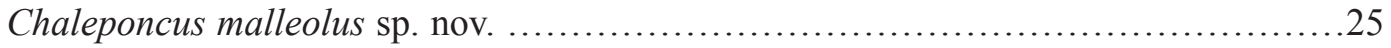

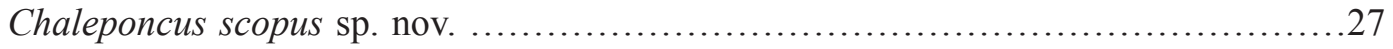

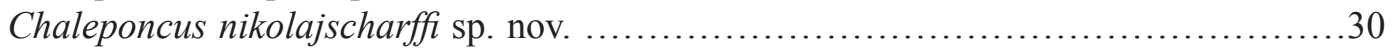

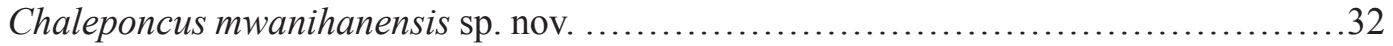

Chaleponcus basiliscus sp. nov. ............................................. 35

Species without an obvious lateral coxal process in which the metaplical shelf-spine ( $\mathrm{mss}$ )

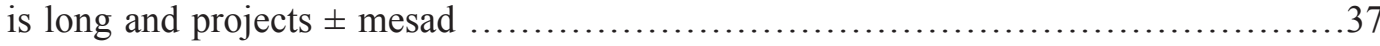

Chaleponcus krai sp. nov. .................................................... 37

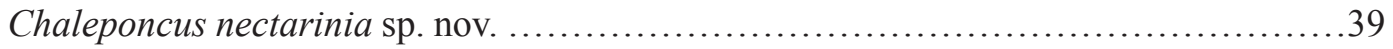

Chaleponcus circumvallatus sp. nov. .......................................... 41

Chaleponcus ibis sp. nov. ...................................................... 44

Chaleponcus vandenspiegeli sp. nov. .........................................46

Species without an obvious lateral coxal process in which the metaplical shelf-spine ( $m s s)$

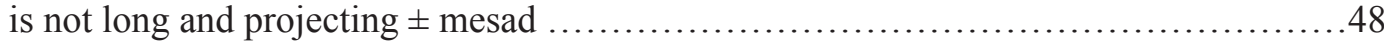

Chaleponcus vilici sp. nov. ...................................................... 48

Chaleponcus teres sp. nov. ....................................................... 51

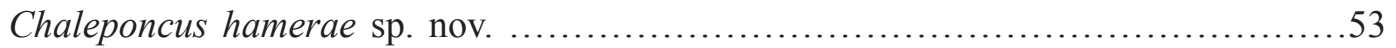

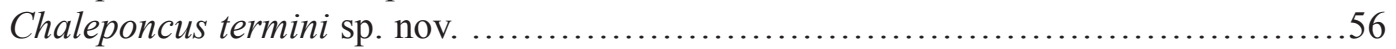

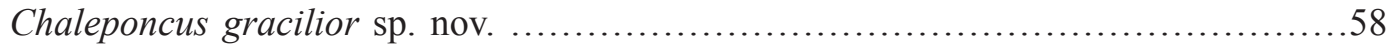

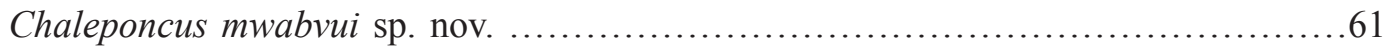

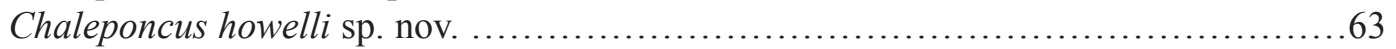

Chaleponcus tintin sp. nov. ...............................................65

Key to species of the Chaleponcus dabagaensis group .............................67

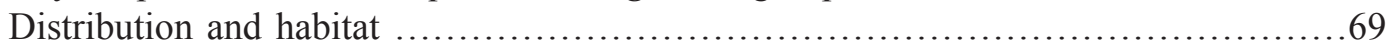

Two notes on general morphology ................................................ 70

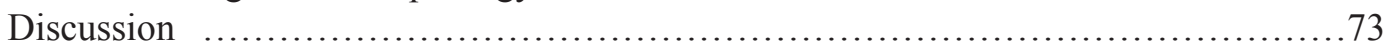

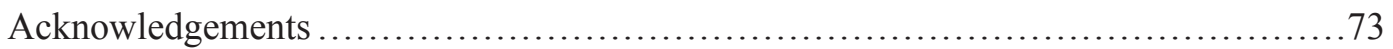

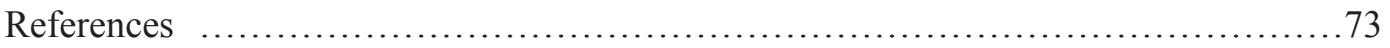

\section{Introduction}

Odontopygidae is an endemic Afrotropical family of millipedes counting around 400 described species, all but one described from the African mainland. The exception, Bandeirenica caboverdus (Pierrard, 1987) was described from the Cape Verde Islands, where it is a significant pest (Jolivet 1986, Nascimento 2012) but it has most likely been introduced from the African mainland. Odontopygidae are thus absent from Madagascar, like the two other major endemic Afrotropical millipede families, Oxydesmidae Cook, 1895 (Hoffman 1990) and Gomphodesmidae Cook, 1896 (Hoffman 2005a).

Thanks to Kraus $(1960,1966)$ it is relatively easy to get an overview of the Odontopygidae, but the family still poses major taxonomical problems; see e.g., Hoffman (1991) and Frederiksen \& Enghoff (2012). Up till now, 57 species of Odontopygidae have been described or recorded from Tanzania (Enghoff et al. in prep.), but unidentified material already present in collections suggests that this is just a small fraction of the actual number of species. The material from the Udzungwa Mts studied by me alone counts 35 species. No less than 21 of these can be referred to the genus Chaleponcus Attems, 1914. Twenty species have been described in Chaleponcus until now (Kraus 1960, 1966; Frederiksen 2013a), mainly from southern Africa north to Zimbabwe and southern Mozambique. One species, $C$. dabagaensis Kraus, 1958, was described from Tanzania but was later (Kraus 1960) excluded from the genus. It was not until very recently that Frederiksen (2013a) "reintroduced" Chaleponcus to Tanzania by describing a new species from the Pare Mts in the northern part of the country. 
Genus concepts in Odontopygidae are to a high degree less than satisfactory (Frederiksen 2013b). Add to this the fact that the identity of the type species of the type genus, Odontopyge Brandt, 1841, was relatively recently (Hoffman 1991) totally re-interpreted, resulting in a complete nomenclatural remix and leaving a considerable number of species described in Odontopyge without a valid generic affiliation. Luckily, Chaleponcus was not affected by this.

The present contribution is a taxonomic treatment of the 21 species of Chaleponcus so far collected in the Udzungwa Mountains in southern Tanzania. The Udzungwa Mountains are part of the Eastern Arc Mountains, which in turn constitute one among 25 biodiversity hotspots regarded as crucial for conservation of biodiversity on a global scale (Myers et al. 2000); see also Burgess et al. (2007).

The Udzungwa Mountains, situated at $7^{\circ} 22^{\prime} \mathrm{S}$ to $8^{\circ} 38^{\prime} \mathrm{S}$ and $35^{\circ} 07^{\prime} \mathrm{E}$ to $36^{\circ} 58^{\prime} \mathrm{E}$ (Fig. 1) and covering more than $16,000 \mathrm{~km}^{2}$, is by far the largest among the eastern Arc mountain blocks. More than $1300 \mathrm{~km}^{2}$ forest remains, spanning altitudes from 300 to $2580 \mathrm{~m}$ asl. The Udzungwas harbour an extremely rich endemic fauna including 17 vertebrate species (Burgess et al. 2007).

There are several forest reserves in the Udzungwa Mts. Fig. 1 shows the location of those forest reserves (henceforward abbreviated FR) from which material for the present paper has been collected.

Several millipede species have been reported from the Udzungwa Mountains (Enghoff 2011a; Enghoff et al. in prep.; Hoffman 1990, 2005a, 2005b; Hoffman \& Howell 1985, 1996; Kraus 1958). Almost

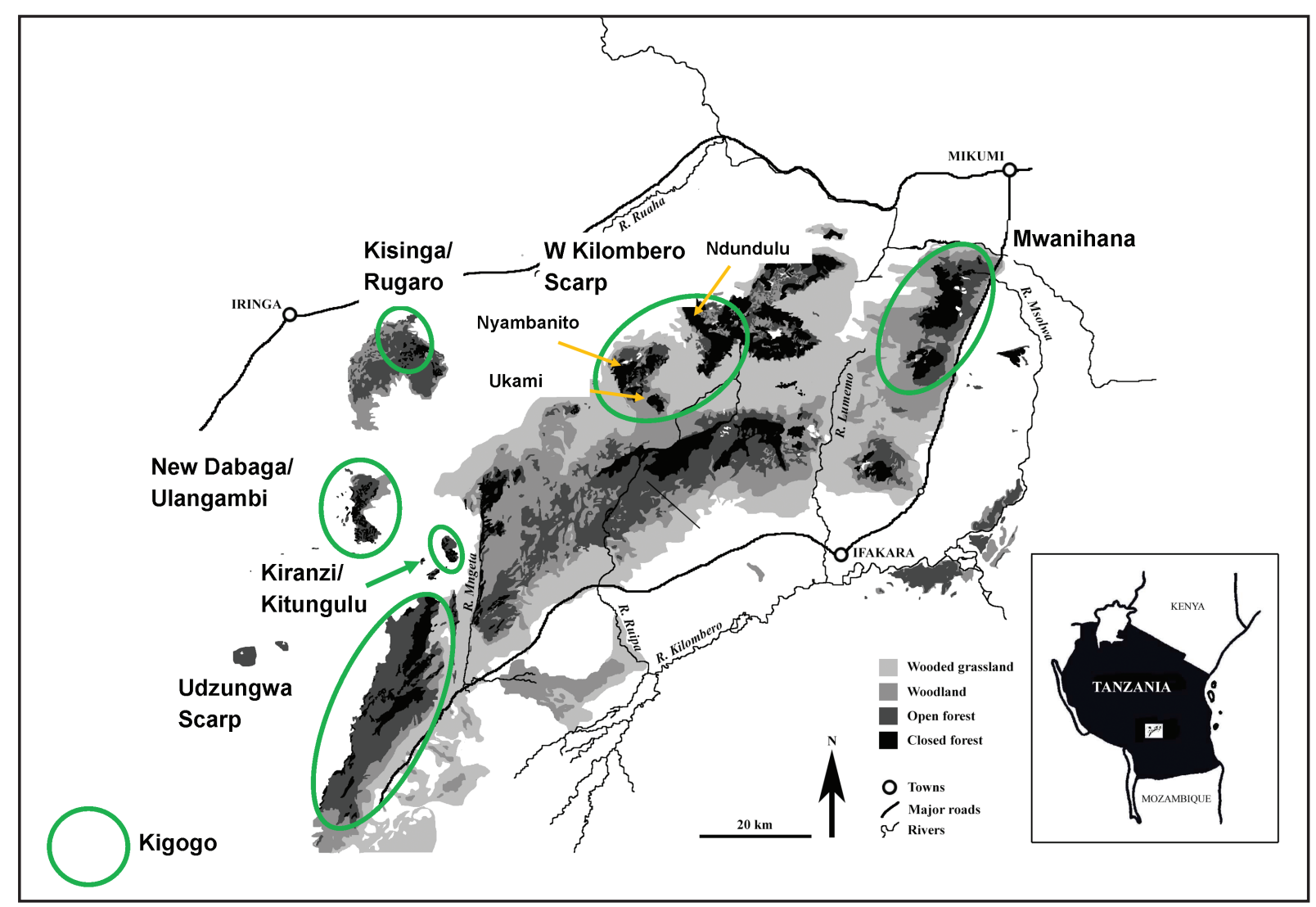

Fig. 1. Map of the Udzungwa Mountains, showing the location of the forest reserves (green rings) where the material studied here was collected, as well as names of individual mountains in West Kilombero FR. Based on fig. 1 in Marshall et al. (2010). 
all of these are as far as known endemic to the Udzungwas. The only odontopygid recorded from the Udzungwas so far is the abovementioned Chaleponcus dabagaensis.

Marshall et al. (2001a, 2001b) analysed the millipede fauna of West Kilombero Scarp FR and New Dabaga/Ulangambi FR, respectively, based on very large collections made by Frontier Tanzania which were sorted into unnamed morphospecies. Marshall et al. (2001b) recognized 38 morphospecies of millipedes from West Kilombero Scarp FR and 13 from New Dabaga/Ulangambi FR, but this is almost certainly an underestimate of the actual number of species present in the analysed material. For example, I regard it likely that most of the six Chaleponcus species described here from West Kilombero Scarp FR would have been lumped as just one morphospecies, and similarly for most of the 11 Chaleponcus species described here from New Dabaga/Ulangambi FR.

\section{Material and methods}

The vast majority of material for this paper comes from the zoological collections of the Natural History Museum of Denmark, University of Copenhagen (ZMUC). Much of the material was collected during several field trips to the Udzungwa Mts by ZMUC staff, but a very substantial part of it was collected by the NGO Frontier Tanzania (http://www.frontiergap.com/About-Us/Background-Mission.aspx) and was subsequently deposited in ZMUC. Smaller collections of odontopygids from the Udzungwas were obtained from the Virginia Museum of Natural History (VMNH), where a very large collection of Tanzanian millipedes was accumulated by the late Richard L. Hoffman, and from Museo di Storia naturale - Zoologia 'La Specola', Firenze (MZF).

Marshall et al. (2001a) described how the material from West Kilombero FR was collected: "Grounddwelling millipedes were primarily sampled by timed searching of $3 \mathrm{~m} \times 3 \mathrm{~m}$ quadrats. ... The leaf litter and topsoil within quadrats was searched thoroughly by hand for a total of eight person hours per quadrat at all trapsites. In addition, the general proximity of all trapsites was searched for two person hours. During such searches, particular attention was paid to rotting logs, the underside of rocks and other such microhabitats, which may have been missed by the quadrat samples." The collecting procedure in New Dabaga/Ulangambi FR was the same (Marshall et al. 2001b). A. Marshall (pers. comm.) has further informed me that during these campaigns the collectors had to dig down to around $15 \mathrm{~cm}$ to find millipedes after initially fruitless searches in the topsoil alone.

A total of 460 male specimens were examined. All samples are kept in $70 \%$ alcohol, and the colours of almost all specimens are quite bleached.

Specimens were examined in alcohol under a stereo microscope. Specimens for scanning electron microscopy (SEM) were transferred to $96 \%$ ethanol, then to acetone, air-dried, mounted on aluminium stubs or on triangles of flexible aluminium tape and in turn mounted on stubs, coated with platinum/ palladium and studied in a JEOL JSM-6335F scanning electron microscope.

\section{Descriptions}

In the light of the very large material at hand, of the uniformity of odontopygid millipede non-gonopod morphology, and of the virtual impossibility of identifying females, only adult males are considered, and the descriptions of non-gonopod morphology are kept to a minimum. The following information is included:

- numbers of body rings (excluding telson)

- midbody diameter

- colour pattern when discernible

- limbus structure

- shape of anal valves

- setation of walking leg tarsi 
The subheading "Distribution and habitat" summarises the label information. Altitudinal ranges are given as the 'maximal' range although the actual range may be narrower. For example, the studied samples of C. nectarinia sp. nov. were collected at $1955 \mathrm{~m}$ asl, $1945 \mathrm{~m}$ asl, $1940 \mathrm{~m}$ asl and 1930-1950 m asl. The altitudinal range for this species is given as $1930-1955 \mathrm{~m}$ asl, although the specimens labelled "1930-1955 m asl" may have been collected within the range specified by the exact altitudes given for the other samples. It should be noted that the 'maximal' range given neglects a possible disjunct altitudinal distribution. For example, for C. netus sp. nov. the 'maximal' altitudinal range 1390-1955 m asl is given, but the samples are grouped in two ranges, viz., $1390-1410 \mathrm{~m}$ asl and 1800-1963 $\mathrm{m}$ asl.

Under the subheading "Coexisting species", species found in the same samples as the species under consideration, as well as additional species found in the same forest reserve, are listed; see also Table 1. This information should be read keeping in mind that sampling was not at all standardized, and that a sample may contain from one to 61 Chaleponcus males.

\section{Gonopod terminology}

The terminology introduced by Frederiksen (2013a,b; Frederiksen \& Enghoff 2012) is used. This terminology largely refrains from attempting to homologize parts of the gonopod telopodite with individual podomeres (femur, tibia, tarsus ...) as was done by previous authors working on the group, notably Kraus $(1960,1966)$.

\section{Positional/directional terms:}

Basal refers to a position on the side nearest to the gonopod sternum. Basad means "directed towards the sternum". Morphologically this refers to "dorsal" and "dorsad", but since gonopods are traditionally depicted upside down, basal and basad are preferred.

Apical refers to a position farthest away from the gonopod sternum. Apicad means "directed away from the sternum". Morphologically this refers to "ventral" and "ventrad", but since gonopods are traditionally depicted upside down, apical and apicad are preferred.

Distal refers to a position at or near the tip of the gonopod coxa, solenomere or telomere. Distad refers to the corresponding directions. The antitheses are proximal and proximad.

\section{Anatomical terms}

The gonopod coxa consists of a longitudinally folded lamella with the free margins projecting mesad. The anterior lamella is called proplica, the posterior lamella, metaplica. In Chaleponcus, proplica and metaplica come together apically and form a hoodlike cucullus. See Fig. 7.

The gonopod telopodite consists of three main parts: basomere, solenomere and telomere. The basomere starts as a straight rod, located in the cavity formed by the coxal pro- and metaplica. It then bends mesad; the bend is termed arculus and is effectuated by a $1 \frac{1}{2}$ turn spiralling of the basomere whereby the spiral loops are displaced mesad (somewhat like a high-spired snail shell). The part of the basomere involved in the $1 \frac{1}{2}$ turn is called the torsotope. The actual right-angle bend takes place after the torsotope when the basomere is "on its way down" (basad) but then bends mesad at right angles and becomes narrower (posttorsal narrowing sensu Frederiksen 2013b). In the terminology of Kraus (1966), the part of the basomere before the 'actual' bend is the prefemur, the posttorsal narrowing is the femur. After the posttorsal narrowing the telopodite is divided into solenomere and basomere. The 'postfemoral' part sensu Kraus (1966) is not well-defined. The start of the solenomere can be difficult to define, but the fine suture running along the solenomere (visible, e.g., on Fig 28B) helps to identify it. See Figs 8 and 10. 
Table 1. Coexistence of Chaleponcus species in the Udzungwa Mts. For each species, coexisting species at two levels are listed: species found in the same samples and additional species found in the same forest reserve. Abbreviations: $\mathrm{FR}=$ forest reserve, $\mathrm{KIG}=$ Kigogo, $\mathrm{KK}=$ Kiranzi/Kitunguli, $\mathrm{KR}=$ Kisinga/ Rugaro, MWA $=$ Mwanihana, NDU $=$ New Dabaga/Ulangambi, US $=$ Udzungwa Scarp, WKS $=$ West Kilombero Scarp.

\begin{tabular}{|c|c|c|c|}
\hline FR & species & in same samples & further species in same FR \\
\hline NDU, WKS & netus & $\begin{array}{l}\text { NDU: dabagaensis, gracilior, } \\
\text { malleolus, mwabvui, nectarinia, } \\
\text { termini, vandenspiegeli, vilici } \\
\text { WKS: circumvallatus }\end{array}$ & $\begin{array}{l}\text { NDU: krai, teres } \\
\text { WKS: basiliscus, gracilior, ibis, } \\
\text { tintin }\end{array}$ \\
\hline $\mathrm{KK}, \mathrm{NDU}$ & dabagaensis & $\begin{array}{l}\text { KK: gracilior } \\
\text { NDU: gracilior, mwabvui, netus, } \\
\text { termini }\end{array}$ & $\begin{array}{l}\text { KK: - } \\
\text { NDU: krai, malleolus, nectarinia, } \\
\text { teres, vandenspiegeli, vilici }\end{array}$ \\
\hline KIG & quasimodo & howelli, mwabvui, scopus & - \\
\hline NDU & malleolus & gracilior, nectarinia, netus, vilici & $\begin{array}{l}\text { dabagaensis, krai, mwabvui, teres, } \\
\text { termini, vandenspiegeli }\end{array}$ \\
\hline KIG & scopus & howelli, mwabvui, quasimodo & - \\
\hline US & nikolajscharffi & hamerae & circumvallatus \\
\hline MWA & mwanihanensis & - & - \\
\hline WKS & basiliscus & ibis & $\begin{array}{l}\text { circumvallatus, gracilior, netus, } \\
\text { tintin }\end{array}$ \\
\hline KR, NDU & krai & $\begin{array}{l}\text { KR: - } \\
\text { NDU: gracilior }\end{array}$ & $\begin{array}{l}\text { KR: gracilior } \\
\text { NDU: - }\end{array}$ \\
\hline $\mathrm{NDU}$ & nectarinia & $\begin{array}{l}\text { malleolus, netus, teres, termini, } \\
\text { vilici }\end{array}$ & $\begin{array}{l}\text { dabagaensis, gracilior, krai, } \\
\text { mwabvui, vandenspiegeli }\end{array}$ \\
\hline US, WKS & circumvallatus & $\begin{array}{l}\text { US: - } \\
\text { WKS: netus }\end{array}$ & $\begin{array}{l}\text { US: hamerae, nikolajscharffi } \\
\text { WKS: basiliscus, gracilior, ibis, } \\
\text { tintin }\end{array}$ \\
\hline WKS & ibis & basiliscus & $\begin{array}{l}\text { circumvallatus, gracilior, netus, } \\
\text { tintin }\end{array}$ \\
\hline NDU & vandenspiegeli & gracilior, netus, termini & $\begin{array}{l}\text { dabagaensis, krai, malleolus, } \\
\text { mwabvui, nectarinia, teres, vilici }\end{array}$ \\
\hline NDU & vilici & $\begin{array}{l}\text { gracilior, malleolus, nectarinia, } \\
\text { netus, teres, termini }\end{array}$ & $\begin{array}{l}\text { dabagaensis, krai, mwabvui, } \\
\text { vandenspiegeli }\end{array}$ \\
\hline NDU & teres & termini, vilici & $\begin{array}{l}\text { dabagaensis, gracilior, krai, } \\
\text { malleolus, mwabvui, nectarinia, } \\
\text { netus, vandenspiegeli }\end{array}$ \\
\hline US & hamerae & nikolajscharffi & circumvallatus \\
\hline NDU & termini & $\begin{array}{l}\text { gracilior, mwabvui, nectarinia, } \\
\text { netus, teres, vilici }\end{array}$ & $\begin{array}{l}\text { dabagaensis, krai, malleolus, } \\
\text { vandenspiegeli }\end{array}$ \\
\hline $\begin{array}{l}\text { KK, KR, } \\
\text { NDU, WKS }\end{array}$ & gracilior & $\begin{array}{l}\text { KK: dabagaensis } \\
\text { KR: - } \\
\text { NDU: dabagaensis, krai, } \\
\text { malleolus, mwabvui, netus, } \\
\text { termini, vilici } \\
\text { WKS: - }\end{array}$ & $\begin{array}{l}\text { KK: - } \\
\text { KR: krai } \\
\text { NDU: nectarinia, teres, } \\
\text { vandenspiegeli } \\
\text { WKS: basiliscus, circumvallatus, } \\
\text { ibis, netus, tintin }\end{array}$ \\
\hline KIG, NDU & mwabvui & $\begin{array}{l}\text { KIG: howelli, quasimodo, scopus } \\
\text { NDU: dabagaensis, gracilior, } \\
\text { netus, termini }\end{array}$ & $\begin{array}{l}\text { KIG: - } \\
\text { NDU: krai, malleolus, nectarinia, } \\
\text { teres, vandenspiegeli, vilici }\end{array}$ \\
\hline $\mathrm{KIG}$ & howelli & mwabvui, quasimodo, scopus & - \\
\hline WKS & tintin & - & $\begin{array}{l}\text { basiliscus, circumvallatus, } \\
\text { gracilior, ibis, netus }\end{array}$ \\
\hline
\end{tabular}




\section{Abbreviations for morphological terms used in descriptions and on illustrations}

Accessory structures may be indicated with ' or with numbers.

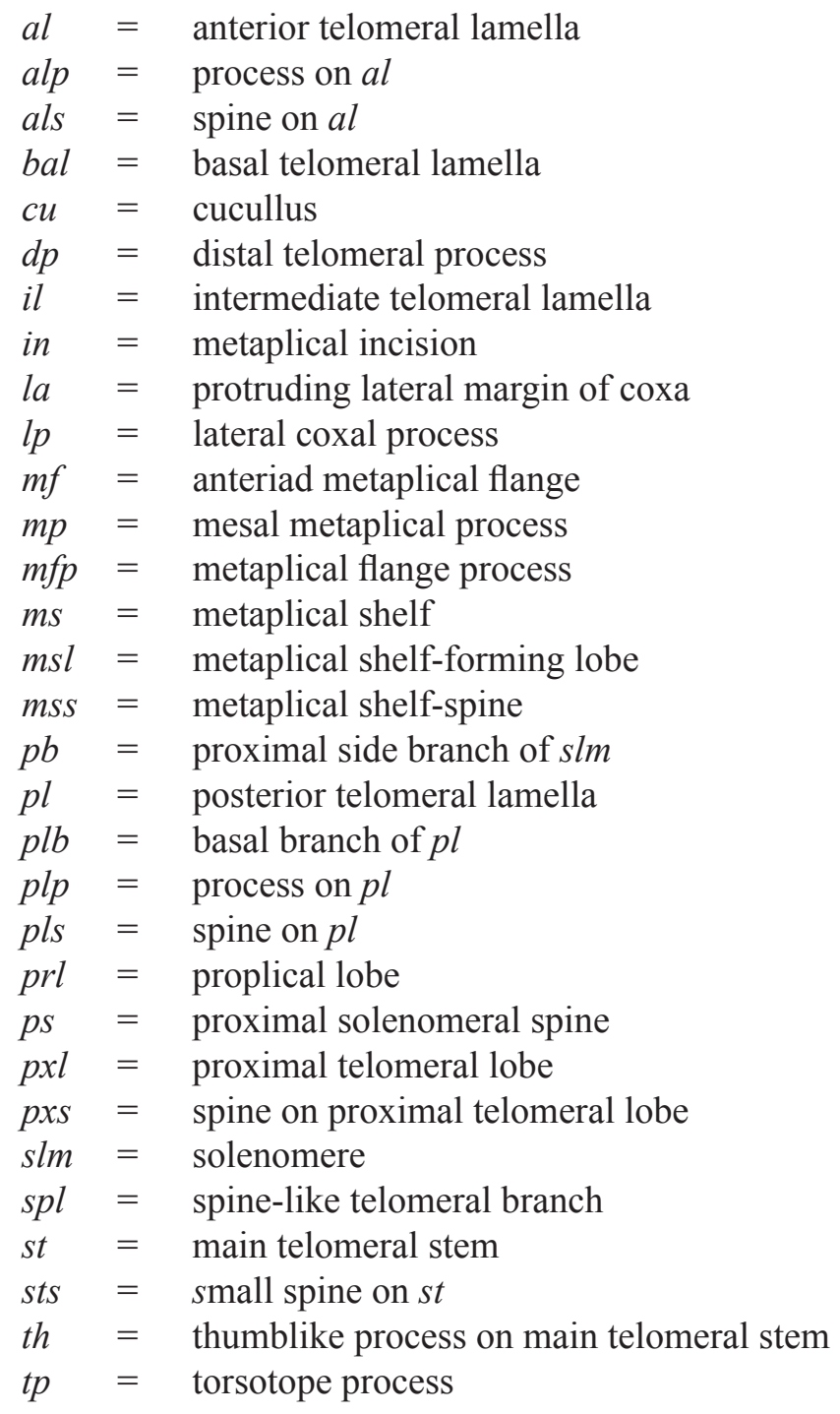

Abbreviations used in the text, other than abbreviations for morphological terms

asl $\quad=$ above sea level

$\mathrm{FR} \quad=$ Forest Reserve

$\mathrm{MZF}=$ Zoological Museum, Firenze

$\mathrm{VMNH}=$ Virginia Museum of Natural History

ZMUC = Natural History Museum of Denmark (Zoological Museum) 


\title{
Results
}

\section{Taxonomy}

\author{
Class Diplopoda Blainville-Gervais, 1844 \\ Order Spirostreptida Brandt, 1833 \\ Family Odontopygidae Attems, 1909 \\ Subfamily Archepyginae Manfredi, 1939
}

The taxon Archepyginae corresponds to Odontopyginae sensu Kraus (1960, 1966), see Hoffman (1991), and includes those odontopygid genera in which the gonopod telopodite has a flexible, mostly spiralled zone (torsotope sensu Hoffman 2008) followed by a delimited, usually narrower zone ("Femur" sensu Kraus 1960, 1968).

Tribe Prionopetalini Hoffman, 1991

This taxon was introduced as a replacement name for Odontopygini sensu Hoffman (1980) and includes those archepygine genera in which the solenomere is long and thin, as opposed to the genera placed by Hoffman $(1980,1991)$ in the tribe Ctenoiulini.

Genus Chaleponcus Attems, 1914

This genus was established by Attems (1914) for three new species, of which C. limbatus Attems, 1914, was subsequently designated as type species by Kraus (1960).

Chaleponcus was treated in detail by Kraus $(1960,1966)$ and was recently addressed by Frederiksen (2013a). Vohland \& Hamer (2013) redescribed two Chaleponcus species from Namibia. From the works of these authors the following diagnosis of Chaleponcus can be extracted, based entirely on gonopod structure, using the terminology suggested by Frederiksen (2013a,b; Frederiksen \& Enghoff 2012) and emended in light of the species described here:

Prionopetalini in which

- the proplica and metaplica of the gonopod coxa come together apically and form a hoodlike structure, here termed cucullus

- the solenomere is very long, whiplike, at least twice as long as the telomere if stretched out, not spiralled terminally, and without accessory branches or outgrowths (except for sometimes at the very base, corresponding to the "Tibialdorn" of Kraus; see species descriptions)

- the telomere is proximally folded like a tube or a trough and distally separates into two or three diverging lamellae

Kraus $(1960,1966)$ included 19 species in Chaleponcus, distributed in southern African as far north as Zimbabwe and southern Mozambique, and Frederiksen (2013a) added a $20^{\text {th }}$ species from northern Tanzania. Kraus $(1960,1966)$ did not include Chaleponcus dabagaensis Kraus, 1958, described from the Udzungwa Mts (not W Usambaras as stated by Frederiksen 2013a); this species Kraus (1960) excluded from the genus and tentatively assigned to another predominantly S African genus, Spinotarsus Attems, 1909. In fact, he described the species as Chaleponcus (Storthoporus) dabagaensis, and as he (1960) listed Storthoporus Attems, 1928, as a synonym of Spinotarsus, the transfer seemed logical. However, C. dabagaensis lacks most characteristics of Spinotarsus, including a spiny proximal lamella on the telomere and the strongly sclerotized lamella ("Bogenlamelle") on the posterior surface of the telomere. C. dabagaensis does have a trait seen in many Spinotarsus species, viz., the longitudinally fluted solenomere; this is a character not seen in other previously described Chaleponcus species but found in most of the species described here. C. dabagaensis also has the spine-bearing shelf, see below, 
and without doubt belongs together with the other Udzungwan species treated in the present paper. I here reallocate it back to Chaleponcus.

The Udzungwa species described here and referred to Chaleponcus differ from their congeners in one conspicuous character, the spine-bearing 'shelf' on the gonopodal coxal metaplica. Many odontopygids have spines in various positions on the gonopod coxa, including the subdistal position on the metaplica where the spine-bearing shelf is situated in the Udzungwan species. This is, e.g., true for Chaleponcus parensis Frederiksen, 2013, Prionopetalum bifidum VandenSpiegel \& Pierrard, 2009, Patinatius attemsi Kraus, 1960, P. bidentatus Kraus, 1960, Spinotarsus viridis Kraus, 1966, Allantogonus spp. (Kraus 1960, Attems 1935), Kompsoprium spp. (Kraus 1960, Attems 1935) and Odontopygista natalica Kraus, 1960. In all these species except one, however, the spine is not associated with a shelflike structure and are most likely not homologous with the 'shelf-borne' spine in the Udzungwan species. The exception is Spinotarsus viridis, where the spine does seem to originate from a horizontal shelf (Kraus 1966: fig. 350); in other characters, however, S. viridis is a typical Spinotarsus.

Based on the probably autapomorphic spine-bearing shelf and the longitudinally fluted solenomere, a species group can be defined for the Udzungwan species of Chaleponcus. Following tradition, the group is named after the first described species in the group and hence will be named the Chaleponcus dabagaensis group.

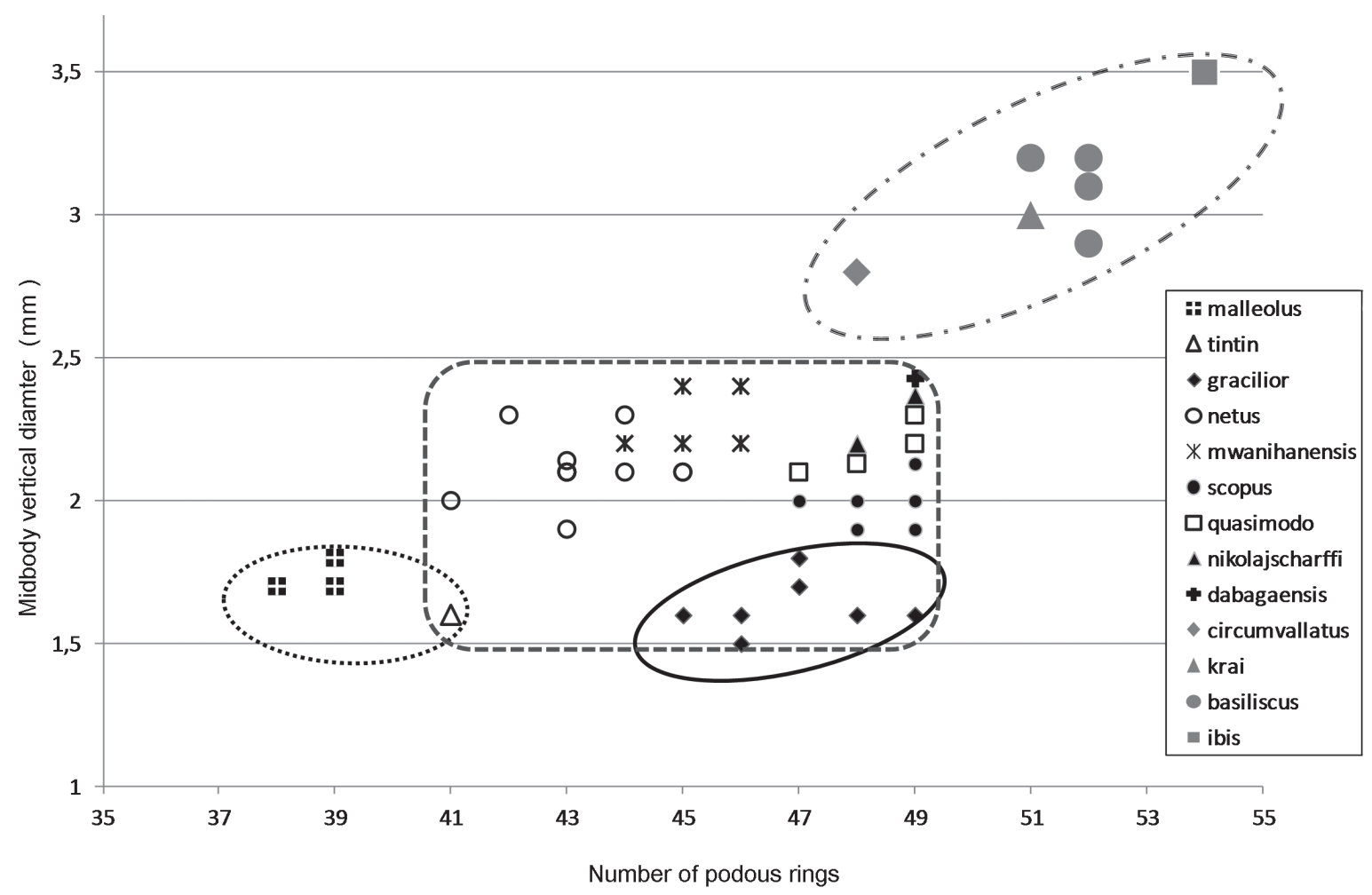

Fig. 2. Body size of males of 13 species of the Chaleponcus dabagaensis group: Number of podous rings and vertical midbody diameter in large, small and 'long, thin' species (cf. text), as well as medium sized species in which the gonopod coxa has an obvious lateral process. 


\section{General description of the Chaleponcus dabagaensis group}

This description only applies to males and, as far as non-gonopodal characters are concerned, only includes a selection ( $c f$. above).

\section{Non-gonopodal characters}

Body LeNGTH. $c a$. 2-5 cm. Midbody vertical diameter $1.6-3.5 \mathrm{~mm} .38-54$ podous rings, no apodous rings in front of telson. The 21 species may conveniently be divided into four size groups ( $c f$. Figs 2-3):

- Large species, diameter 2.8-3.5 mm, 48-54 podous rings: C. basiliscus sp. nov., C. circumvallatus sp. nov., $C$. ibis sp. nov., $C$. krai sp. nov.

- Medium-sized species, diameter 1.6-2.4 mm, 41-49 podous rings: $C$. dabagaensis, $C$. hamerae sp. nov., C. howelli sp. nov., C. mwabvui sp. nov., C. mwanihanensis sp. nov., C. nectarinia sp. nov., C. netus sp. nov., C. nikolajscharffi sp. nov., C. quasimodo sp. nov., C. scopus sp. nov., C. teres sp. nov., $C$. termini sp. nov., $C$. vandenspiegeli sp. nov., $C$. vilici sp. nov.

- Small species, diameter 1.6-1.8 mm, 38-41 podous rings: $C$. malleolus sp. nov., $C$. tintin sp. nov.

- 'Long, thin species', diameter $1.5-1.8 \mathrm{~mm}, 45-49$ podous rings: C. gracilior sp. nov.

Colour. Bleached in most studied specimens, but a pale middorsal longitudinal band is often discernible.

LimBus (examined on the dorsal side of midbody rings). Lobulate to serrate. Lobes often triangular and pointed, but sometimes rounded or spatulate, sometimes very shallow, rarely virtually absent, often longitudinally striolate, sometimes apically denticulate. See Fig. 4.

ClaWS OF WALKING LEGS. With a long (> claw proper) accessory claw. Tip of tarsus usually with a moderate number of strong setae ("normal setation"), but in two species, C. circumvallatus sp. nov. and C. ibis sp. nov., with a dense whorl of stout setae surrounding the claw like a palisade. See Fig. 5.

TELSON. Preanal ring with wrinkled/coriaceous sculpture dorsally. Anal valves with wrinkled/coriaceous sculpture, except along caudal and ventral margins; in almost all species each with a dorsal denticle of variable size, and often also with a smaller ventral denticle; denticles when present well set off from rest

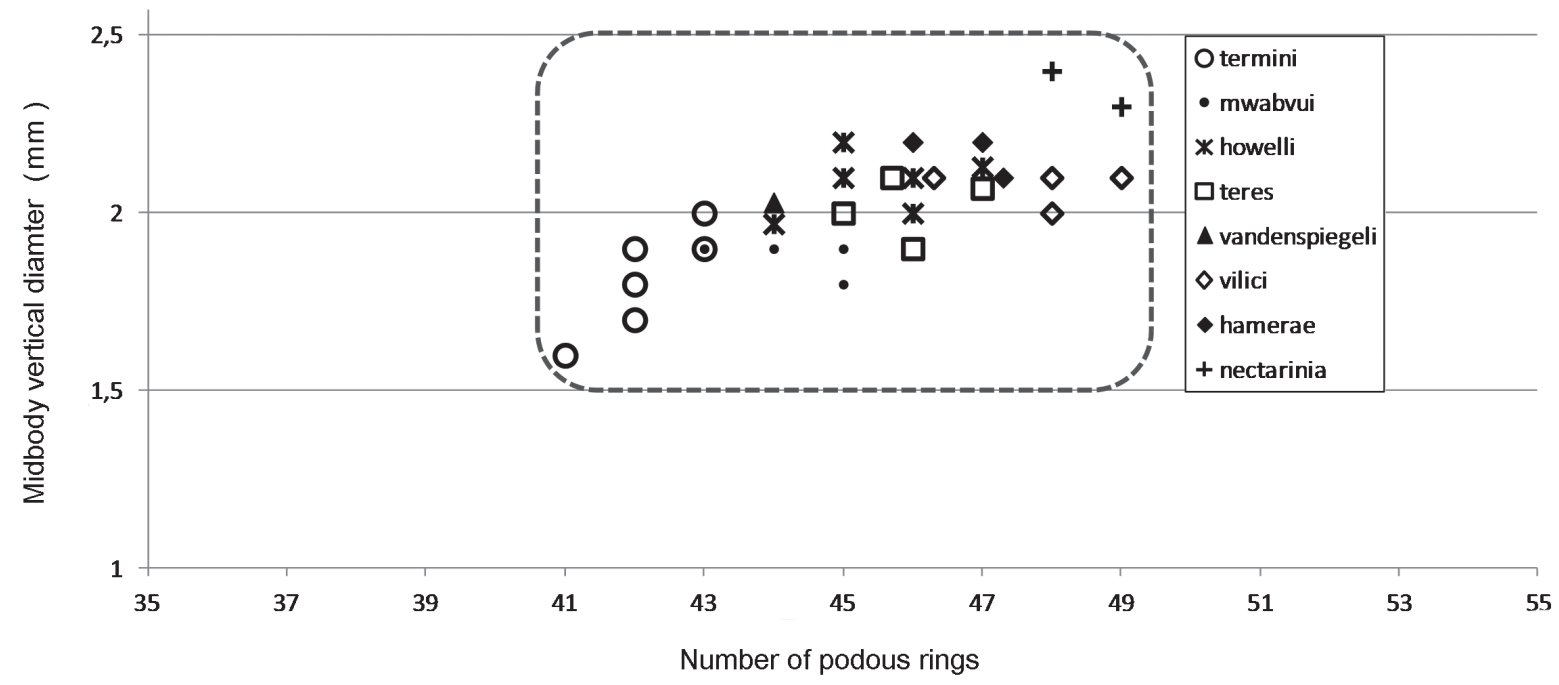

Fig. 3. Body size of males of 8 species of the Chaleponcus dabagaensis group: Number of podous rings and vertical midbody diameter in medium-sized species in which the gonopod coxa has no obvious lateral process. 
of valve rather than just being "sharp corners" (compare Fig. 6A-C, with fig. 3 in Frederiksen 2013b). Each valve with three setae. Free margin ('lip') of anal valves raised in most species and provided with three small extensions ('ravelins') on which the setae are borne. These setiferous tubercles not protruding in lateral view. See Fig. 6.

BoDY RING 7. Body ring 7 of males modified, with posterior shallow concavities for accommodation of gonopods. The detailed shape of the concavities varies among species, in parallel with variations of gonopod shape, but this has not been studied in detail here.

\section{Gonopods}

Coxa (Fig. 7). In anterior or posterior view $3-4 \times$ as long as broad. Free margin of proplica straight, shallowly concave or shallowly sinuous from base to proplical lobe $(\mathrm{prl})$ at $c a .2 / 3$ of the length of the proplica. Metaplica basally with an anteriad flange $(\mathrm{mf})$ usually ending in a blunt or triangular process $(m f p)$. Free margin of metaplica variable, but at $c a .2 / 3$ of its length, the metaplica carries a metaplical shelf $(\mathrm{ms})$ on which a metaplical shelf-spine ( $\mathrm{mss}$ ) is inserted. Distal to $\mathrm{prl}$ and $\mathrm{ms}$, proplica and metaplica join to form an apical 'hood', the cucullus (cu). The cucullus may take many different shapes and together with the metaplical shelf-spine defines the general 'profile' of the gonopod coxa which is often species-specific (Fig. 9).

Telopodite (Figs 8, 10). Basomere including torsotope without spines, arculus $90^{\circ}$. First full $\left(360^{\circ}\right)$ turn of torsotope very tight, leaving no space inside the spiral, but last half $\left(180^{\circ}\right)$ turn, a more open spiral, leaving room for a triangular to semicircular torsotope process $(t p)$ on the basal side of the spiral ( $t p$ was described for C. dabagaensis by Kraus (1958) as a blunt peg in the position corresponding to that of a femoral spine: "Kein Femoraldorn, auf der Vorderseite jedoch an dessen Stelle ein stumpfer Zapfen"). The torsion of the torsotope begins with an anteriad bend. Posttorsal narrowing unremarkable, not very pronounced.

SOLENOMERE ( $\mathrm{slm}$ ). Solenomore originating on apical side of telopodite, just after posttorsal narrowing, whiplike, taeniate, irregularly curving in specimens prepared for SEM, longitudinally fluted (sometimes indistinctly) and sometimes also with tiny retrorse spines in distal part. A slender proximal spine ( $p s)$ often originating from base of solenomere, sometimes accompanied by a small \pm lamellar outgrowth and/or a second small spine.

TeLOMERE. Telomore highly variable, originating on basal side of telopodite, just after posttorsal narrowing, starting with a proximal lobe ( $p x l)$ lying closely against posterior base of $s l m$. Telomere continuing distally to $p x l$ in simple, large main stem ( $s t$ ), anterior margin of $s t$ forming shallow lobe $\left(s t^{\prime}\right)$ lying closely against proximal part of $s l m$. Distal part of telomere very complicated, consisting of several lamellar parts; two or three lamellae can be distinguished, but these may each have accessory lamellae, carry variously shaped spines and have more or less serrated margins. I have been unable to homologize the various lamellae etc. of the telomere between species; thus, what is called anterior lamella in one species may be homologous with what it called posterior lamella in another. For example, the very characteristic anterior lamella in $C$. krai sp. nov. is remarkably similar to the posterior lamella in C. nectarinia sp. nov., but whether these two structures are homologous, or whether different parts of the telomere have evolved convergently to serve similar needs, remains unclear.

\section{Included species (alphabetically)}

Chaleponcus basiliscus sp. nov., C. circumvallatus sp. nov., C. dabagaensis Kraus, 1958, C. gracilior sp. nov., C. hamerae sp. nov., C. howelli sp. nov., C. ibis sp. nov., C. krai sp. nov., C. malleolus sp. nov., C. mwabvui sp. nov., C. mwanihanensis sp. nov., $C$. nectarinia sp. nov., C. netus sp. nov., $C$. 
nikolajscharffi sp. nov., C. quasimodo sp. nov., C. scopus sp. nov., C. teres sp. nov., C. termini sp. nov., C. tintin sp. nov., C. vandenspiegeli sp. nov., C. vilici sp. nov.
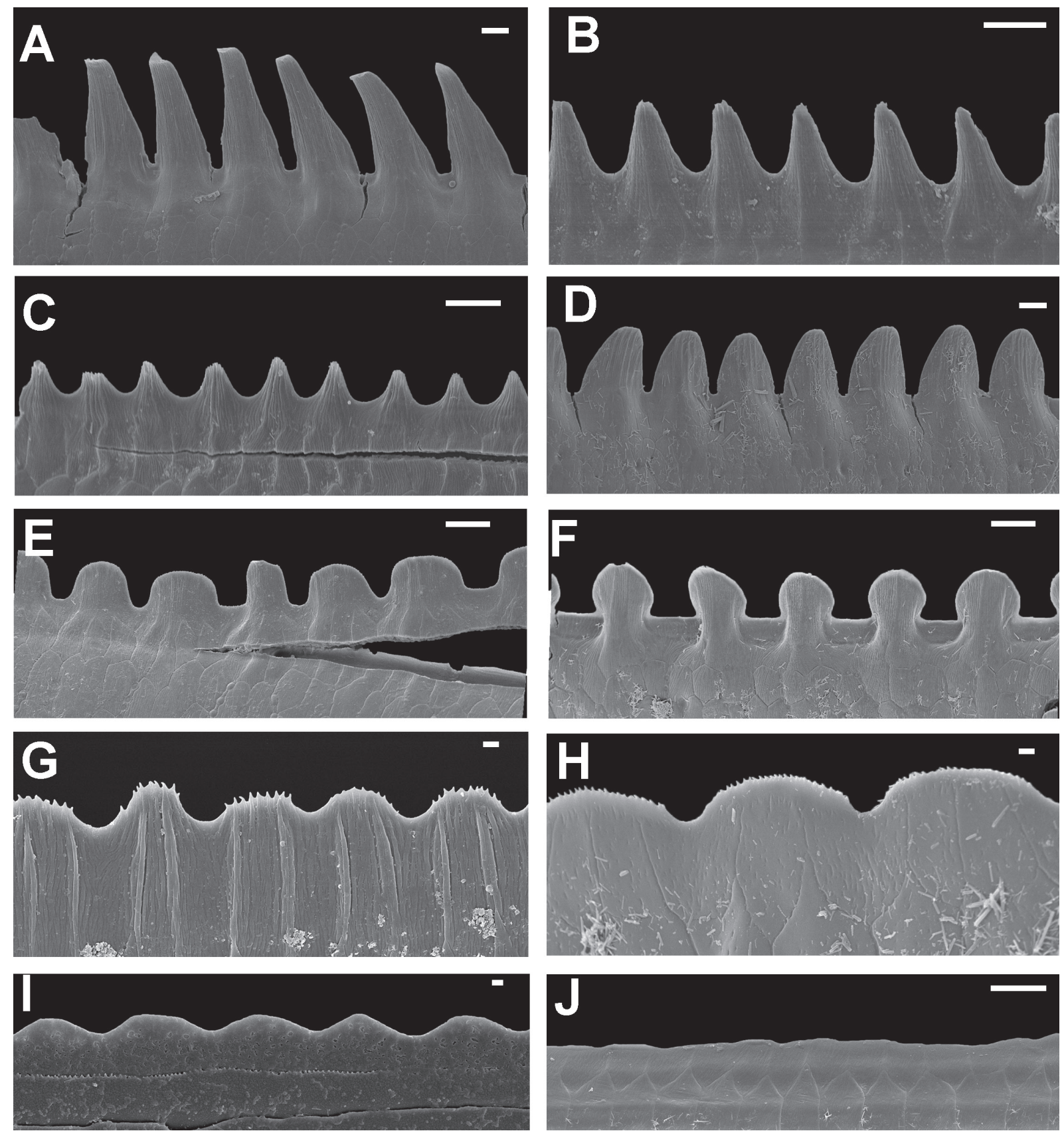

Fig. 4. Limbus types in Chaleponcus species, SEM micrographs, external view, except I: internal view. - A. Lobes pointed, more than twice as long as broad (C. scopus sp. nov.). B. Lobes pointed, slightly less than twice as long as broad (C. howelli sp. nov.). C. Lobes pointed, almost equilateral triangles $(C$. netus sp. nov.), D. Lobes rounded, slightly longer than broad (C. dabagaensis Kraus, 1958). E. Lobes broadly rounded, slightly shorter than broad $(C$. hamerae sp. nov.). F. Lobes spatulate $(C$. gracilior $\mathrm{sp}$. nov.). G. Lobes rounded, broader than long, spinose, ridged (C. krai sp. nov.). H. Lobes ca. 3 times as broad as high, rounded, spinose (C. teres sp. nov.). I. Lobes rounded, much broader than high, smooth $(C$. malleolus sp. nov.). J. No lobes (C. circumvallatus sp. nov.). Scales: $0.01 \mathrm{~mm}(\mathrm{~A}-\mathrm{F}, \mathrm{J}), 0.001 \mathrm{~mm}(\mathrm{G}-\mathrm{I})$. 

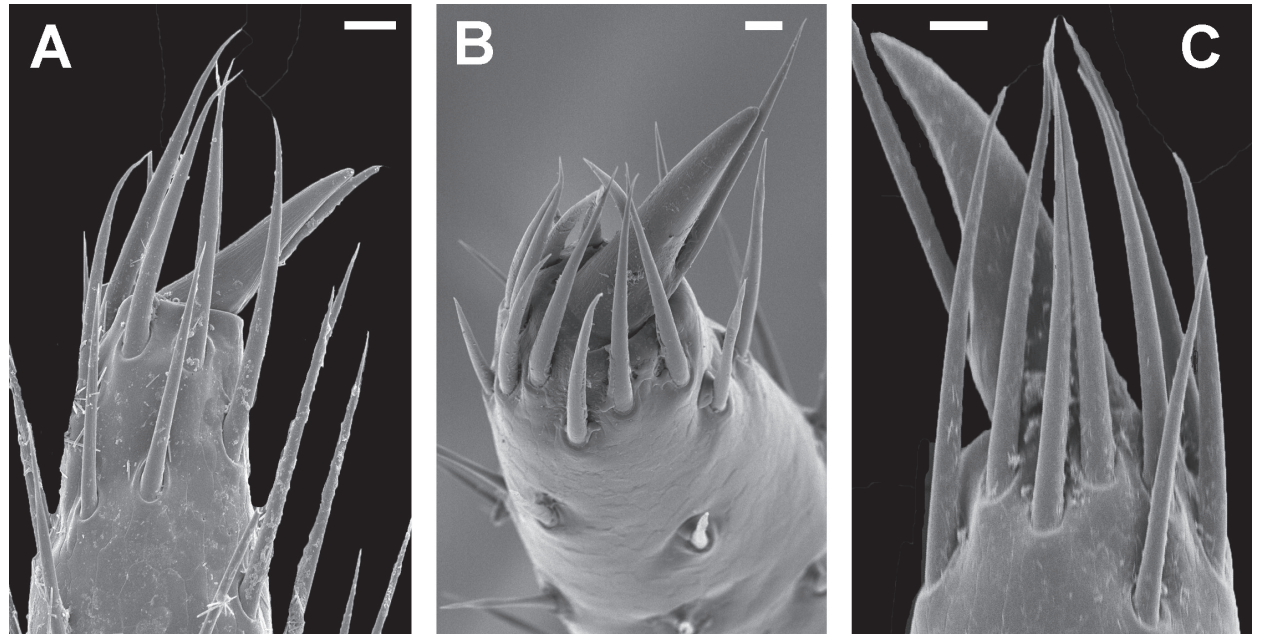

Fig. 5. Chaleponcus spp., tip of tarsus and claw of walking legs. - A. C. mwanihanensis sp. nov. as an example of normal setation. B-C. C. circumvallatus sp. nov. with the claw surrounded by a 'palisade' of setae. Scales $0.1 \mathrm{~mm}$.
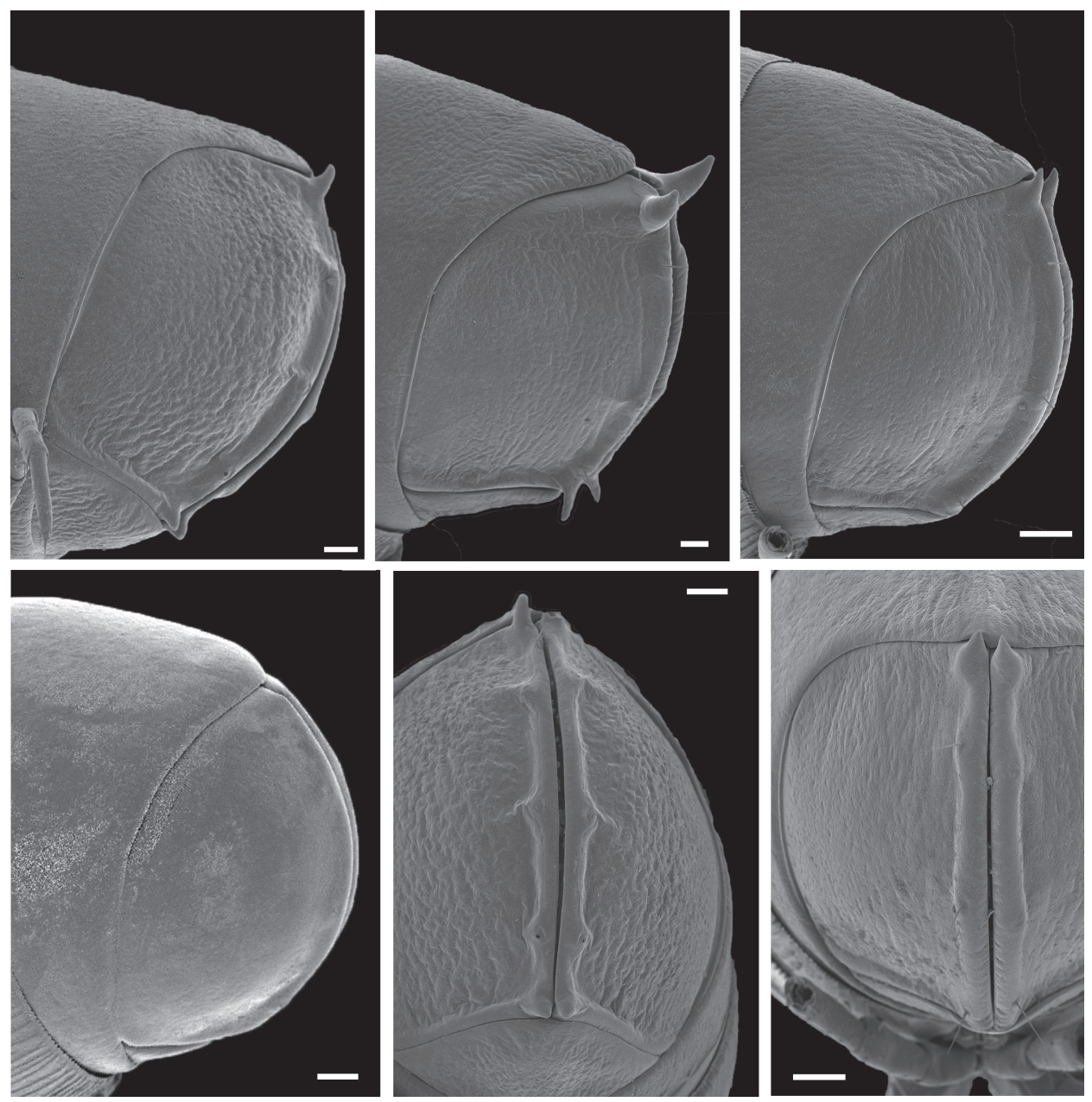

Fig. 6. Telson types in Chaleponcus species. - A. Dorsal and ventral anal valve spines well developed $(C$. nectarinia sp. nov.). B. Spines very long (C. circumvallatus sp.nov.). C. Dorsal spine well developed, ventral spinebarely indicated(C.mwabvuisp.nov.).D.Nospines(C.teressp.nov.).E. Setiferoustubercleson ravelins (C. nectarinia sp. nov.). F. With setiferous tubercles, not on ravelins (C. mwabvui sp. nov.). Scales $0.1 \mathrm{~mm}$. 
The species cannot easily be arranged in subgroups. For practical reasons the descriptions are organised as follows:

- Species in which the gonopod coxa has an obvious lateral process (exceptionally, C. basiliscus sp. nov., two processes): C. netus sp. nov., C. dabagaensis Kraus, 1958, C. quasimodo sp. nov., C. malleolus sp. nov., C. scopus sp. nov., C. nikolajscharffi sp. nov., C. mwanihanensis sp. nov., $C$. basiliscus sp. nov.

- Species without an obvious lateral coxal process in which the metaplical shelf-spine (mss) is long and projects \pm mesad: $C$. krai sp. nov., C. nectarinia sp. nov., C. circumvallatus sp. nov., C. ibis sp. nov., C. vandenspiegeli sp. nov.

- Species without an obvious lateral coxal process in which the metaplical shelf-spine (mss) is not long and projecting \pm mesad (C. vilici sp. nov. has the lateral side of the coxa somewhat angled,

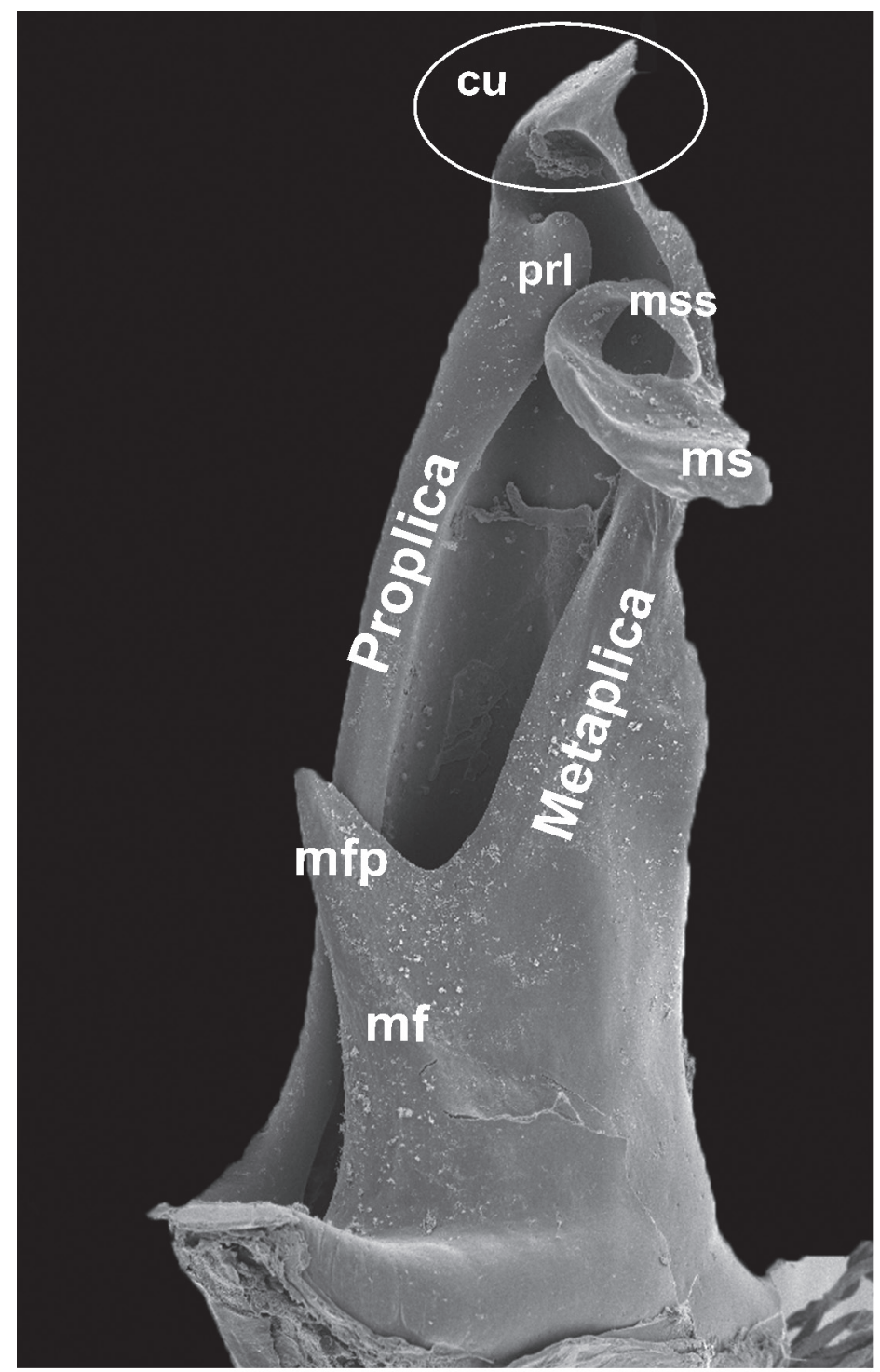

Fig. 7. Gonopod coxa terminology, left coxa of Chaleponcus termini sp. nov., mesal(-posterior) view. $c u$ = cucullus, $m f=$ anteriad metaplical flange, $m f p=$ metaplical flange process, $m s=$ metaplical shelf, $m s s$ $=$ metaplical shelf-spine, $p r l=$ proplical lobe. 

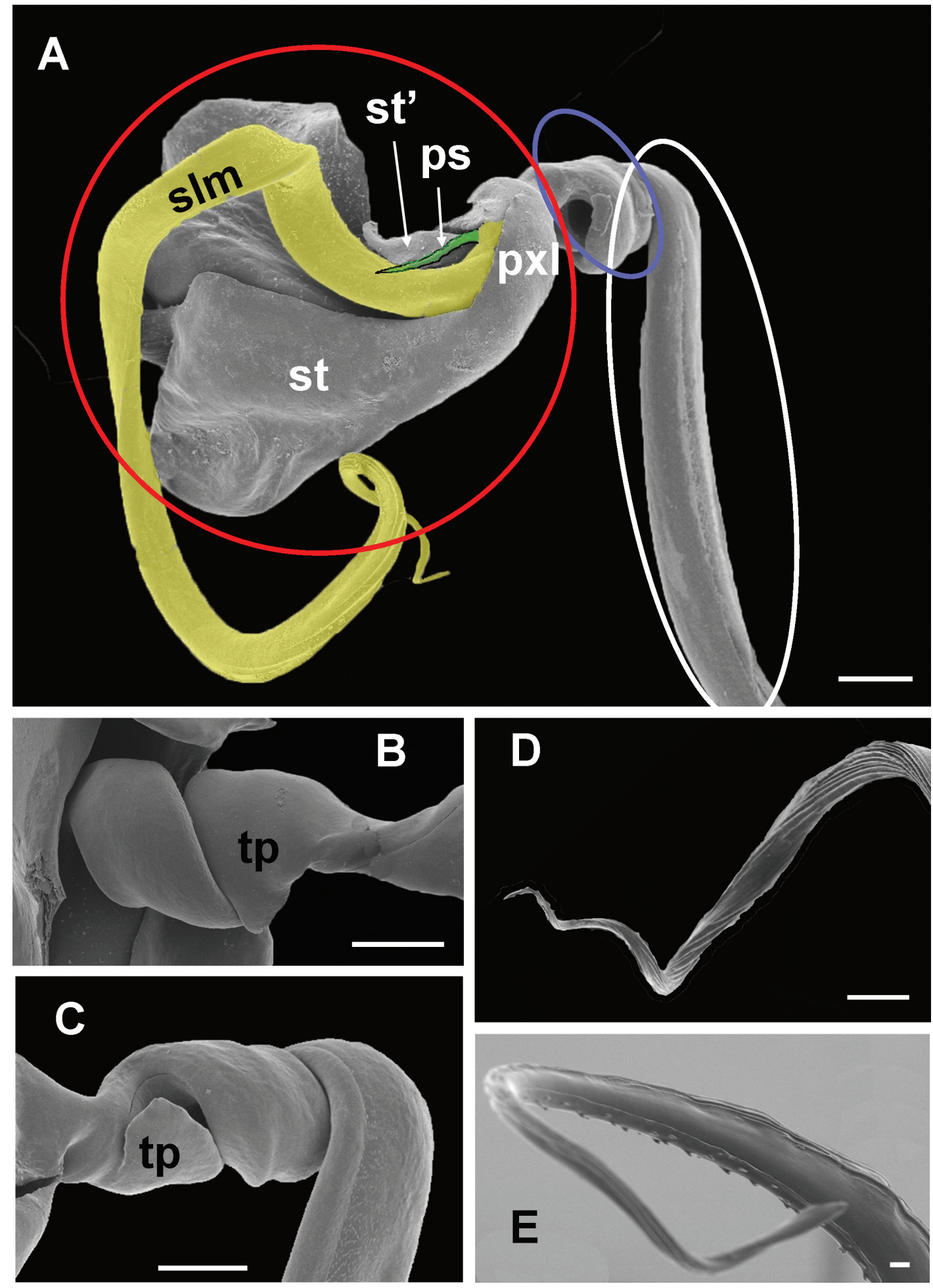

Fig. 8. Gonopod telopodite terminology. - A. Left telopodite of Chaleponcus termini sp. nov., posterior view. White oval $=$ basomere, blue oval $=$ torsotope, red oval $=$ telomere, yellow $=$ solenomere $(\mathrm{s} / \mathrm{m})$, green $=$ proximal spine of solenomere $(p s), p x l=$ proximal lobe of telomere, $s t=$ main stem of telomere, $s t^{\prime}=$ shallow lobe of $s t$. B-C. Torsotope (left gonopod) with torsotope process ( $\left.t p\right)$. B. C. vilici sp. nov., mesal-anterior view. C. C. netus sp. nov., posterior view. D. Solenomere (C. dabagaensis) to show longitudinal fluting. E. Tip of solenomere (C. netus sp. nov.) to show spinulation. Scales: $0.1 \mathrm{~mm}$ (AD), $0.01 \mathrm{~mm}(\mathrm{E})$. 
which reminds of a small lateral process): $C$. vilici sp. nov., C. teres sp. nov., C. hamerae sp. nov., C. termini sp. nov., C. gracilior sp. nov., C. mwabvui sp. nov., C. howelli sp. nov., C. tintin sp. nov.
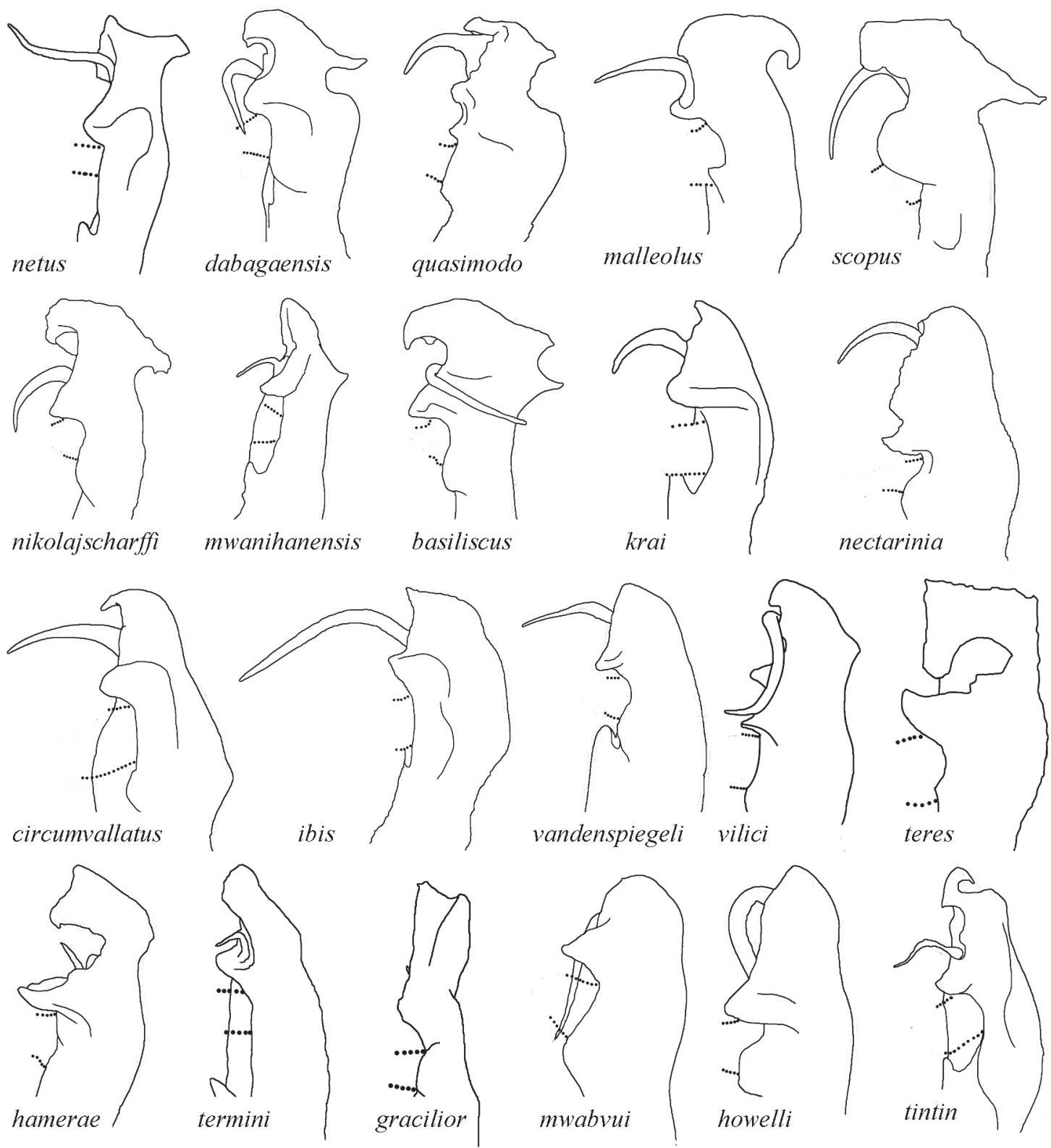

Fig. 9. Chaleponcus spp., outline of coxite of left gonopod, posterior view. (The 'transverse' plane of the gonopod is usually slightly at angles with the exact transverse plane of the millipede, so it may be necessary to tilt the gonopod slightly in order to obtain the view shown on the drawings.) The stippled lines indicate the place where the telopodital basomere emerges from the coxal cavity. Not to scale. 
ENGHOFF H., Chaleponcus millipedes from Udzungwa Mountains

\section{Species in which the gonopod coxa has an obvious lateral process}

(exceptionally, C. basiliscus sp. nov., two processes)

Chaleponcus netus sp. nov. urn:1sid:zoobank.org:act:244DB18B-A3BC-43C6-9B7F-B1C309C14737

Figs 4, 8-11, 34

\section{Diagnosis}

Medium-sized. Differs from all other group members by the presence of a long, gently curved, longitudinally fluted spine (pxs) on the proximal lobe of the telomere. The profile of the coxa (Fig. 9) is also distinctive, as is the spine-like tip of the anterior lamella $(\mathrm{al})$ of the telomere.

\section{Etymology}

The name is a Latin adjective meaning "woven" or "knit" and refers to the intricately interwoven gonopod telopodites.

\section{Material studied (total: 66 ふぇึ)}

Holotype

TANZANIA: ${ }^{\lambda}$, Iringa Region, Iringa District, Udzungwa Mts, New Dabaga/Ulangambi FR, 08 $00^{\circ}$ 26.6” S, 3556'06.1" E, montane forest, $1910 \mathrm{~m}$ asl, plot Kinyonga, casual, 24 Oct. 2000, Frontier Tanzania (ZMUC).

\section{Paratypes}

All from TANZANIA, Iringa Region, Iringa District, Udzungwa Mts, all collected by Frontier Tanzania,

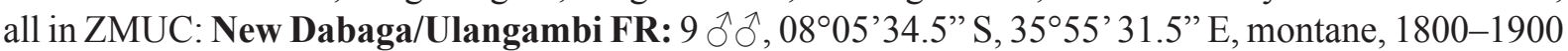

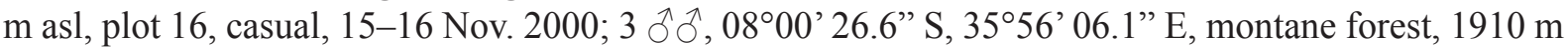

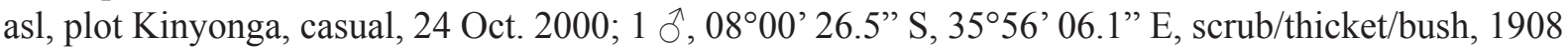
$\mathrm{m}$ asl, plot Kinyonga, 19 Oct. 2000. West Kilombero Scarp FR: 1 ô, $07^{\circ} 50^{\prime} 38.4^{\prime \prime}$ S, 36 $22^{\circ}$ ' 17.6" E, montane forest, $1390 \mathrm{~m}$ asl, plot Paradiso, 12 Nov. 2000; 6 o $^{\lambda} \mathrm{o}^{\top}, 07^{\circ} 50^{\prime} 38.4^{\prime \prime} \mathrm{S}, 36^{\circ} 22^{\prime}$ ' 17.6" E, montane

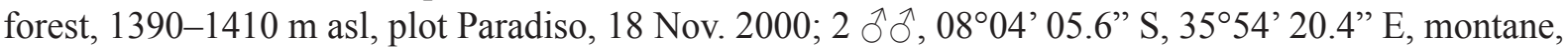

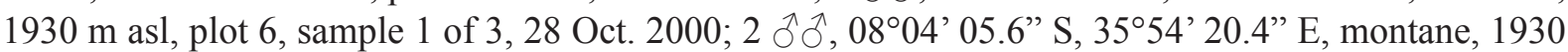

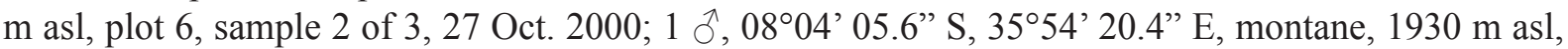

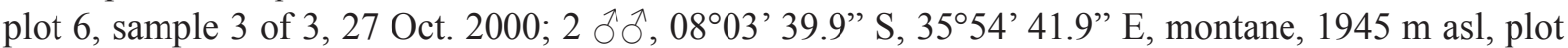

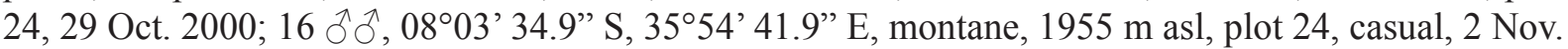

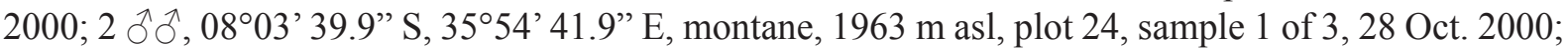

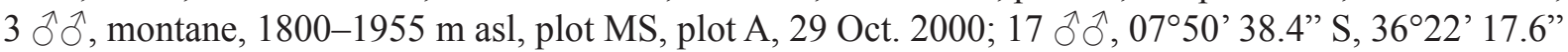
E, montane forest, 1390-1410 m asl, plot Paradiso, 12-18 Nov. 2000.

\section{Type locality}

TANZANIA: Iringa Region, Iringa District, Udzungwa Mts, New Dabaga/Ulangambi FR, 0800' 26.6” $\mathrm{S}, 35^{\circ} 56^{\prime} 06.1^{\prime \prime} \mathrm{E}$, montane forest, $1910 \mathrm{~m}$ asl.

\section{Description (male)}

DiAMETER. $1.9-2.3 \mathrm{~mm}, 41-45$ podous rings.

CoLour. After 12 years in alcohol pale yellowish, with paramedian dark bands flanking a broad middorsal light stripe, a narrow blackish lateral stripe at ozopore level. 

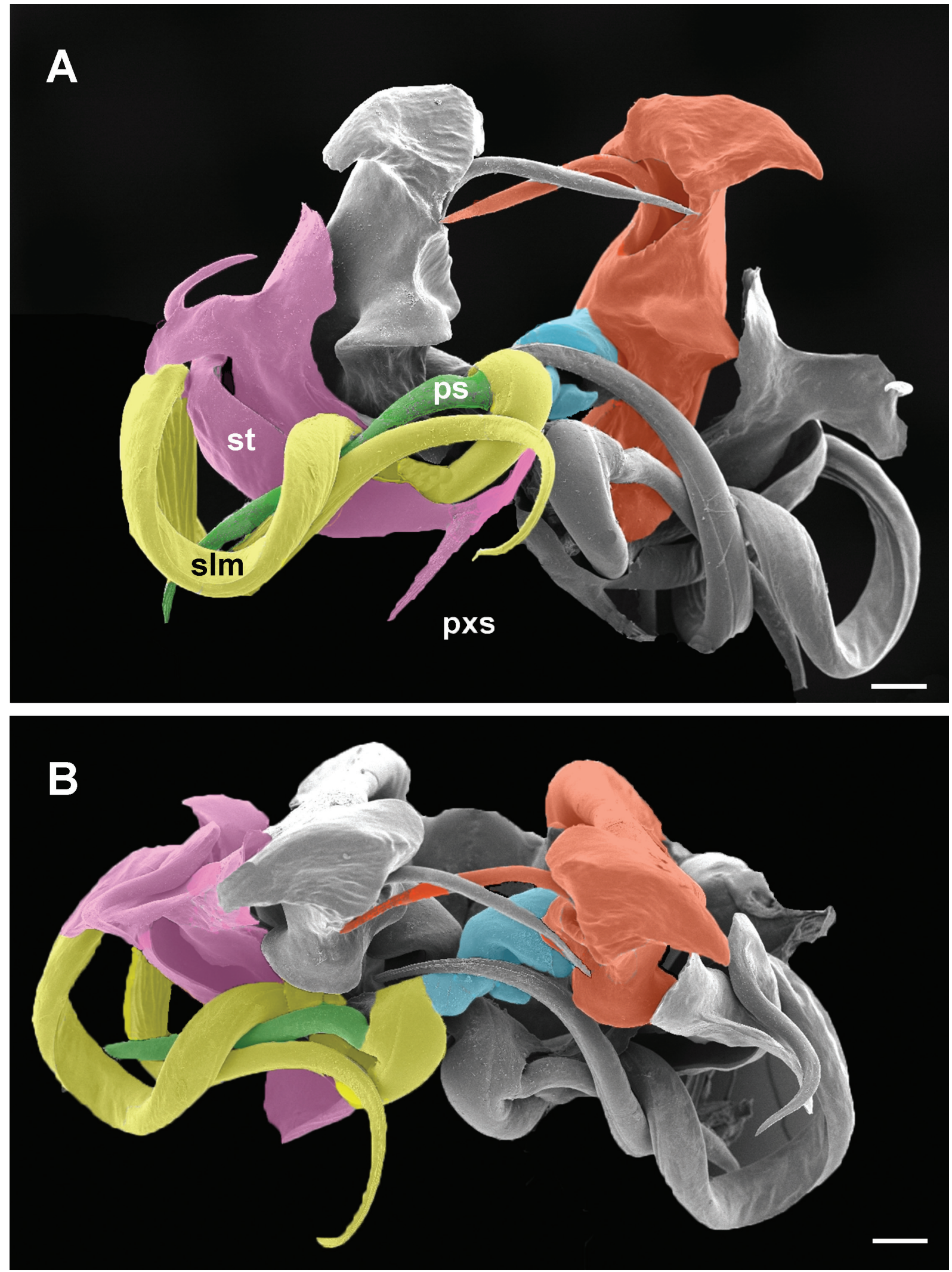

Fig. 10. Chaleponcus netus sp. nov., left gonopod, coloured. - A. Posterior view. B. Ventral view. Orange $=$ coxite, blue $=$ torsotope, yellow $=$ solenomere $(\mathrm{slm})$, green $=$ proximal spine of solenomere $(p s)$, pink $=$ telomere. $p x s=$ spine on proximal telomeral lobe, $s t=$ main stem of telomere. Scales $0.1 \mathrm{~mm}$. 

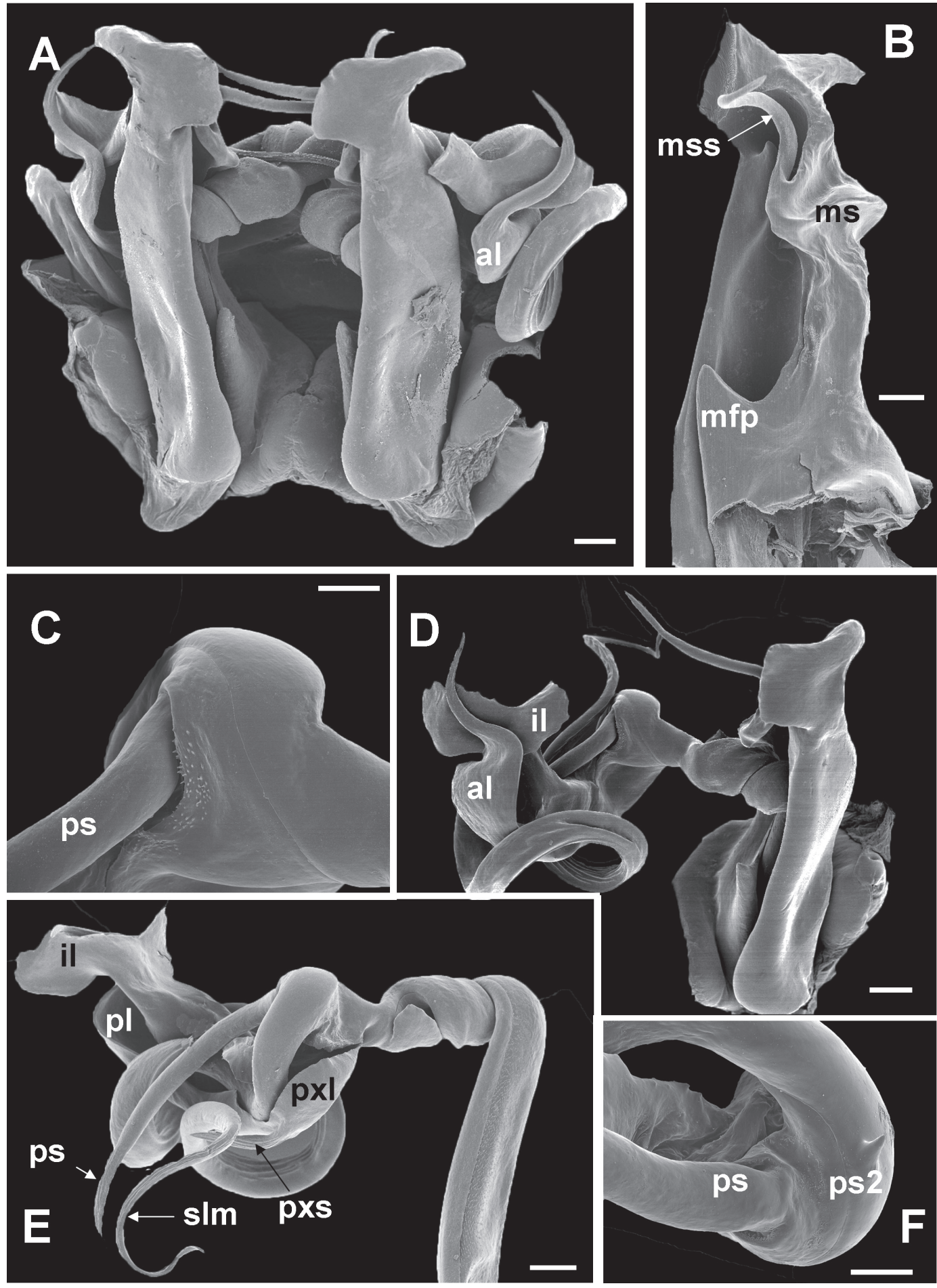

Fig. 11. Chaleponcus netus sp. nov., gonopods. - A. Gonopods, anterior view. B. Left coxite, mesal view. C. Base of proximal solenomere spine ( $p s)$ with spinose socket. D. Right gonopod, anterior (and slightly mesal) view. E. Left gonopod telopodite, posterior view. F. Base of proximal solenomere spine $(p s)$ in a different individual, with denticle (ps2). $a l=$ anterior lamella of telomere, $i l=$ intermediate lamella of telomere, $m f p=$ metaplical flange process, $m s=$ metaplical shelf, $m s s=$ metaplical shelfspine, $p l=$ posterior lamella of telomere, $p s=$ proximal spine of solenomere, $p s 2=$ additional proximal spine of solenomere, $p x l=$ proximal lobe of telomere, $p x s=$ spine on proximal lobe of telomere. Scales: $0.1 \mathrm{~mm}(\mathrm{~A}-\mathrm{B}, \mathrm{D}-\mathrm{E}), 0.05 \mathrm{~mm}(\mathrm{C}, \mathrm{F})$. 
AnAL valves. Each with a long, slightly curving dorsal spine and a small to well-developed, triangular ventral one; marginal rim raised, setiferous tubercles on small 'ravelins'.

LimBus (Fig. 4C). With almost equilateral triangular lobes with rounded, spinulose tips, separated by parabolic sinuses; lobes striate on external surface.

TARSAL SETATION. Normal.

GonOPOD COXA (Figs 9-11). About $4 \times$ as long as wide. Lateral margin very shallowly convex from base up to beyond level of $\mathrm{prl}$ and $\mathrm{ms}$, then curving lateral and together with apical margin forming blunt, disto-lateral process of cucullus; main part of cucullus subrectangular in anterior view. Metaplical flange $(\mathrm{mf})$ ending in blunt process; metaplical mesal margin straight up to level of arculus, then abruptly turning mesad at $c a .130^{\circ}$ angle (base of $m s s$ ), then turning apicad at $c a$. right angles. Metaplical shelf $(\mathrm{ms})$ regularly rounded, projecting posteriad as well as mesad. Metaplical shelf-spine ( $\mathrm{mss}$ ) originating from anterior-mesal end of $m s$, very long, first directed apicad, then mesad and apically slightly obliquely distad, in situ crossing over with opposite mss.

GonOPOD TELOPODITE (Figs 8, 10-11). Solenomere with a very long, gently curved proximal spine ( $p s$ ) set in a socket with more or less spinulose rim; sometimes a tiny denticle (ps2) at base of ps. Proximal lobe of telomere $(p x l)$ with a long, gently curved, longitudinally fluted spine ( $p x s)$. Telomere distally with three branches:

- an S-shaped anterior lamella $(a l)$, broad at base, then narrowing and ending in curved spine-like tip,

- a large, irregularly shaped intermediate lamella $(i l)$,

- a small, rounded posterior lamella $(p l)$.

\section{Distribution and habitat}

Known from New Dabaga/Ulangambi FR and West Kilombero FR, Udzungwa Mts. Altitudinal range: 1390-1963 m asl. Habitat: montane forest; one sample from scrub/thicket/bush.

\section{Coexisting species}

In New Dabaga/Ulangambi FR C. dabagaensis, C. gracilior sp. nov., C. malleolus sp. nov., C. mwabvui sp. nov., C. nectarinia sp. nov., C. termini sp. nov., C. vandenspiegeli sp. nov. and $C$. vilici sp. nov. were found in the same samples as $C$. netus sp. nov. In addition, $C$. krai sp. nov. and $C$. teres sp. nov. were found in New Dabaga/Ulangambi FR. In West Kilombero Scarp FR C. circumvallatus sp. nov. was found in the same sample as C. netus sp. nov. In addition, C. basiliscus sp. nov., C. gracilior sp. nov., $C$. ibis sp. nov., and C. tintin sp. nov. were found in West Kilombero Scarp FR.

Chaleponcus dabagaensis Kraus, 1958

Figs 4, 8-9, 12

Chaleponcus (Storthoporus) dabagaensis Kraus, 1958

Chaleponcus (Storthoporus) dabagaensis: Kraus 1960: 192, under "Species incertae sedis".

\section{Diagnosis}

Medium-sized. Differs from all other group members by the presence of a thumblike process $(t h)$ on the main stem of the telomere; also by the profile of the gonopod coxa (Fig. 9), especially its 'hunch-backed' lateral side, shared only by C. quasimodo sp. nov.

\section{Type locality}

TANZANIA: Iringa Region, Iringa District, Udzungwa Mts, Kwabuni Estate at Dabaga, 2100 m asl. 
Material studied (total: 9 ふぇ)

\section{Type material}

Holotype $\widehat{\jmath}$ (Überseemuseum Bremen), paratypes 5 q $q$ (Überseemuseum Bremen and Senckenberg Museum Frankfurt), all from type locality; not studied.

\section{Other material}

All from TANZANIA, Iringa Region, Iringa District, Udzungwa Mts, all in ZMUC: Kiranzi-Kitungulu

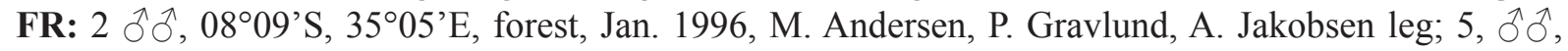

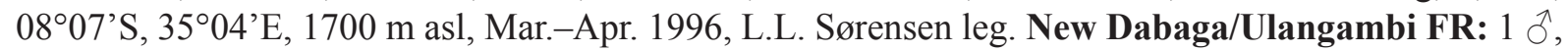
0806'47.4" S, 35 $56^{\circ} 50.4^{\prime \prime}$ E, montane, $1855 \mathrm{~m}$ asl, plot MS - plot A, 11 Nov. 2000, Frontier Tanzania

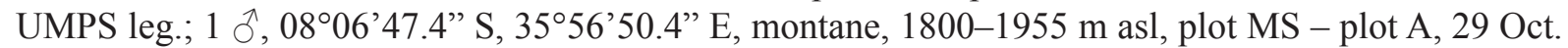
2000, Frontier Tanzania leg.

\section{Description (male)}

[data in square brackets from Kraus (1958), translated]

Diameter. 2.4 [2.4] mm, 49 [49] podous rings.

Colour. [Horn yellow, dorsally with darker marbling and medially with broad, yellow, longitudinal stripe; a blackish lateral stripe at ozopore level].

ANAL VALVES. Each with a long, slightly curving dorsal spine and a small, triangular ventral one; marginal rim raised; setiferous tubercles well developed, on small 'ravelins'.

LimBus (Fig. 4D). With tongue-shaped, apically rounded lobes separated by narrow sinuses, lobes almost meeting at base, lobes striate on external surface.

TARSAL SETATION. Normal.

GonOpod COXA (Figs 9, 12). About $4 \times$ as long as wide. Lateral margin straight up to level of $m s$, then curving mesad and then lateral, leaving a deep, rounded incision and giving the entire coxa a 'hunchback' profile; apical margin gently convex, laterally gently concave, forming long, slightly curved lateral cucullar process. Metaplical flange $(\mathrm{mf})$ ending in approximately right-angled-rounded corner; metaplical mesal margin basally straight, with rounded-triangular process $(m p)$ just below level of arculus. Metaplical shelf ( $m s)$ simply rounded, projecting posteriad as well as mesad, continuing without transition in metaplical shelf-spine $(\mathrm{mms})$; $\mathrm{mms}$ of medium length, curving first mesad, then obliquely basad, tip reaching level of basomere.

GoNOPOD TELOPODITE (Figs 8, 12). Solenomere with a small, straight proximal spine ( $p s$ ) with an associated lobe (as in C. gracilior sp. nov., but simpler). Main stem of telomere (st) with a characteristic thumblike process $(t h)$ distally. Telomere distally with two branches:

- a large, convoluted anterior lamella (al) with smooth edges, continuous with st on basal side of telomere,

- a posterior-distal lamella $(p l)$ forming direct distal continuation of st but separated from it by rounded- triangular incision; margins of $p l$ in part strongly serrated.

\section{Distribution and habitat}

Known from New Dabaga/Ulangambi FR and Kiranzi-Kitungulu FR, Udzungwa Mts. Altitudinal range: 1700-1955 m asl, $2100 \mathrm{~m}$ asl according to Kraus (1958). Habitat: montane forest. Recorded by Kraus (1958) from "Halbregenwald" (= semi-rain forest). 


\section{Coexisting species}

In Kiranzi-Kitungulu FR, $C$. gracilior sp. nov. was found in the same sample as $C$. dabagaensis. In New Dabaga/Ulangambi FR C. gracilior sp. nov., C. mwabvui sp. nov., C. netus sp. nov. and C. termini sp.
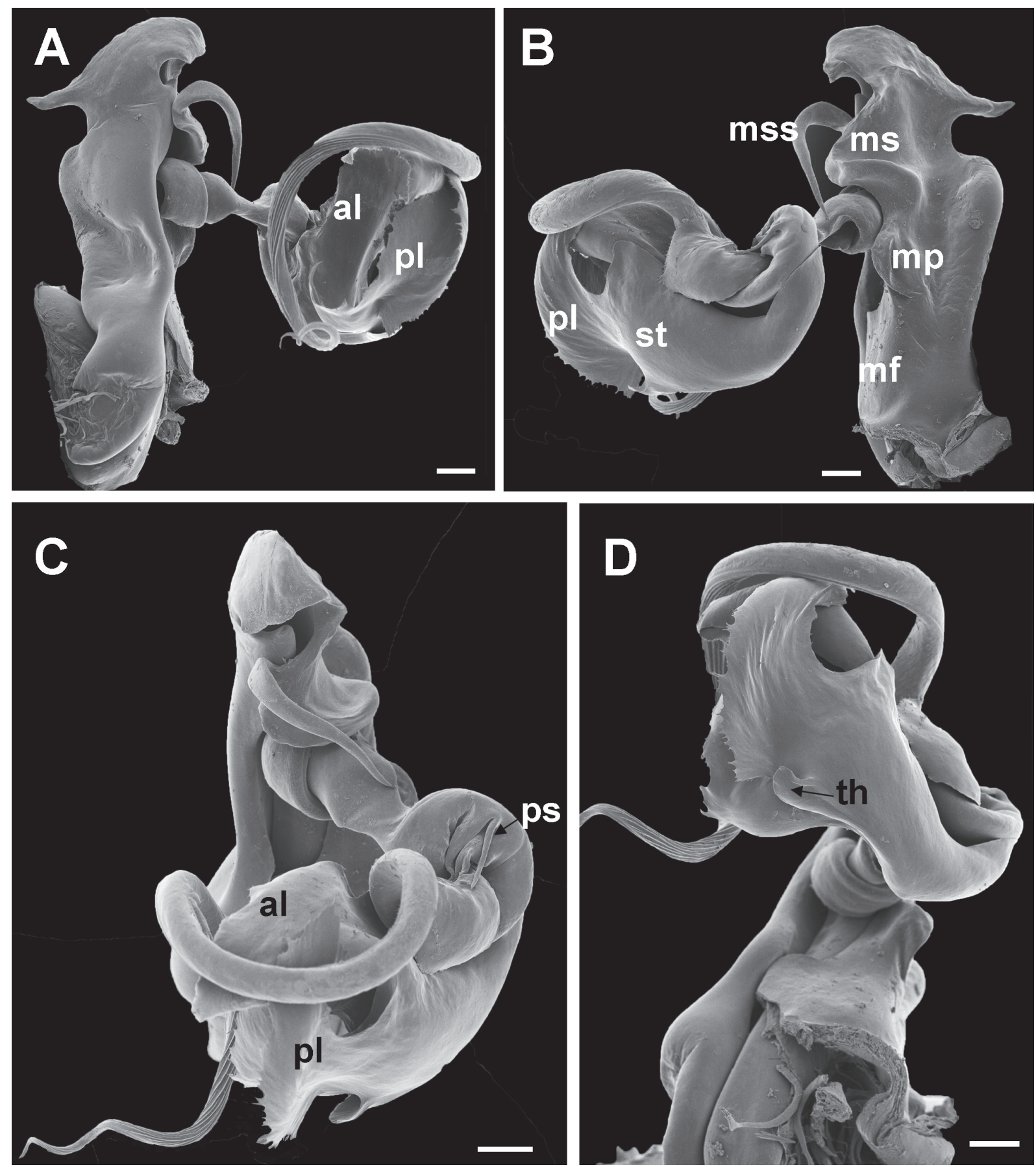

Fig. 12. Chaleponcus dabagaensis Kraus, 1958, left gonopod. - A. Anterior view. B. Posterior view. C. Mesal-ventral view. D. Mesal-dorsal view. $a l=$ anterior lamella of telomere, $m f=$ metaplical flange, $m p=$ mesal metaplical process, $m s=$ metaplical shelf, $m s s=$ metaplical shelf-spine, $p l=$ posterior lamella of telomere, $p s=$ proximal spine of solenomere, $s t=$ main telomeral stem, $t h=$ thumblike process of telomere main stem. Scales $0.1 \mathrm{~mm}$. 
nov. were found in the same samples as $C$. dabagaensis. In addition, $C$. krai sp. nov., C. malleolus sp. nov., $C$. nectarinia sp. nov., C. teres sp. nov., $C$. vandenspiegeli sp. nov. and $C$. vilici sp. nov. were found in New Dabaga/Ulangambi FR.

\section{Notes}

The original description by Kraus (1958) leaves no doubt that the specimens at hand (which include topotypes) belong to C. dabagaensis. See under "Genus Chaleponcus" for a review of the history of this species.

Chaleponcus quasimodo sp. nov. urn:1sid:zoobank.org:act:37A2F533-120D-45C5-8C49-B77A4C2DA088

Figs 9, 13

\section{Diagnosis}

Medium-sized. Differs from all other group members except $C$. dabagaensis by the 'hunch-backed' profile of the gonopod coxa (Fig. 9); differs from C. dabagaensis by the profile of the coxal tip and by the absence of a thumblike process on the main stem of the telomere.

\section{Etymology}

The name is a noun, here in apposition, and refers to Quasimodo, the hunch-back of Notre-Dame, title figure of the novel by Victor Hugo (1839).

Material studied (total: $9 \precsim \widehat{\diamond})$

\section{Holotype}

TANZANIA: ${ }^{\Uparrow}$, Iringa Region, Mufindi District, Udzungwa Mts, Kigogo FR, 1700 m, 8-10 Oct. 1984, pitfall traps in montane rain forest. N. Scharff leg. (ZMUC).

\section{Paratypes}

All from TANZANIA, Iringa Region, Mufindi District, Udzungwa Mts, Kigogo FR, all in ZMUC: 1 , $1700 \mathrm{~m}, 8-10$ Oct. 1984, pitfall traps in montane rain forest. N. Scharff leg.; 7 đo ${ }^{\lambda}, 1900 \mathrm{~m}, 7-15$ Oct. 1984, pitfall traps in montane rain forest. N. Scharff leg.

\section{Type locality}

TANZANIA, Iringa Region, Mufindi District, Udzungwa Mts, Kigogo FR, 1700 m, montane rain forest.

\section{Description (male)}

DiAMETER. 2.1-2.3 $\mathrm{mm}, 47-49$ podous rings.

CoLour. After 30 years in alcohol almost completely bleached, with traces of paramedian darker bands flanking a broad middorsal light stripe, sometimes a thin dark line in middle of stripe.

ANAL VALVES. Each with a long, slightly curving dorsal spine and a small, triangular ventral one; marginal rim raised, setiferous tubercles on small 'ravelins'.

LimBus. With broadly rounded lobes, as long as broad or slightly longer, striate on outer surface.

TARSAL SETATION. Normal.

Gonopod CoXa (Figs 9, 13). About $3 \times$ as long as wide. Lateral margin straight up to level of $m s$, then curving mesad and then lateral, leaving a deep, rounded incision and giving the entire coxa a 

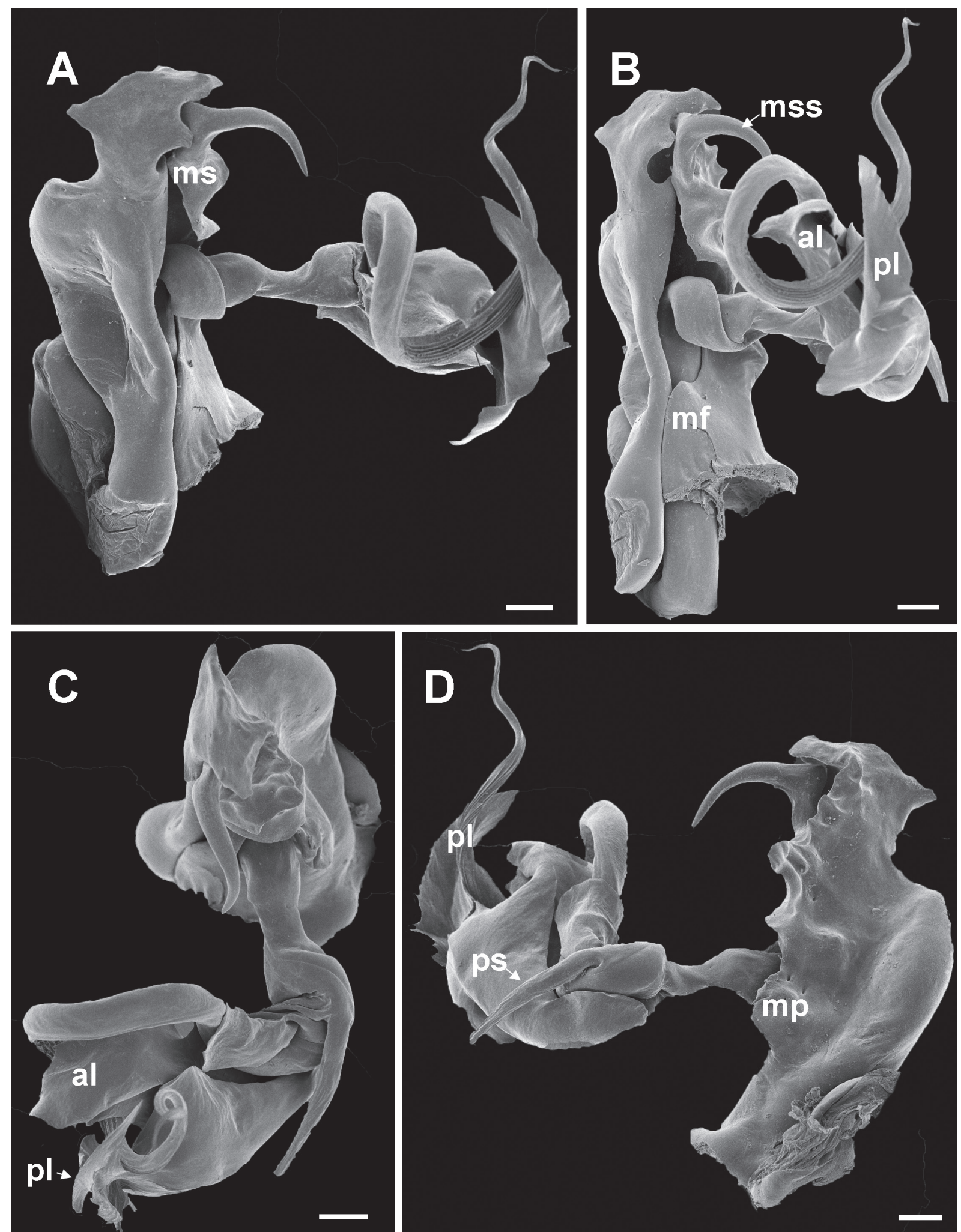

Fig. 13. Chaleponcus quasimodo sp. nov., left gonopod. A. Anterior view. B. Anterior-mesal view. C. Ventral view. D. Posterior view. $a l=$ anterior lamella of telomere, $m f=$ metaplical flange, $m p=$ mesal metaplical process, $m s=$ metaplical shelf, $m s s=$ metaplical shelf-spine, $p l=$ posterior lamella of telomere, $p s=$ proximal spine of solenomere. Scales $0.1 \mathrm{~mm}$. 
'hunchback' profile; apical margin slightly convex, irregularly undulate, forming $c a$. $70^{\circ}$ angles with lateral margin. Mesal margin of proplica with two mesad processes apically, one above, one below metaplical shelf-spine $(\mathrm{mss})$. Metaplical flange $(\mathrm{mf})$ ending in approximately right-angled-rounded corner, hardly projecting; metaplical mesal margin with rounded-triangular process $(\mathrm{mp})$ just below level of arculus, distally with triangular incision with coarsely nodose margin. Metaplical shelf $(m s)$ of moderate size, projecting slightly posteriad as well as mesad, continuing without transition in metaplical shelf-spine (mss); mss of medium length, curving obliquely basad.

GonOPOD TELOPODITE (Fig. 13). Solenomere with medium long, almost straight proximal spine (ps). Telomere distally with two relatively small and simple branches:

- an anterior lamella $(a l)$,

- a posterior lamella $(p l)$.

\section{Distribution and habitat}

Known only from Kigogo FR, Udzungwa Mts. Altitudinal range: 1700-1900 m. Habitat: montane rain forest.

\section{Coexisting species}

All four species known from Kigogo FR, i.e., C. quasimodo sp. nov., C. scopus sp. nov., C. howelli sp. nov. and C. mwabvui sp. nov., were found in the same samples.

Chaleponcus malleolus sp. nov. urn:1sid:zoobank.org:act:85393BDE-7999-4CD5-BFA2-2B21A022E2A8

Figs 4, 9, 14

\section{Diagnosis}

Small (smallest species in the $C$. dabagaensis group). Differs from all other group members, except $C$. teres sp. nov., by the absence of a dorsal spine on each anal valve. Further differs from all other group members by the profile of the gonopod coxal tip (Fig. 9), especially the strongly curved, hooklike lateral process.

\section{Etymology}

The name is a Latin noun, here in apposition, meaning 'little hammer', and refers to the gonopod coxa profile.

Material studied (total: 14 ふぇ)

\section{Holotype}

TANZANIA: $\widehat{\partial}$, Iringa Region, Iringa District, Udzungwa Mts, New Dabaga/Ulangambi FR, $08^{\circ} 00^{\prime}$ 26.6” S, 3556'06.1” E, montane forest, $1910 \mathrm{~m}$ asl, plot Kinyonga, casual, 24 Oct. 2000, Frontier Tanzania (ZMUC).

\section{Paratypes}

All from TANZANIA, Iringa Region, Iringa District, Udzungwa Mts, New Dabaga/Ulangambi FR, all collected by Frontier Tanzania, all in ZMUC: $1 \partial^{7}, 08^{\circ} 00^{\prime} 26.6^{\prime \prime}$ S, 35 $56^{\circ} 06.1^{\prime \prime}$ E, montane forest, 1910

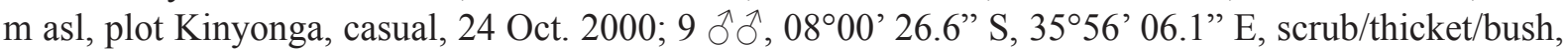

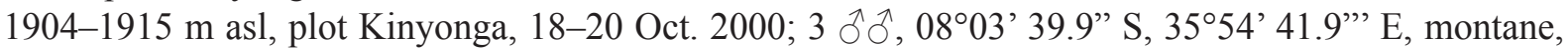
$1945 \mathrm{~m}$ asl, plot 24, 29 Oct. 2000. 

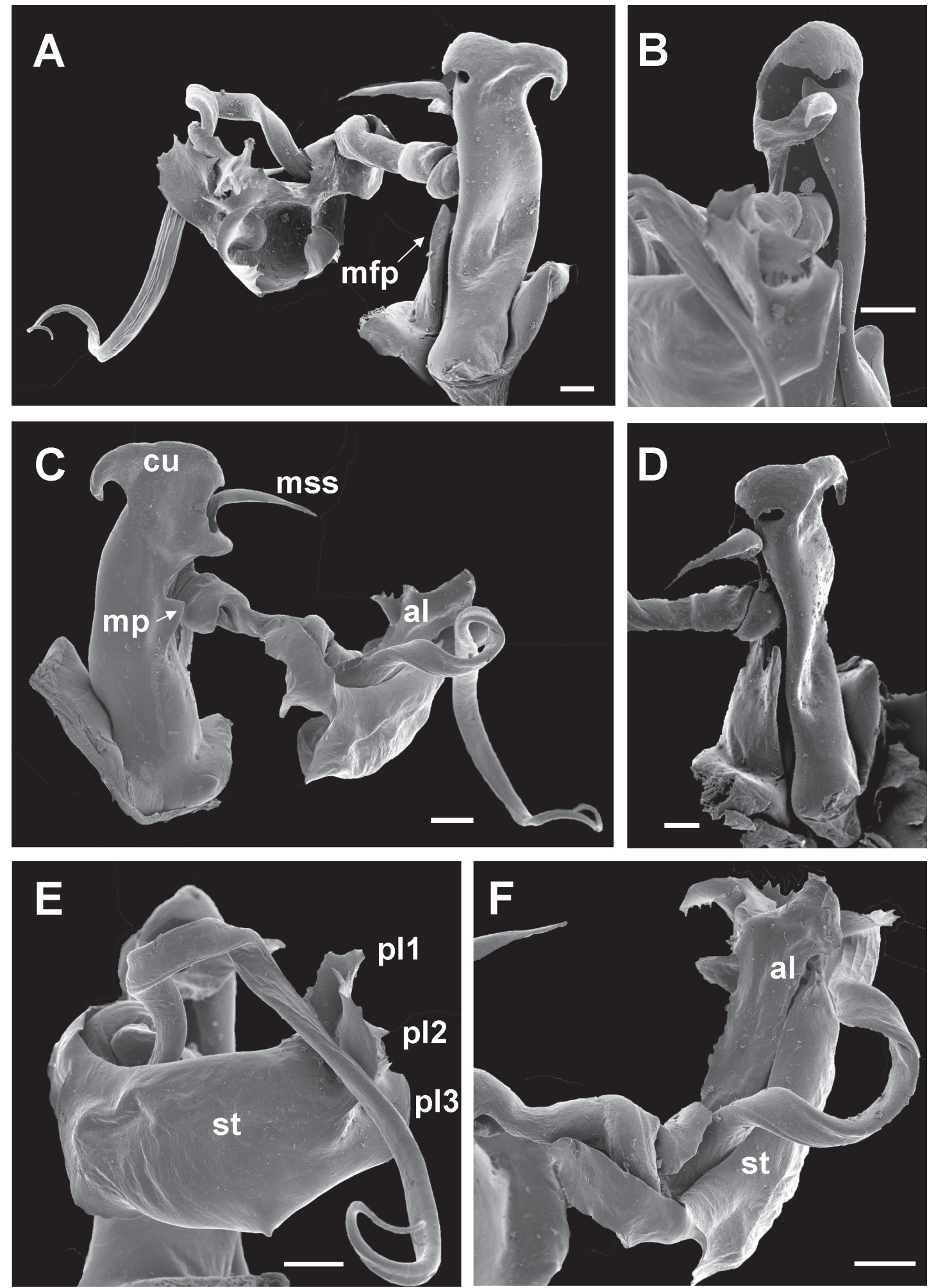

Fig. 14. Chaleponcus malleolus sp. nov., right gonopod. A. Anterior view. B. Mesal view, focus on coxa. C. Posterior view. D. Anterior-mesal view. E. Mesal view, focus on telopodite. F. Telopodite, ventral-posterior view. $a l=$ anterior lamella of telomere, $c u=$ cucullus, $m f p=$ metaplical flange process, $m p=$ mesal metaplical process, $m s s$; metaplical shelf-spine, $p l 1, p l 2, p l 3=$ lobes of posterior lamella of telomere, $s t=$ main stem of telomere. Scales $0.1 \mathrm{~mm}$. 


\section{Type locality}

TANZANIA: Iringa Region, Iringa District, Udzungwa Mts, New Dabaga/Ulangambi FR, 0800’26.6” S, 35 56' 06.1” E, montane forest, $1910 \mathrm{~m}$ asl.

\section{Description (male)}

DiAMETER. $1.7-1.8 \mathrm{~mm}, 38-39$ podous rings.

CoLour. After 13 years in alcohol pale yellowish, traces of dark dorsolateral bands and a pale middorsal band.

ANAL valves. Neither dorsal nor ventral spines; marginal rim not raised, setiferous tubercles small, not on 'ravelins'.

LimBus (Fig. 4I). With very low, smooth lobes, $c a$. 0.2 times as long as broad.

\section{TARSAL SETATION. Normal.}

GONOPOD COXA (Figs 9, 14). Almost $4 \times$ as long as wide; lateral margin very slightly convex up to level of proplical lobe, then curving laterad and then basad, forming cucullar hook together with otherwise almost straight apical margin; cucullus $(\mathrm{cu})$ short, with big lateral, basad, blunt-tipped strongly curved hook. Metaplical flange ending in blunt, apicad process $(m f p)$; metaplical mesal margin straight, but with triangular process $(\mathrm{mp})$ just below level of arculus. Metaplical shelf mainly projecting mesad, continuing without transition in metaplical shelf-spine (mss). mss medium long, curving almost exclusively in horizontal plane, first anteriad, then mesad.

Gonopod telopodite (Fig. 14). Solenomere without a spine or other secondary branches. Telomere simple, distally with 2 , closely adjoining branches:

- an oblong anterior lamella (al),

- a posterior lamella forming a direct distal continuation of main stem $(s t)$ and distally with three short lobes: apical ( $p l l)$ and intermediate ( $p l 2)$ lobe, with irregularly jagged edges, basal lobe ( $p l 3$ ) smooth-edged, semicircular.

\section{Distribution and habitat}

Only known from New Dabaga/Ulangambi FR. Altitudinal range: 1904-1945 m asl. Habitat: montane forest, scrub/thicket/bush.

\section{Coexisting species}

C. gracilior sp. nov., C. nectarinia sp. nov., C. netus sp. nov. and C. vilici sp. nov. were found in the same samples as $C$. malleolus sp. nov. In addition, $C$. dabagaensis, $C$. krai sp. nov., C. mwabvui sp. nov., C. teres sp. nov., C. termini sp. nov. and C. vandenspiegeli sp. nov. and were found in New Dabaga/ Ulangambi FR.

Chaleponcus scopus sp. nov. urn:1sid:zoobank.org:act:A4A8E1FE-3CE6-4D04-A1EE-80A63ED9FB79

Figs 4, 9, 15

\section{Diagnosis}

Medium-sized. Differs from all other group members by the profile of the gonopod coxal tip (Fig. 9), especially the shape of the lateral process. Very similar to C. nikolajscharffi sp. nov., sharing, i.a., a nontransverse metaplical shelf and a groove for accommodating the solenomere formed by two telomere 
lobes; differing from $C$. nikolajscharffi sp. nov. by being thinner and having a differently shaped lateral coxal process.

\section{Etymology}

The name is a Latin noun in apposition and refers to the profile of the gonopod coxa, which somewhat resembles the head profile of the hammerhead stork (Scopus umbretta).

Material studied (total: $16 \curvearrowright ึ$ )

Holotype

TANZANIA: đ̊, Iringa Region, Mufindi District, Udzungwa Mts, Kigogo FR, 1700 m, 8-10 Oct. 1984, pitfall traps in montane rain forest. N. Scharff leg. (ZMUC).

\section{Paratypes}

All from TANZANIA, Iringa Region, Mufindi District, Udzungwa Mts, Kigogo FR, all in ZMUC: 6 $\widehat{\partial}^{\lambda}{ }^{\lambda}, 1700 \mathrm{~m}, 8-10$ Oct. 1984, pitfall traps in montane rain forest, N. Scharff leg.; $9 \partial^{\lambda}{ }^{\lambda}, 1900 \mathrm{~m}, 7-15$ Oct. 1984, pitfall traps in montane rain forest, N. Scharff leg.

\section{Type locality}

TANZANIA: Iringa Region, Mufindi District, Udzungwa Mts, Kigogo FR, 1700 m, 8-10 Oct. 1984, montane rain forest.

\section{Description (male)}

DiAMETER. $1.9-2.0 \mathrm{~mm}, 47-49$ podous rings.

Colour. After 30 years in alcohol with traces of paramedian darker bands flanking a broad middorsal light stripe; dark bands divided into separate dots on each diplosegment in anterior part of body.

AnAl valves. Each with a long dorsal spine and a well-developed, but small, triangular ventral one; marginal rim raised, setiferous tubercles well developed, on 'ravelins'.

Limbus (Fig. 4A). With very long, slender triangular lobes; lobes $c a .2 \frac{1}{2} \times$ as long as broad, almost meeting at base, striate on external surface.

TARSAL SETATION. Normal.

GonOPOD COXA (Figs 9, 15). About $3 \frac{1}{2} \times$ as long as wide. Lateral margin basally slightly convex, curving strongly laterad $c a$. at level of $\mathrm{prl}$, forming semicircular incision, and continuing in slender, curved, pointed lateral process $(l p)$; apical margin sloping apico-mesad from process, irregularly undulate and with blunt-angled projection $c a .2 / 3$ from tip of $l p$; cucullus $(c u)$ mesally projecting as roundedsubrectangular lobe with irregularly undulate margin. Metaplical flange $(m f)$ with very low rounded anteriad protrusion, no process; metaplical mesal margin basally straight, then overlaid by lamelloid process $(\mathrm{mp})$ covering arculus. Metaplical shelf not transverse as in most other species: posterior surface of metaplica with large lobe $(\mathrm{msl})$ roofing arculus; lobe concave on posterior face, folded anteriad and on anterior face giving rise to metaplical shelf-spine ( $\mathrm{mss}$ ). $\mathrm{mms}$ of medium length, curving first obliquely anteriad, then mesad, then obliquely basad, not reaching level of torsus.

Gonopod telopodite (Fig. 15). Solenomere with a long, gently sinuous, mesad, proximal spine ( $p s$ ) arising from a wrinkled area. Telomere distally with two branches:

- a very large anterior lamella $(\mathrm{al})$, increasing in diameter towards tip, with a broadly rounded smoothedged tip and a small, thumblike process $\left(a l^{\prime}\right)$; solenomere resting between $a l^{\prime}$ and main body of $a l$., 
- a small, rounded posterior lamella $(p l)$ with irregular edges.

\section{Distribution and habitat}

Known only from Kigogo FR, Udzungwa Mts. Altitudinal range: 1700-1900 m asl. Habitat: montane rain forest.
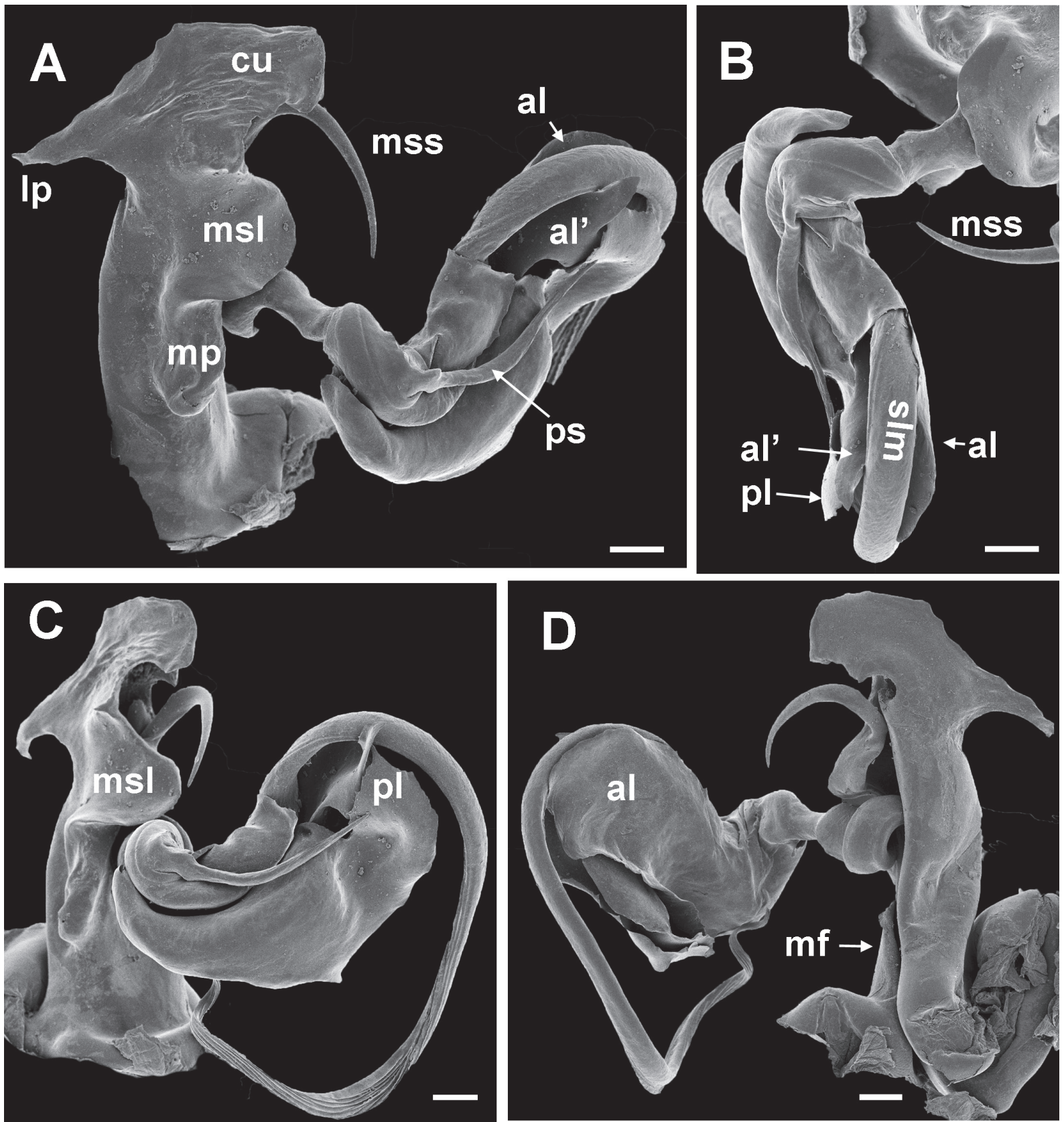

Fig. 15. Chaleponcus scopus sp. nov., right gonopod. A. Posterior view. B. Ventral-posterior view. C. Mesal-posterior view. D. Anterior view. $a l=$ anterior lamella of telomere, $a l$ ' $=$ thumblike process of $a l, c u=$ cucullus, $l p=$ lateral coxal process, $m f=$ metaplical flange, $m p=$ mesal metaplical process, $m s l$ $=$ metaplical shelf-forming lobe, $m s s=$ metaplical shelf-spine, $p l=$ posterior lamella of telomere, $p s=$ proximal solenomeral spine, $s l m=$ solenomere. Scales $0.1 \mathrm{~mm}$. 


\section{Coexisting species}

All four species known from Kigogo FR, i.e., C. quasimodo sp. nov., C. scopus sp. nov., C. howelli sp. nov. and C. mwabvui sp. nov., were found in the same samples.

\section{Note}

Very similar to and probably closely related to C. nikolajscharffi sp. nov. from Udzungwa Scarp FR.

Chaleponcus nikolajscharffi sp. nov. urn:1sid:zoobank.org:act:FA4BA44E-0547-4E9C-A4A4-781E2298A650

Figs $9,16,34$

\section{Diagnosis}

Medium-sized. Differs from all other group members by the profile of the gonopod coxal tip (Fig. 9). Very similar to C. scopus sp. nov., sharing, i.a., a non-transverse metaplical shelf and a groove for accommodating the solenomere formed by two telomere lobes; differing from $C$. scopus sp. nov. by apparently having the solenomere-conducting groove formed by the anterior and the posterior telomeral lamellae, instead of by the anterior lamella and a process from the latter, as well as by having a differently shaped lateral coxal process.

\section{Etymology}

The name honours my colleague, arachnologist Nikolaj Scharff (ZMUC), collector of this and numerous other Tanzanian millipedes.

Material studied (total: 11 ふึ)

\section{Holotype}

TANZANIA: $\widehat{\jmath}$, Iringa Region, Udzungwa Mts, Udzungwa Scarp FR, above Chita village, $1500 \mathrm{~m}$, 2-13 Nov. 1984, pitfall traps, montane rain forest. N. Scharff leg. (ZMUC).

\section{Paratypes}

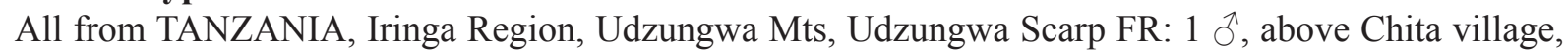
1450-1650 m, 4-9 Nov. 1984, pitfall traps, montane rain forest, N. Scharff leg. (ZMUC); 2 ๙ิ ô, above Chita village, 1600-1650 m, 8-13 Nov. 1984, pitfall traps, montane rain forest, N. Scharff leg. (ZMUC); $2 \widehat{\jmath}$, above Chita village, $1400 \mathrm{~m}, 4-5$ Nov. 1984, pitfall traps, montane rain forest, N. Scharff leg. (ZMUC); 1 ${ }^{\lambda}$, above Chita village, $1500 \mathrm{~m}, 2-13$ Nov. 1984, pitfall traps, montane rain forest, N. Scharff leg. (ZMUC); $2 \jmath^{\lambda}, 11 \mathrm{~km}$ SE of Masisiwe village, Kihanga Stream, $1800 \mathrm{~m}, 08^{\circ} 22^{\prime} 05.7^{\prime \prime} \mathrm{S}$,

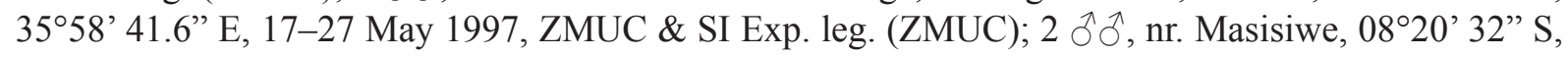
3558’03” E, 12-15 Jul. 2004, A. Sforzi \& L. Bartolozzi leg. (MZF, nº Mag. 2695).

\section{Type locality}

TANZANIA: Iringa Region, Udzungwa Mts, Udzungwa Scarp FR, above Chita village, $1500 \mathrm{~m}$, montane rain forest.

\section{Description (male)}

DiAMETER. $2.2-2.4 \mathrm{~mm}, 48-49$ podous rings.

Colour. After 10 years in alcohol with a broad light middorsal stripe formed by an hourglass-shaped spot on each body ring; stripe flanked by brownish paramedian bands; older specimens unicolourous light brown/pinkish. 
ANAL VALVES. Each with a long, slightly curving spine and a well-developed, triangular ventral one; marginal rim raised, setiferous tubercles well developed, on 'ravelins'.
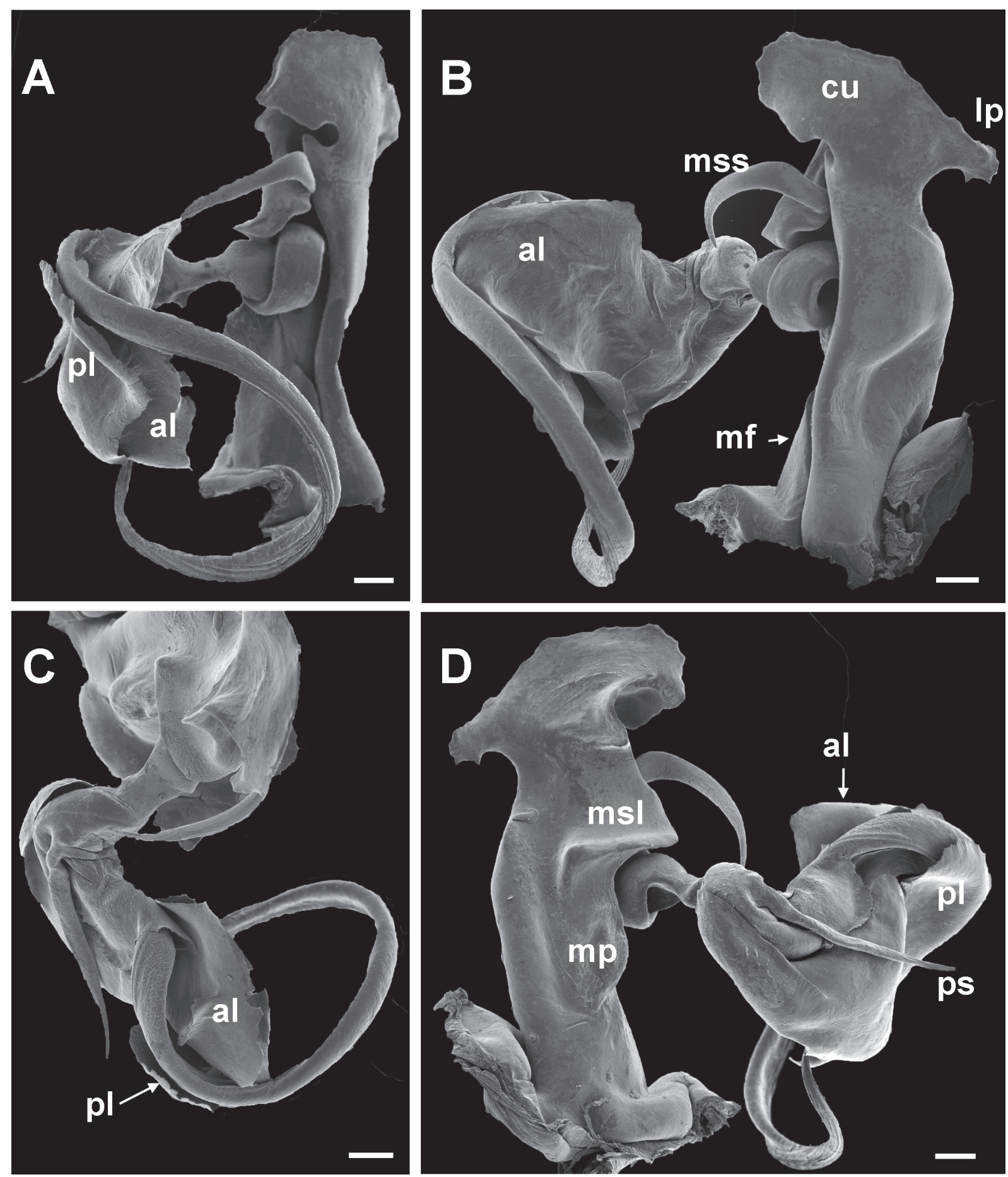

Fig. 16. Chaleponcus nikolajscharffi sp. nov., right gonopod. A. Mesal view. B. Anterior view. C. Ventral view. D. Posterior view. $a l=$ anterior lamella of telomere, $c u=$ cucullus, $l p=$ lateral coxal process, $m f=$ metaplical flange, $m p=$ mesal metaplical process, $m s l=$ metaplical shelf-forming lobe, $m s s=$ metaplical shelf-spine, $p l=$ posterior lamella of telomere, $p s=$ proximal spine of solenomere. Scales $0.1 \mathrm{~mm}$. 
LimBus. With long, slender triangular lobes; lobes $c a .2 \frac{1}{2} \times$ as long as broad, almost meeting at base, striate on external surface.

Tarsal Setation. Normal.

Gonopod COXA (Figs 9, 16). About $4 \times$ as long as wide. Lateral margin basally slightly convex, curving strongly laterad $c a$. at level of $\mathrm{prl}$, forming semicircular incision, and meeting apical margin in irregularly knobbed laterad process $(l p)$; apical margin sloping apico-mesad from process, irregularly undulate; cucullus $(\mathrm{cu})$ transverse, mesally projecting as rounded lobe with irregularly undulate margin. Metaplical flange $(\mathrm{mf})$ ending in low, rounded process; metaplical mesal margin basally straight, further distally overlaid by lamelloid process $(\mathrm{mp})$ covering arculus. Metaplical shelf not transverse as in most other species: posterior surface of metaplica with large lobe $(\mathrm{msl})$ roofing arculus; lobe concave on posterior face, folded anteriad and on anterior face giving rise to metaplical shelf-spine ( $m s s)$. $m m s$ of medium length, curving first anteriad, then mesad, then basad, reaching level of torsus.

Gonopod telopodite (Fig. 16). Solenomere with a long, straight, mesad proximal spine ( $p s$ ) originating from a wrinkled area. Telomere distally with two branches, $a l$ and $p l$, both curving anteriad, both broad, in part with irregularly serrate edges, lying closely together and accommodating solenomere.

\section{Distribution and habitat}

Known only from Udzungwa Scarp FR. Altitudinal rang: 1400-1800 m asl. Habitat: montane rain forest.

\section{Coexisting species}

C. hamerae sp. nov. was found in the same samples as $C$. nikolajscharffi sp. nov. In addition, $C$. circumvallatus sp. nov. was found in Udzungwa Scarp FR.

\section{Notes}

Very similar and probably closely related to C. scopus sp. nov. from Kigogo FR.

Very peculiar, mushroom-like inter-cytoscutal structures were observed with the scanning electron microscope in this species; see "Two notes on general morphology" and Fig. 34.

Chaleponcus mwanihanensis sp. nov. urn:1sid:zoobank.org:act:84D1DB74-24F4-44A7-BF38-DD31A0FAAE15

Figs 5, 9, 17

\section{Diagnosis}

Medium-sized. Without a proximal spine on the solenomere, a character shared only by $C$. malleolus sp. nov. and $C$. hamerae sp. nov. Differing from these species (and indeed from all other species in the group) by the profile of the gonopod coxa (Fig. 9).

\section{Etymology}

The name is a Latin adjective referring to the type locality.

Material studied (total: 17 ふふ)

\section{Holotype}

TANZANIA: §̊, Morogoro Region, Kilombero District, Udzungwa Mts, Mwanihana FR, 1800-1850 m, pitfall traps, montane rain forest 25-29 Sep. 1984, N. Scharff leg. (ZMUC). 

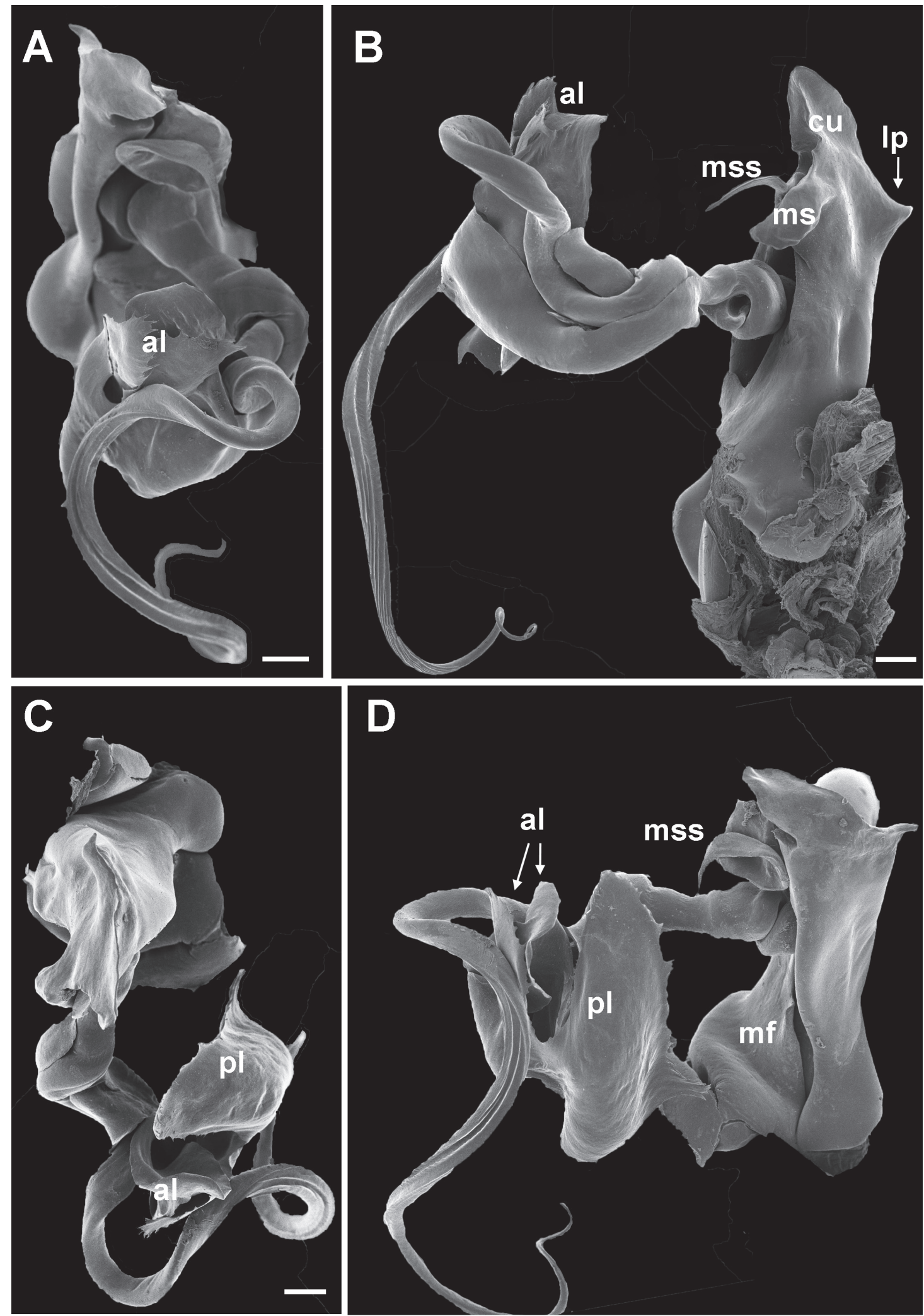

Fig. 17. Chaleponcus mwanihanensis sp. nov., gonopods. A. Left gonopods, mesal-ventral view. B. Left gonopod, posterior view. C. Right gonopod, ventral view. D. Right gonopod, anterior view. $a l=$ anterior lamella of telomere, $c u=$ cucullus, $l p=$ lateral coxal process, $m f=$ metaplical flange, $m s=$ metaplical shelf, $m s s=$ metaplical shelf-spine, $p l=$ posterior lamella of telomere. Scales $0.1 \mathrm{~mm}$. 


\section{Paratypes}

All from TANZANIA, Morogoro Region, Kilombero District, Udzungwa Mts, Mwanihana FR, all in

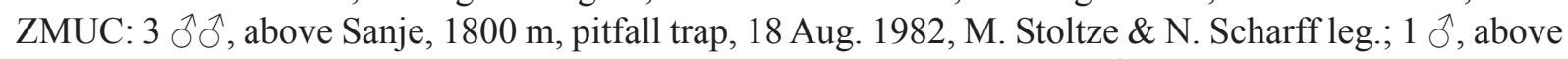
Sanje, 1800 m, litter, 18 Aug. 1982, M. Stoltze \& N. Scharff leg.; 9 ふ઼ , 1800-1850 m, pitfall traps, montane rain forest, 25-29 Sep. 1984, N. Scharff leg.; 3 え ${ }^{2}, 1800-1850 \mathrm{~m}$, litter in montane rain forest, 28-29 Sep. 1984, N. Scharff leg.

\section{Type locality}

TANZANIA: Morogoro Region, Kilombero District, Udzungwa Mts, Mwanihana FR, 1800-1850 m, montane rain forest.

\section{Description (male)}

DiAMETER. $2.2-2.4 \mathrm{~mm}, 44-46$ podous rings.

Colour. After 30 years in alcohol bleached but with traces of a broad, light dorsal stripe, flanked by dark dorsolateral bands, and thin dark lines at ozopore level.

AnAL valves. Each with a very long and slender, slightly curving spine and a small, triangular ventral one; marginal rim raised, setiferous tubercles well developed, on small 'ravelins'.

LimBus. With broadly rounded lobes, separated by short stretches ( $c a .1 / 4-1 / 2$ lobe width) of straight margin; lobes $c a$. as broad as long; deeply striate on external surface. Surface between lobes forming shallow concavity behind straight margin.

TARSAL SETATION (Fig. 5A). Normal.

Gonopod COXA (Figs 9, 17). About $3 \frac{1}{2} \times$ as long as wide. Lateral margin basally straight, then curving slightly laterad and forming lateral triangular process $(l p)$ before continuing to rounded coxal tip; cucullus $(\mathrm{cu})$ hence approximately triangular in outline. Metaplical flange $(m f)$ ending in approximately equilateral triangular process; metaplical mesal margin straight up to level of metaplical shelf $(\mathrm{ms})$. $m s$ simple, regularly rounded, projecting mesad as well as posteriad, continuing anterior-mesally in metaplical shelf-spine ( $m s s$ ) without a marked transition. mss short to medium long, curving first anteriad, then mesad, then posteriad, almost only in horizontal plane.

Gonopod telopodite (Fig. 17). Solenomere without spines or other secondary branches. Telomere distally with two branches, both curving $180^{\circ}$ anteriad: Anterior lamella (al) smaller than posterior lamella $(p l)$, both with several lobes with partly serrate-laciniate edges. Due to $180^{\circ}$ curvature, distal part of $p l$ dominating the anterior view, forming a roughly ellipsoid structure with the long axis oriented basal-apical.

\section{Distribution and habitat}

Known only from Mwanihana FR. Altitudinal range: 1800-1850 m asl. Habitat: montane rain forest.

\section{Coexisting species}

None known. 
ENGHOFF H., Chaleponcus millipedes from Udzungwa Mountains

\section{Chaleponcus basiliscus sp. nov. urn:1sid:zoobank.org:act:AFC2BE4A-F296-4A7E-A396-0C99903FBBBE}

Figs 9, 18

\section{Diagnosis}

Large. Differing from all other species in the group by the double lateral coxal process (Fig. 9).

\section{Etymology}

The name is a noun in apposition and refers to the (remote) resemblance of the cucullus profile to the reptile Basiliscus or its mythological namesake.

Material studied (total: $4 \stackrel{う}{ð}$ )

Holotype

TANZANIA: $\widehat{\jmath}$, Iringa Region, Iringa District, Udzungwa Mts, West Kilombero FR, Udekwa village, Nyambanito Mt., Ukami Forest, $07^{\circ}$ 42’49” S, 36²5’15” E, Jul.-Nov. 1994. D. Moyer leg. (ZMUC).

Paratypes

TANZANIA: $3 \precsim \widehat{\jmath}$, data as holotype (ZMUC).

\section{Type locality}

TANZANIA: Iringa Region, Iringa District, Udzungwa Mts, West Kilombero FR, Udekwa village, Nyambanito Mt, Ukami Forest, $07^{\circ} 42^{\prime} 49^{\prime \prime} \mathrm{S}, 36^{\circ} 25^{\prime} 15^{\prime \prime}$ E.

\section{Description (male)}

DiAMETER. 2.9-3.2 $\mathrm{mm}, 51-52$ podous rings.

CoLour. After 20 years in alcohol with traces of a longitudinal light stripe flanked by paramedian darker bands.

AnAL VALVES. Each with a long, curved dorsal spine and a tiny ventral one.

LimBus. With triangular lobes; lobes slightly longer than broad, striate on outer surface.

TARSAL SETATION. Normal.

GonOPOD COXA (Figs 9, 18). About $3 \frac{1}{2} \times$ as long as width of shaft. Lateral margin straight up to level of metaplical shelf $(\mathrm{ms})$, then curving strongly laterad and forming two triangular lateral processes, $l \mathrm{p} 1$ and $l p 2$; distal margin regularly convex; cucullus $(\mathrm{cu})$ mesally ending in process with two blunt-triangular processes on basal side. Metaplical shelf $(\mathrm{ms})$ regularly rounded, mainly projecting mesad. Metaplical shelf-spine ( $m s s$ ) long. The position of $m s s$ on Fig. 18 is abnormal or an artefact - in the left gonopod of the specimen in question, and also in the other specimens of $C$. basiliscus sp. nov., mss is directed first distad, then regularly curving mesad-basad, as in many other species.

Gonopod TElopodite (Fig. 18). Solenomere with a very long, almost straight proximal spine ( $p s$ ); the erect position of $p s$ may be abnormal or an artefact - in other gonopods studied the spine is directed mesad. Telomere distally divided into two relatively small, only slightly lobed lamellae with almost smooth margins.

\section{Distribution and habitat}

Known only from Nyambanito Mt. in West Kilombero Scarp FR. No altitude or habitat information. 


\section{Coexisting species}

C. ibis sp. nov. was found in the same sample as C. basiliscus sp. nov. In addition, C. circumvallatus sp. nov., C. gracilior sp. nov., C. netus sp. nov. and C. tintin sp. nov. were found in West Kilombero Scarp FR.
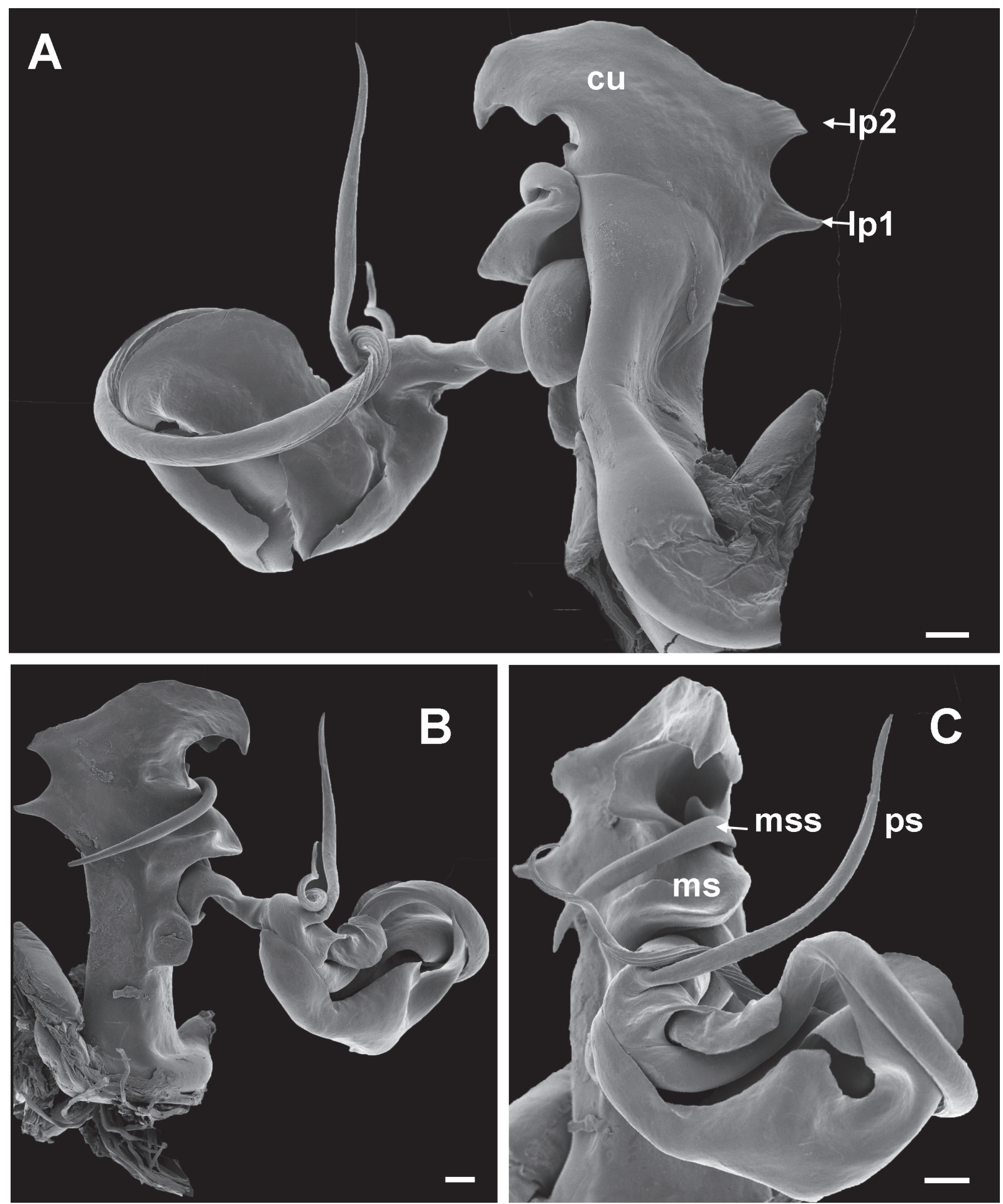

Fig. 18. Chaleponcus basiliscus sp. nov., right gonopod. A. Anterior view. B. Posterior view. C. Mesal view. $c u=$ cucullus, $l p 1$ and $l p 2=$ lateral coxal processes, $m s=$ metaplical shelf, $m s s=$ metaplical shelfspine, $p s=$ proximal spine of solenomere. Scales $0.1 \mathrm{~mm}$. 
ENGHOFF H., Chaleponcus millipedes from Udzungwa Mountains

Species without an obvious lateral coxal process in which the metaplical shelf-spine (mss) is long and projects \pm mesad

\author{
Chaleponcus krai sp. nov. \\ urn:1sid:zoobank.org:act:751A38C1-6F20-4375-A119-79C08025F6C5
}

Figs 4, 9, 19

\title{
Diagnosis
}

Large. Gonopod coxa (Fig. 9) without a lateral process; metaplical shelf-spine long, stout. Telomere with characteristically shaped anterior lamella divided into a horizontal lobe with deeply laciniate edges and a long, straight, distal spine-like part.

\section{Etymology}

The name honours Otto Kraus in recognition of his extremely valuable monographs on Odontopygidae; the name is constructed on a pretended Latin origin of his surname.

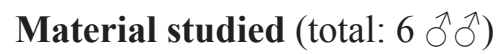

\section{Holotype}

TANZANIA: ${ }^{\wedge}$, Iringa Region, Iringa District, New Dabaga/Ulangambi FR, 0805' 37.9” S, 3554' 05.6" E, fallow/cultivation, 1900-1920 m asl, plot FP, casual, 26-28 Nov. 2000, Frontier Tanzania UMPS leg. (ZMUC).

\section{Paratypes}

All from TANZANIA, Iringa Region, Iringa District: $2 \hat{\jmath} \widehat{\partial}$, data as holotype (ZMUC); $3 \hat{\partial} \widehat{\partial}$, Kalimbazi Mtn, near Mazombe, 2000-2100 m asl, forest floor, Jan. 1984, Jan Kielland (VMNH).

\section{Type locality}

TANZANIA: Iringa Region, Iringa District, New Dabaga/Ulangambi FR, 0805’37.9” S, 3554’05.6” E, fallow/cultivation, 1900-1920 m asl.

\section{Description (male)}

DiAMETER. 3.0-3.2 $\mathrm{mm}, 51$ podous rings.

Colour. After 12 years in alcohol faded, with traces of pale dorsal band, bordered by dark paramedian bands.

ANAL VALVES. Each with a long, slightly curving dorsal spine and a well-developed ventral one; marginal rim raised, setiferous tubercles on 'ravelins'.

LimBus (Fig. 4G). With low, apically truncated and strongly serrated lobes; lobes less than half as long as wide, indistinctly striate on external surface.

TARsal SETATION. Normal.

GonOpOD COXA (Figs 9, 19). Almost $4 \times$ as long as wide. Lateral margin regularly convex from base to tip; cucullus $(\mathrm{cu})$ small, triangular in outline. Metaplical flange ending in long, triangular process $(\mathrm{mfp})$, pointing distad. Metaplical shelf $(m s)$ regularly rounded, projecting posteriad as well as mesad just distal to arculus. Metaplical shelf-spine ( $m s s$ ) originating from anterior-mesal end of $m s$, massive, long, regularly curved, first anteriad, then disto-mesad, in situ crossing over with opposite mss. 
Gonopod telopodite (Fig. 19). Solenomere with very long, straight proximal spine ( $p s)$, distally with three branches:

- an anterior lamella (al) divided into a horizontal lobe with deeply laciniate edges and a long, straight, distal spine-like part,
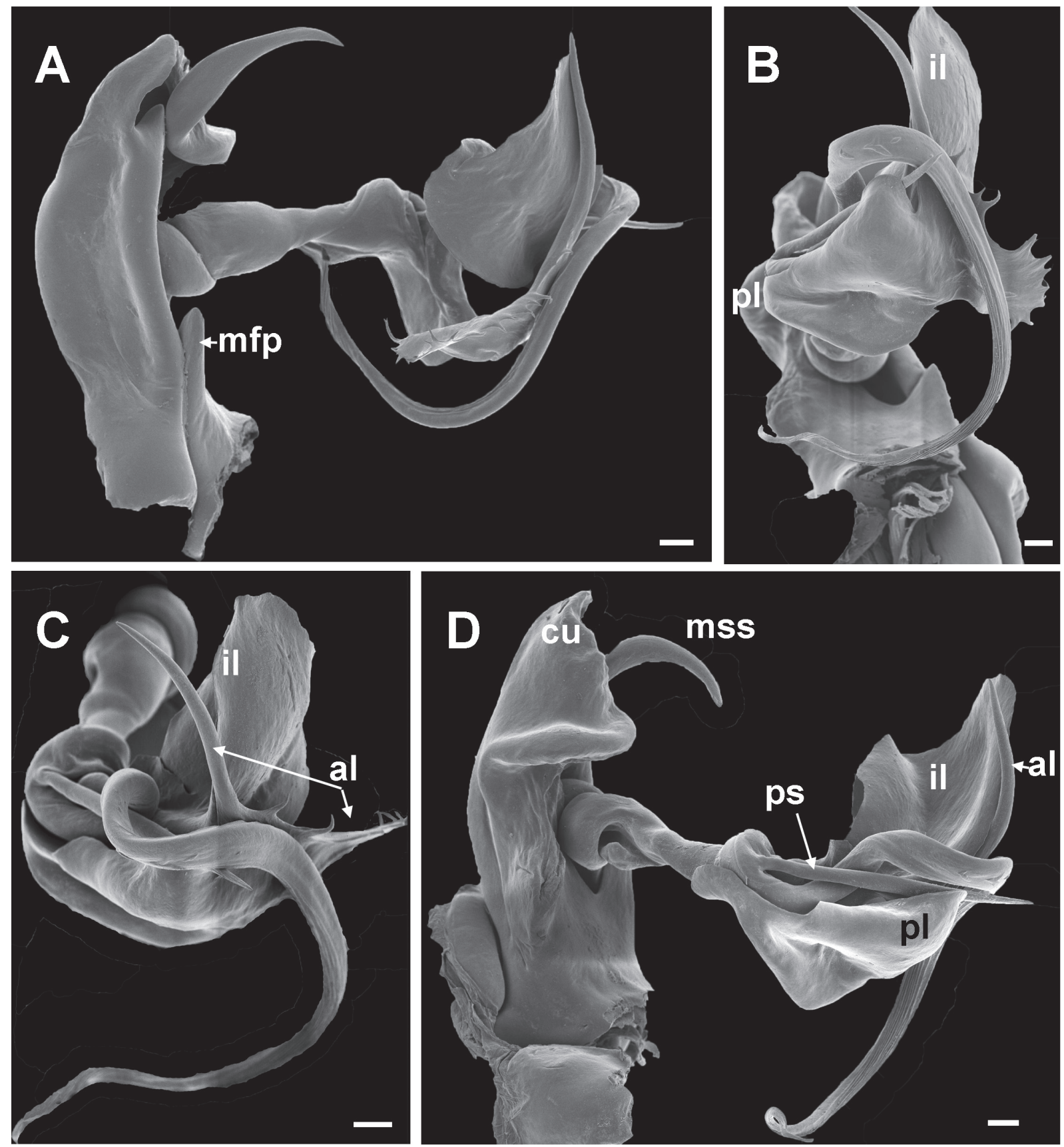

Fig. 19. Chaleponcus krai sp. nov., gonopods. Specimens from New Dabaga-Ulangambi (A) and Kalimbazi Mtn (B-D). A. Left gonopod, anterior view. B-D. Right gonopod. B. Mesal-dorsal view. C. Telopodite, mesal view. D. Posterior view. $a l=$ anterior lobe of telomere, $c u=$ cucullus, $i l=$ intermediate lobe of telomere, $m f p=$ metaplical flange process, $m s s=$ metaplical shelf-spine, $p l=$ posterior lobe of telomere, $p s=$ proximal spine of solenomere. Scales $0.1 \mathrm{~mm}$. 
- a large, simple intermediate lamella (il), projecting distad and closely appressed to spine-like part of $a l$,

- a small, inconspicuous, rounded posterior lamella $(p l)$.

\section{Distribution and habitat}

Known from New Dabaga-Ulangambi FR and from Kalimbazi Mtn, near Mazombe. Altitudinal range: 1900-2100 m asl. Habitat: fallow/cultivation; forest floor.

\section{Coexisting species}

In New Dabaga-Ulangambi FR C. gracilior sp. nov. was found in the same sample as $C$. krai sp. nov. In addition, $C$. vilici sp. nov., $C$. teres sp. nov., $C$. termini sp. nov., $C$. netus sp. nov., $C$. nectarinia sp. nov., C. malleolus sp. nov., C. mwabvui sp. nov., C. dabagaensis and C. vandenspiegeli sp. nov. occur in New Dabaga/Ulangambi FR. C. gracilior sp. nov. also occurs on Kalimbazi Mtn.

\section{Note}

The anterior telomeral lamella of $C$. krai sp. nov. is remarkably similar to the posterior lamella in $C$. nectarinia sp. nov., $c f$. note in the general description of the $C$. dabagaensis group.

Chaleponcus nectarinia sp. nov. urn:1sid:zoobank.org:act:CA316ECB-0AD5-450C-B2A8-ED38EEE4DA87

Figs 6, 9, 20

\section{Diagnosis}

Medium-sized. Gonopod coxa (Fig. 9) without a lateral process; metaplical shelf-spine long. Telomere with characteristically shaped posterior lamella divided into a horizontal lobe with spinose edges and a long, straight, distal spine-like part.

\section{Etymology}

The name (noun in apposition) refers to the somewhat sunbird (Nectarinia)-like profile of the gonopod coxal tip.

Material studied (total: 6 ふぇ゙)

\section{Holotype}

TANZANIA: ${ }^{\top}$, Iringa Region, Iringa District, Udzungwa Mts, New Dabaga/Ulangambi FR, $08^{\circ} 03^{\prime}$ 34.9" S, 35 54' 41.9" E, montane, $1955 \mathrm{~m}$ asl, plot 24, casual, 2 Nov. 2000, Frontier Tanzania leg. (ZMUC).

\section{Paratypes}

All from TANZANIA, Iringa Region, Iringa District, Udzungwa Mts, New Dabaga/Ulangambi FR, all collected by Frontier Tanzania, all in ZMUC: 2 o $^{\top}{ }^{\prime}, 08^{\circ} 03^{\prime} 34.9^{\prime \prime} \mathrm{S}, 35^{\circ} 54^{\prime} 41.9^{\prime \prime} \mathrm{E}$, montane, $1955 \mathrm{~m}$

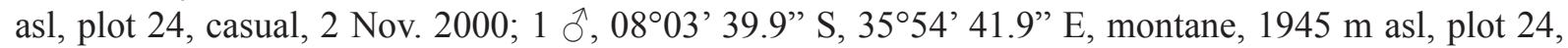
29 Oct. 2000; 1 đ’, $08^{\circ} 04^{\prime} 05.7^{\prime \prime} \mathrm{S}, 35^{\circ} 54^{\prime}$ ' 13.8” E, montane, $1940 \mathrm{~m}$ asl, plot 1, sample 1 of 3, 16 Oct.

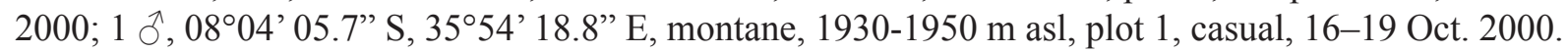

\section{Type locality}

TANZANIA: Iringa Region, Iringa District, Udzungwa Mts, New Dabaga/Ulangambi FR, 0803' 34.9” S, 3554’ 41.9” E, montane, $1955 \mathrm{~m}$ asl. 


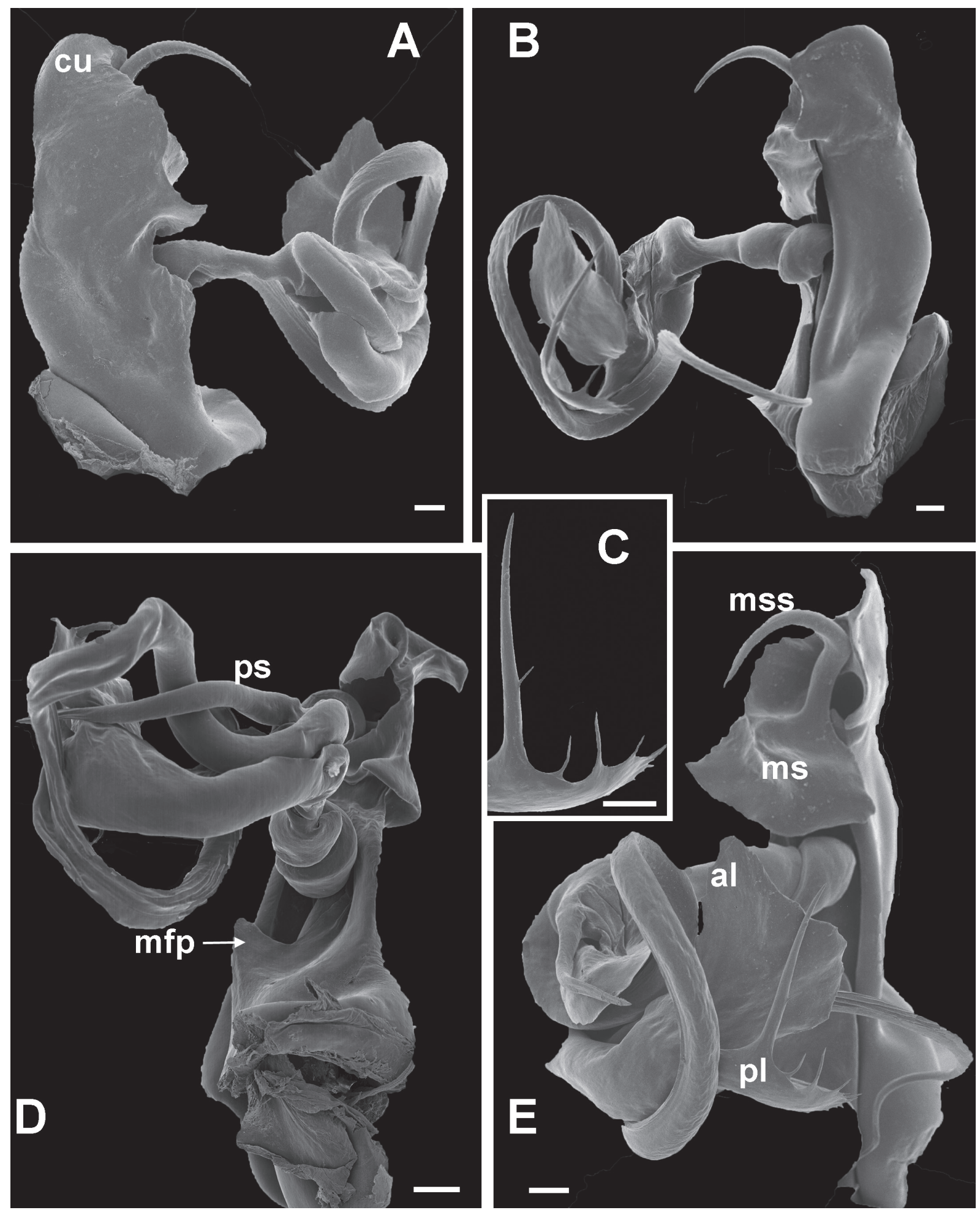

Fig. 20. Chaleponcus nectarinia sp. nov., gonopods. A. Right gonopod, posterior (-lateral) view. B. Right gonopod, anterior view. C. Tip of posterior lamella of telomere. D. Left gonopod, mesal (-posterior) view. E. Right gonopod, mesal view. $a l=$ anterior lobe of telomere, $c u=$ cucullus, $m f p=$ metaplical flange process, $m s=$ metaplical shelf, $m s s=$ metaplical shelf-spine, $p l=$ posterior lobe of telomere, $p s=$ proximal spine of solenomere. Scales $0.1 \mathrm{~mm}$. 


\section{Description (male)}

DiAMETER. $2.3-2.4 \mathrm{~mm}, 48-49$ podous rings.

CoLour. After 13 years in alcohol still with a broad light middorsal band, dorsolaterally dark brownish, laterally brownish-yellow.

Anal valves (Fig. 6A, E). Each with a long, slightly curving dorsal spine and a well-developed, triangular ventral one; marginal rim raised, setiferous tubercles well developed, on 'ravelins'.

LimBus. With long, triangular, apically rounded lobes; lobes $c a$. twice as long as broad, striate on external surface.

TARSAL SETATION. Normal.

GonOPOD COXA (Figs 9, 20). About $4 \times$ as long as wide. Lateral margin slightly convex, continuous with convex apical margin; cucullus $(\mathrm{cu})$ hence regularly rounded; proplical lobe in anterior view hidden by projecting baso-mesal corner of cucullus. Metaplical flange ending in approximately equilateral triangular process $(m f p)$; metaplical mesal margin basally shallowly concave, with semicircular incision at level of arculus. Metaplical shelf $(\mathrm{ms})$ projecting mainly mesad, with approximately right-angled meso-posterior corner. Metaplical shelf-spine (mss) medium length, arising from distal surface of $m s$, first directed apicad, then curving mesad almost in one plane, tip pointing meso-basad.

Gonopod telopodite (Fig. 20). Solenomere with a long, gently curved, proximal spine ( $p s$ ) originating next to a wrinkled area. Telomere distally with two branches, both curving anteriad:

- a broad anterior lamella $(a l)$ with approximately smooth edges,

- a slender posterior lamella $(p l)$ dividing into a long apicad spine and an anteriad lobe with spinose edge.

\section{Distribution and habitat}

Known only from New Dabaga/Ulangambi FR. Altitudinal range: 1930-1955 m asl. Habitat: montane forest.

\section{Coexisting species}

C. malleolus sp. nov., C. netus sp. nov., C. teres sp. nov., C. termini sp. nov., and C. vilici sp. nov. were found in the same samples as $C$. nectarinia sp. nov. In addition, $C$. dabagaensis, $C$. gracilior sp. nov., $C$. krai sp. nov., C. mwabvui sp. nov. and C. vandenspiegeli sp. nov. occur in New Dabaga/Ulangambi FR.

\section{Note}

The posterior telomeral lamella of $C$. nectarinia sp. nov. is remarkably similar to the anterior lamella in C. krai sp. nov., $c f$. note in the general description of the C. dabagaensis group.

Chaleponcus circumvallatus sp. nov. urn:1sid:zoobank.org:act:67292AA6-2D3C-4DE4-BCF0-55719766C6E7

Figs 4-6, 9, 21

\section{Diagnosis}

Large. Gonopod coxa (Fig. 9) without a lateral process; metaplical shelf-spine long. Telomere with a smooth anterior lamella and a posterior lamella ending in two long spines. Claws of walking legs surrounded by 'palisade' of setae, a character shared only with C. ibis sp. nov. 


\section{Etymology}

The name is a Latin adjective meaning "surrounded by palisade" and refers to the 'palisade' of setae surrounding the claws.

Material studied (total: $2 \widehat{\diamond}$ )

\section{Holotype}

TANZANIA: $\widehat{\jmath}$, Tanzania, Iringa Region, Udzungwa Mts, Udzungwa Scarp FR, above Chita village, 1600-1650 m, 8-12 Nov. 1984, montane rain forest, N. Scharff leg. (ZMUC).

\section{Paratype}

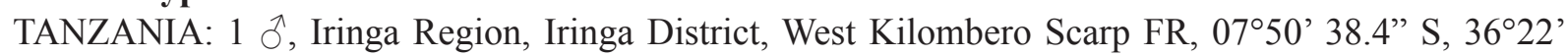
17.6" E, montane forest, 1390-1410 m asl, plot Paradiso, 18 Nov. 2000, Frontier Tanzania UMPS leg. (ZMUC).

\section{Type locality}

TANZANIA: Tanzania, Iringa Region, Udzungwa Mts, Udzungwa Scarp FR, above Chita village, $1600-1650 \mathrm{~m}$, montane rain forest.

\section{Description (male)}

DiAMETER. $2.8 \mathrm{~mm}, 48$ podous rings.

CoLour. After 14 years in alcohol uniform straw yellow, metazonites slightly darker, no traces of a dorsal light band.

Anal valves (Fig. 6B). Each with a very long and stout, slightly curving dorsal spine and a very long and slender ventral one; marginal rim raised; setiferous tubercles well developed, on small 'ravelins'.

LimBus (Fig. 4J). Almost rectilinear, with just the slightest indication of lobes.

TARSAL SETATION (Fig. 5 B-C). Unusual: claws surrounded and almost hidden by numerous stiff setae, accessory claw much longer than claw.

Gonopod coxa (Figs 9, 21). Stout, $c a .3 \times$ as long as wide. Lateral margin slightly convex in basal 2/3, then straight, then continuing in smooth curve in apical margin; cucullus $(c u)$ hence regularly rounded. Metaplical flange ending in long triangular process $(m f p)$; metaplica posterior-mesally with large triangular process $(\mathrm{mp})$, delimiting semicircular sinus together with base of metaplical shelf. Metaplical shelf $(m s)$ regularly rounded, projecting mesad as well as posteriad. Metaplical shelf-spine (mss) originating from anterior-mesal end of $m s$, massive, long, regularly curved, first anteriad, then distomesad.

GonOPOD TELOPODITE (Fig. 21). Solenomere with a very long, straight, mesad proximal spine ( $p s$ ). Telomere distally with two branches, both curving anteriad:

- a rounded anterior lamella $(a l)$ with small, rectangular accessory lamella ( $\left.a l^{\prime}\right)$ on its mesal surface,

- a posterior lamella $(p l)$ ending in an apicad and a basad-anteriad spine.

\section{Distribution and habitat}

Known from West Kilombero Scarp FR and Udzungwa Scarp FR. Altitudinal range 1390-1650 m asl. Habitat: montane forest. 


\section{Coexisting species}

C. hamerae sp. nov. and C. nikolajscharffi sp. nov. also occur in Udzungwa Scarp FR. In West Kilombero Scarp FR $C$. netus sp. nov. was found in the same sample as $C$. circumvallatus sp. nov. In addition, $C$. basiliscus sp. nov., C. gracilior sp. nov., C. ibis sp. nov. and C. tintin sp. nov. occur in West Kilombero Scarp FR.
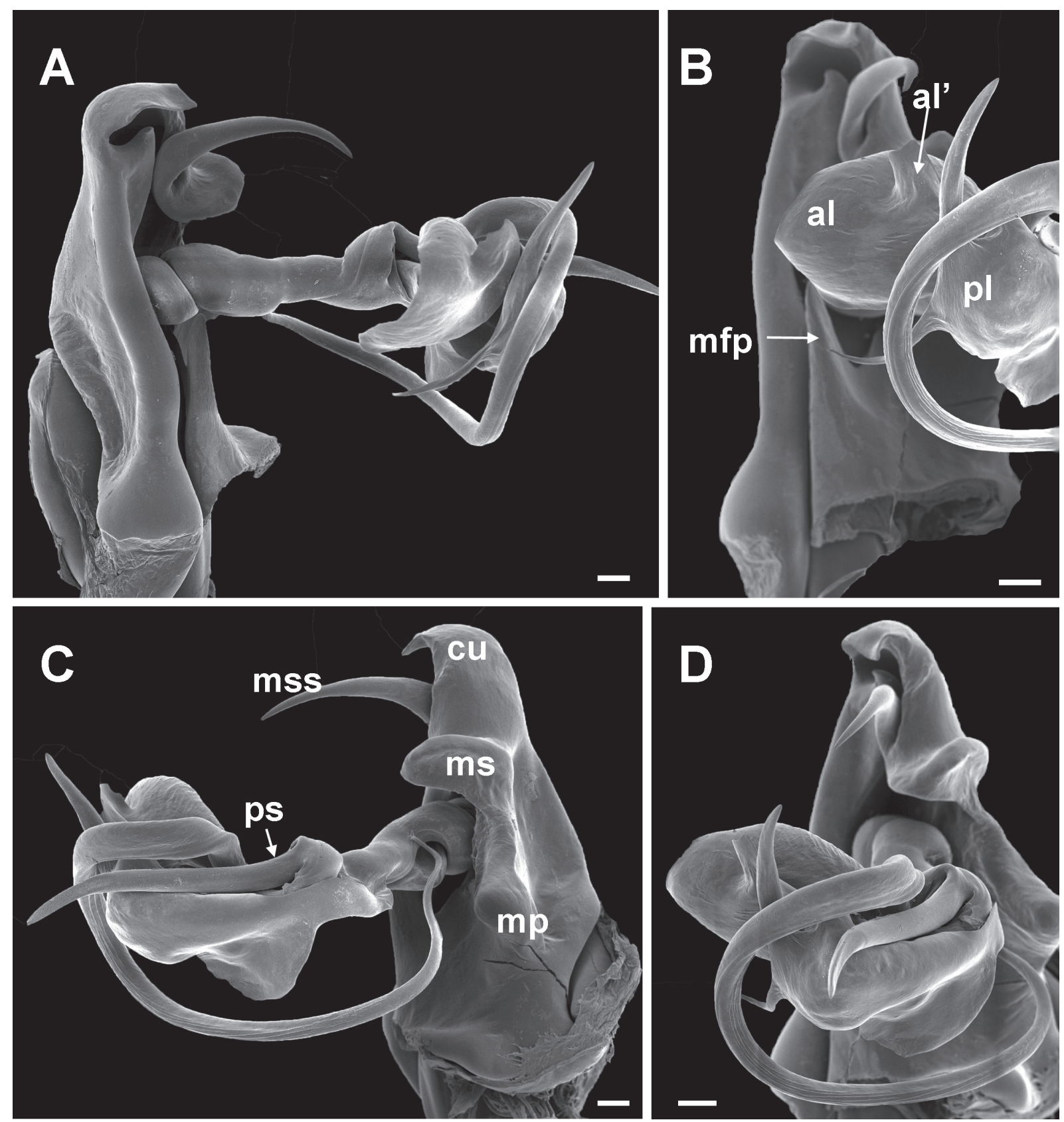

Fig. 21. Chaleponcus circumvallatus sp. nov., left gonopod. A. Anterior view. B. Mesal-anterior view. C. Posterior view. D. Mesal-posterior view. $a l=$ anterior lobe of telomere, $a l$ ' $=$ accessory lamella, $c u=$ cucullus, $m f p=$ metaplical flange process, $m p=$ mesal metaplical process, $m s=$ metaplical shelf, $m s s=$ metaplical shelf-spine, $p l=$ posterior lobe of telomere, $p s=$ proximal spine of solenomere. Scales $0.1 \mathrm{~mm}$. 


\section{Notes}

Resembles the smaller $C$. nectarinia sp. nov. and the similar-sized $C$. krai sp. nov. in gonopod morphology, including in the possession of a telomeral lobe with a long spine. Differs from these species in the detailed shape of this lobe. Differs from all other species in the C. dabagaensis group except $C$. ibis sp. nov. by the peculiar distal setation of the walking leg tarsi. Although females are generally not considered in this study, it deserves mention that a female specimen found together with the male $C$. circumvallatus sp. nov. from West Kilombero Scarp FR and sharing its size and general morphology, also has the strange tarsal setation. The function of this is uncertain; maybe it is an adaptation for walking on soft substrates (I.B. Enghoff pers. comm.).

Chaleponcus ibis sp. nov. urn:1sid:zoobank.org:act:E6764255-8F2F-4B2D-8F3C-26F40FA01EB0

Figs 9, 22

\section{Diagnosis}

Large. Gonopod coxa (Fig. 9) without a lateral process; metaplical shelf-spine very long. Telomere with a rugged anterior lamella and posterior lamella ending in short, parallel, elongate lobes. Claws of walking legs surrounded by 'palisade' of setae, a character shared only with $C$. circumvallatus sp. nov.

\section{Etymology}

The name is a noun in apposition and refers to the somewhat ibis bill-like metaplical shelf-spine.

Material studied (total: 1 đ)

Holotype

TANZANIA: $\widehat{\partial}^{\curvearrowright}$, Iringa Region, Iringa District, Udzungwa Mts, West Kilombero FR, Udekwa village, Nyambanito Mt., Ukami Forest, $07^{\circ}$ 42’49” S, 36²5’15” E, Jul.-Nov. 1994. D. Moyer leg. (ZMUC).

\section{Type locality}

TANZANIA: Iringa Region, Iringa District, Udzungwa Mts, West Kilombero FR, Udekwa village, Nyambanito Mt., Ukami Forest, $07^{\circ} 42$ '49” S, 36²5’15” E.

\section{Description (male)}

DiAMETER. $3.5 \mathrm{~mm}, 54$ podous rings (the largest of all species in the group).

Colour. After 20 years in alcohol ground colour greyish, posterior part of metazonites yellow-brownish; traces of a broad dorsal dark stripe (most other species have traces of a light stripe).

ANAL VALVES. Each with a strong, apparently broken dorsal and smaller, but well-developed ventral spine. Margin raised, setiferous tubercles on ravelins.

LimBus. With triangular lobes; lobes $c a$. as long as wide, margin micro-dentate, outer surface striate.

TARSAL SETATION. Unusual: claws surrounded and almost hidden by numerous stiff setae, accessory claw much longer than claw (as in C. circumvallatus sp. nov., Fig. 5B, C).

Gonopod coxa (Figs 9, 22). Stout, $c a .3 \times$ as long as wide. Lateral margin irregularly convex, continuing in smooth curve in apical margin; cucullus $(c u)$ hence regularly rounded. Metaplica posterio-mesally with triangular process $(m p)$. Metaplical shelf $(m s)$ relatively small, giving rise to very long, slightly curved metaplical shelf-spine (mss). 
Gonopod telopodite (Fig. 22). Solenomere with a very long, straight, mesad proximal spine ( $p s$ ). Telomere distally with two branches, both curving anteriad:

- an irregular shaped anterior lamella (al) with coarsely dentate proximal part and a smooth, subrectangular distal part (which maybe corresponds to the accessory lobe, al', in C. circumvallatus sp. nov.),

- a posterior lamella $(p l)$ ending in two short, parallel, elongate lobes.
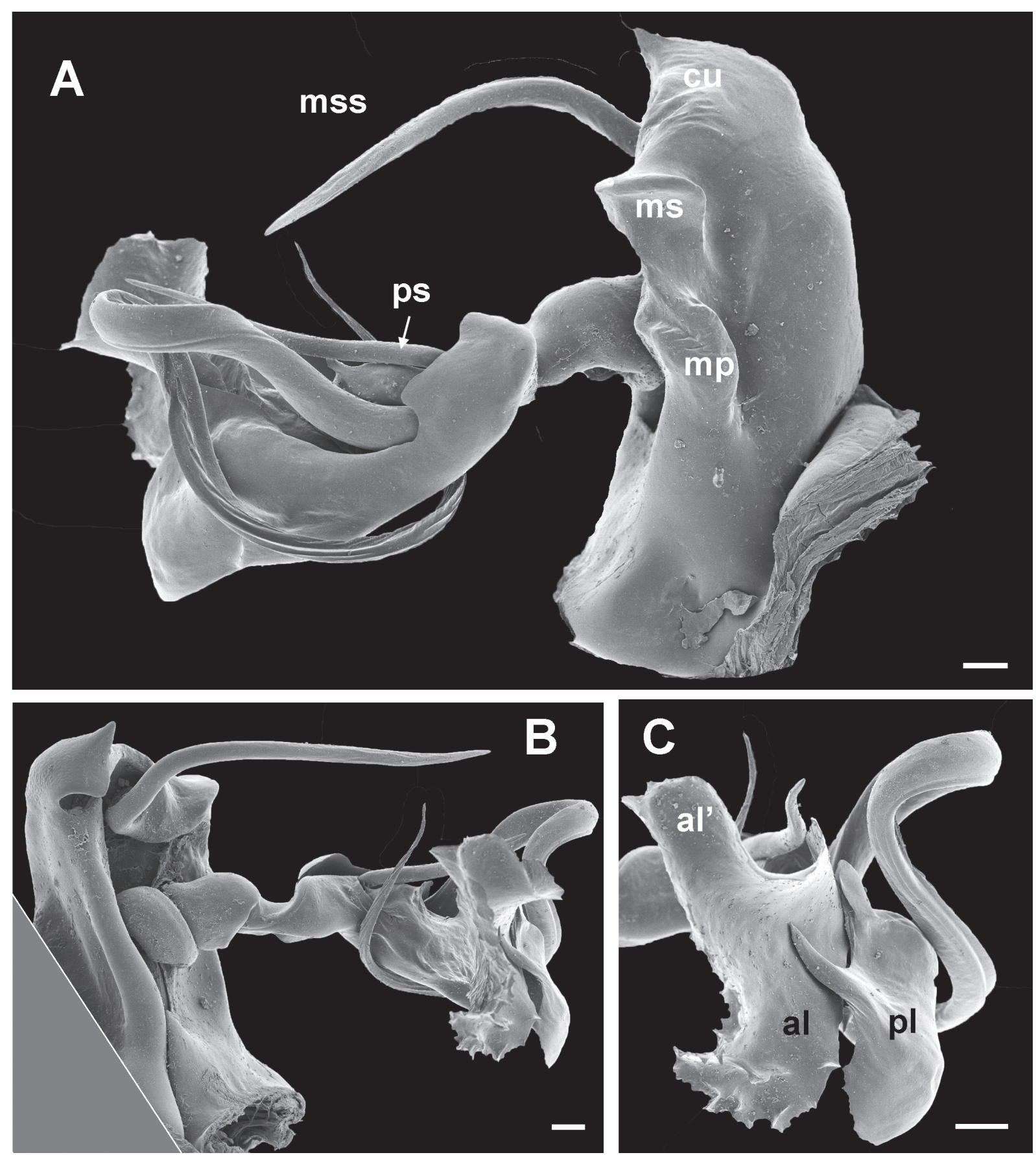

Fig. 22. Chaleponcus ibis sp. nov., left gonopod. A. Posterior view. B. Anterior view. C. Telopodite, mesal-anterior view. $a l=$ anterior lobe of telomere, $a l^{\prime}=$ accessory lamella?, $c u=$ cucullus, $m p=$ mesal metaplical process, $m s=$ metaplical shelf, $m s s=$ metaplical shelf-spine, $p l=$ posterior lobe of telomere, $p s=$ proximal spine of solenomere. Scales $0.1 \mathrm{~mm}$. 


\section{Distribution and habitat}

Known only from Nyambanito Mt. in West Kilombero Scarp FR. No altitude or habitat information.

\section{Coexisting species}

C. basiliscus sp. nov. was found in the same sample as C. ibis sp. nov. In addition, C. circumvallatus sp. nov., $C$. gracilior sp. nov., C. netus sp. nov. and C. tintin sp. nov. were found in West Kilombero Scarp FR.

\section{Notes}

Resembles the almost similar-sized $C$. circumvallatus sp. nov. both in the unusual tarsal setation and in gonopod structure. C. ibis sp. nov. differs from C. circumvallatus sp. nov., i.a., in having distinct lobes on the limbus, in having the metaplical shelf-spine (mss) much longer, in having the proximal part of the anterior telomeral lobe $(a l)$ coarsely dentate, and in having two relatively short, parallel elongate lobes on the posterior telomeral lamella, as opposed to the two very long, diverging spines in C. circumvallatus sp. nov.

Chaleponcus vandenspiegeli sp. nov. urn:1sid:zoobank.org:act:A2C22BA2-915D-47DC-A49C-9EE26F52F8D9

Figs 9, 23

\section{Diagnosis}

Medium-sized. Gonopod coxa (Fig. 9) without a lateral process; metaplical shelf-spine long. Telomere with an anterior lamella ending in two short, parallel processes and a posterior lamella with serrate margin.

\section{Etymology}

The name honours Didier VandenSpiegel in recognition of his taxonomic work on Afrotropical millipedes.

Material studied (total: 1 ○)

\section{Holotype}

TANZANIA: $\widehat{\jmath}$, Iringa Region, Iringa District, New Dabaga/Ulangambi FR, $08^{\circ} 05^{\prime} 34.5^{\prime \prime} \mathrm{S}, 35^{\circ} 55^{\prime}$ ' 31.5” E, montane, 1800-1900 m asl, plot 16, casual, 15-16 Nov. 2000, Frontier Tanzania leg. (ZMUC).

\section{Type locality}

TANZANIA: Iringa Region, Iringa District, Udzungwa Mts, New Dabaga/Ulangambi FR, $08^{\circ} 05^{\prime} 34.5^{\prime}$ ” $\mathrm{S}, 35^{\circ} 55^{\prime} 31.5^{\prime}$ E, $1800-1900 \mathrm{~m}$ asl.

Description (male)

DiAMETER. $2.0 \mathrm{~mm}, 44$ podous rings.

CoLour. After 14 years in alcohol generally straw-yellow, with a broad, light middorsal stripe formed by an hourglass-shaped spot on each body ring; stripe flanked by dark paramedian zones.

ANAL VALVES. Each with a small dorsal and a very small ventral denticle; mesal margin raised, setiferous tubercles not on ravelins.

LimBus. With slender triangular lobes; lobes $c a$. twice as long as broad. 
TARSAL SETATION. Normal.

Gonopod COXA (Figs 9, 23). About $3 \frac{1}{2} \times$ as long as broad. Metaplical flange ending in rounded, projecting lobe ( $m f p)$; metaplica with large rounded process $(m p)$ just basal to arculus. Metaplical shelf $(\mathrm{ms})$ relatively small. Metaplical shelf-spine ( $\mathrm{mss}$ ) medium-long, directed mesad, bent at $\mathrm{ca} .120^{\circ}$ at midlength.
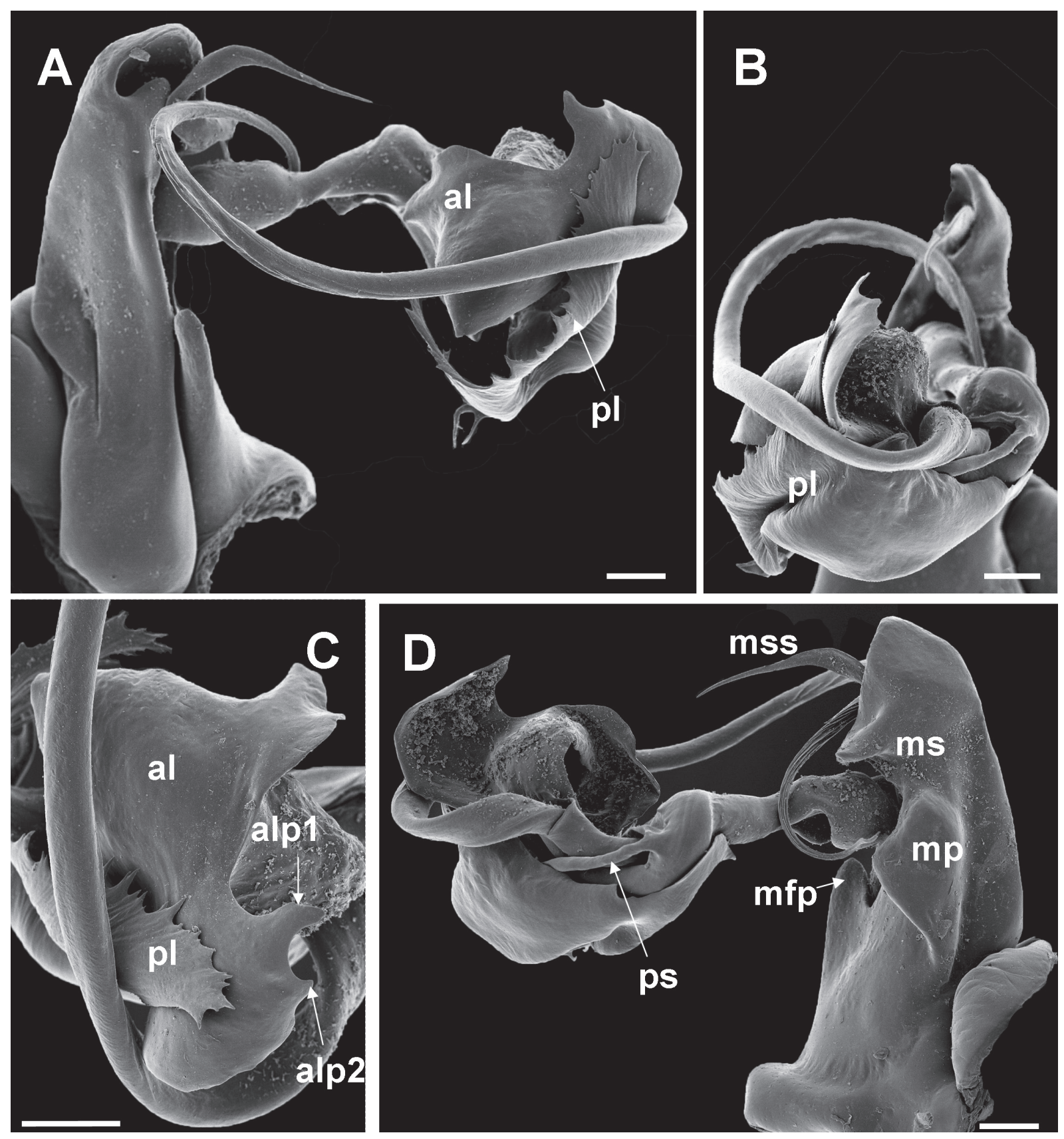

Fig. 23. Chaleponcus vandenspiegeli sp. nov., left gonopod. A. Anterior view. B. Mesal view. C. Tip of telomere and part of solenomere, ventral view. D. Posterior view. $a l=$ anterior lamella of telomere, alp 1 and $a l p 2=$ processes from $a l, m f p=$ metaplical flange process, $m p=$ mesal metaplical process, $m s$ $=$ metaplical shelf, $m s s=$ metaplical shelf-spine, $p l=$ posterior lamella of telomere,$p s=$ proximal spine of solenomere. Scales $0.1 \mathrm{~mm}$. 
GonOPOD TELOPODITE (Fig. 23). Solenomere with a medium-long proximal spine ( $p s$ ). Telomere distally with two branches which both bend anteriad:

- a relatively simple anterior lamella $(a l)$ with a number of lobes etc. along its margin, including two short, parallel processes (alp1, alp2),

- a strongly convoluted posterior lamella $(p l)$ which because of its bending over is largely visible in anterior view; margin of $p l$ strongly serrate.

\section{Distribution and habitat}

Known only from Udzungwa Mts, New Dabaga/Ulangambi FR. Altitudinal range: 1800-1900 m asl. Habitat: montane forest.

\section{Coexisting species}

C. gracilior sp. nov., C. netus sp. nov. and C. termini sp. nov. were found in the same sample as $C$. vandenspiegeli sp. nov. In addition, $C$. dabagaensis, $C$. krai sp. nov., C. malleolus sp. nov., C. mwabvui sp. nov., C. nectarinia sp. nov., C. teres sp. nov. and C. vilici sp. nov. occur in New Dabaga/Ulangambi FR.

\section{Note}

The gonopods of $C$. vandenspiegeli sp. nov. somewhat resemble those of the much bigger species $C$. krai sp. nov. The two processes of the anterior telopodal lamella in C. vandenspiegeli sp. nov. are in almost the same position in relation to the rest of the gonopod as the two parallel lobes on the posterior telopodal lamella in C. ibis sp. nov.

\section{Species without an obvious lateral coxal process in which the metaplical shelf-spine (mss) is not long and projecting \pm mesad}

(C. vilici sp. nov. has the lateral side of the coxa somewhat angled which reminds of a small lateral process)

\section{Chaleponcus vilici sp. nov. urn:Isid:zoobank.org:act:F44D3A63-1E8A-4D6E-AE7D-6BC61723D34F}

Figs 8-9, 24

\section{Diagnosis}

Medium-sized. Differs from all other species of the C. dabagaensis group by the two-levelled metaplical shelf and the course of the metaplical shelf-spine, which fits between the two levels of the shelf. Gonopod coxa (Fig. 9) without a lateral process; metaplical shelf-spine long.

\section{Etymology}

The name honours Richard L. Hoffman (1927-2012) global grand-master of diplopodology through much of the last half of the previous, as well as the first decade of the present century. Vilici is the genitive case of the Latin noun vilicus, meaning 'steward', which is also the original meaning of the name Hoffman.

Material studied (total: 37 ふぇ)

\section{Holotype}

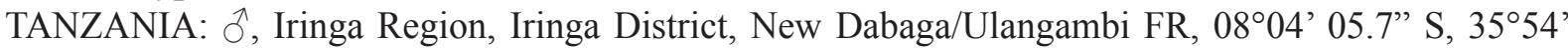
18.8” E, montane, 1930-1950 m asl, plot 1, casual, 16-19 Oct. 2000, Frontier Tanzania leg. (ZMUC). 


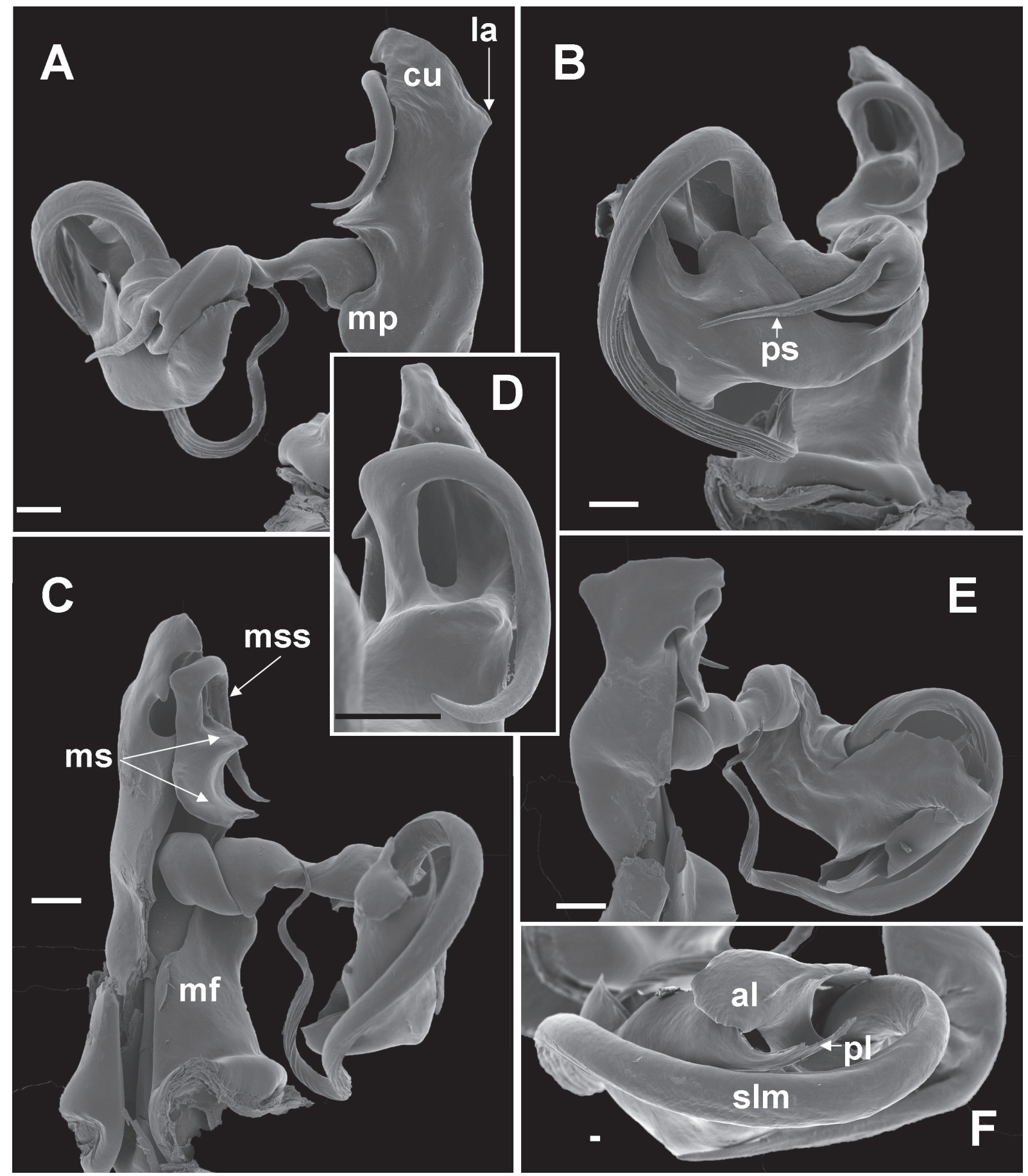

Fig. 24. Chaleponcus vilici sp. nov., left gonopod. A. Posterior view. B. Mesal view. C. Mesal-anterior view. D. Close-up of metaplical shelf-spine, mesal view. E. Anterior (and slightly apical/ventral) view. F. Telopodite, distal view, showing solenomere and the two distal telomere branches. $a l=$ anterior lamella of telomere, $c u=$ cucullus, $l a=$ lateral angle of coxa, $m f=$ metaplical flange, $m p=$ mesal metaplical process, $m s=$ metaplical shelf, $m s s=$ metaplical shelf-spine, $p l=$ posterior lamella of telomere, $s l m=$ solenomere. Scales: $0.1 \mathrm{~mm}(\mathrm{~A}-\mathrm{D}), 0.01 \mathrm{~mm}(\mathrm{E}-\mathrm{F})$. 
Paratypes

All from TANZANIA, Iringa Region, Iringa District, New Dabaga/Ulangambi FR, all collected by

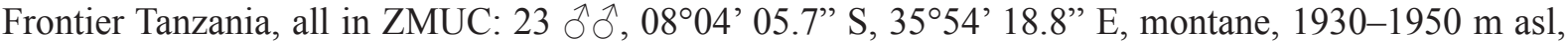

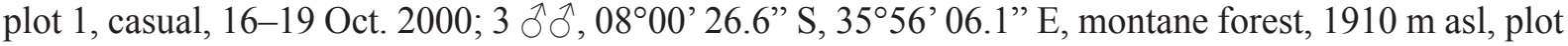

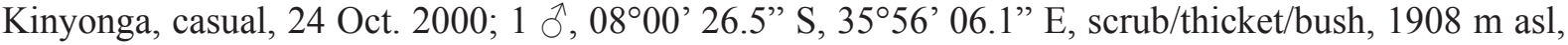

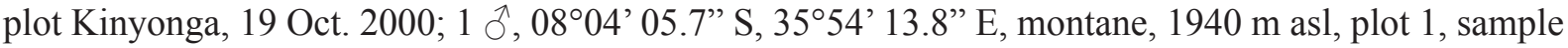
1 of 3, 16 Oct. 2000; 7 ふえ $0^{\circ}, 08^{\circ} 03^{\prime} 34.9^{\prime \prime} \mathrm{S}, 35^{\circ} 54^{\prime} 41.9^{\prime \prime}$ E, montane, $1955 \mathrm{~m}$ asl, plot 24, casual, 2 Nov. 2000; 1 đ', 0804' 05.6” S, 3554' 20.4” E, montane, $1930 \mathrm{~m}$ asl, plot 6, sample 3 of 3, 27 Oct. 2000.

\section{Type locality}

TANZANIA: Iringa Region, Iringa District, Udzungwa Mts, New Dabaga/Ulangambi FR, 0804'05.7”' S, 35'54'18.8” E, montane, 1930-1950 m asl.

\section{Description (male)}

DiAMETER. 2.0-2.1 mm, 46-49 podous rings.

CoLour. After 12 years in alcohol pale brown below ozopores, blackish above, dorsally with a light band with a thin dark midline, telson blackish.

ANAL VALVES. Each with a long, slightly curving dorsal spine, no ventral spine; marginal rim raised, setiferous tubercles on 'ravelins'.

LimBus. With long, triangular, apically rounded lobes, $c a .1 \frac{1}{2}$ times longer than wide, lobes striate on external surface.

\section{TARSAL SETATION. Normal.}

GonOPOD COXA (Figs 9, 24). About $3 \times$ as long as wide. Lateral margin shallowly S-shaped: slightly convex in middle, then slightly concave, subdistally with a protruding angle (la), apical margin starting from la oblique, shallowly sinuous; cucullus $(c u)$ hence triangular, apically with small mesad process. Metaplical flange $(\mathrm{mf})$ ending in blunt, rounded angle, no process; metaplical mesal margin with 3 processes: a rounded, semicircular process $(\mathrm{mp}$ ) basal to arculus and two processes, formed by metaplical shelf, distal to arculus. Metaplical shelf $(\mathrm{ms})$ massive, with two levels separated by concavity into which tip of metaplical shelf-spine ( $m s s$ ) fits. $m s s$ long, slender, originating from distal surface of $m s$, from there first projecting distad, then turning posteriad at right angles and curving smoothly basad, and then anteriad, fitting between two levels of $m s$, in mesal view (Fig. 24D) almost forming a letter D (mss frequently broken).

Gonopod telopodite (Figs 8B, 24). Solenomere ( $\mathrm{slm}$ ) with a long, straight proximal spine ( $\mathrm{ps}$ ). Telomere distally with two relatively small branches, folded around each other somewhat like a pair of onefingered hands, the 'finger' of the anterior lamella ( $a l$ ) having smooth edges, that of the slenderer posterior lamella $(p l)$ having jagged edges.

\section{Distribution and habitat}

Known only from Udzungwa Mts, New Dabaga/Ulangambi FR. Altitudinal range: 1908-1955 m asl.

\section{Coexisting species}

C. gracilior sp. nov., C. malleolus sp. nov., C. nectarinia sp. nov., C. netus sp. nov., C. teres sp. nov. and $C$. termini sp. nov. were found in the same samples as $C$. vilici sp. nov. In addition, $C$. dabagaensis, $C$. krai sp. nov., C. mwabvui sp. nov. and C. vandenspiegeli sp. nov. occur in New Dabaga/Ulangambi FR. 


\section{Chaleponcus teres sp. nov. urn:1sid:zoobank.org:act:F4EB8A22-2F19-438F-8C65-DB6091867337}

Figs 4, 6, 9, 25

\section{Diagnosis}

Medium-sized. Differs from all other group members, except $C$. malleolus sp. nov., by the absence of a dorsal spine on each anal valve. Further characterized by the subquadratic outline of the cucullus and the structure of the telomere, especially the presence of a slender, sinuous, spine-like branch. Gonopod coxa (Fig. 9) without a lateral process; metaplical shelf-spine long.

\section{Etymology}

The name is a Latin adjective meaning "smooth" and refers to the spineless anal valves.

Material studied (total: 29 ふぇ゙)

\section{Holotype}

TANZANIA: $\widehat{\lambda}$, Iringa Region, Iringa District, Udzungwa Mts, New Dabaga/Ulangambi FR, $08^{\circ} 04^{\prime}$ 05.7” S, 3554' 18.8” E, montane, 1930-1950 m asl, plot 1, casual, 16-19 Oct. 2000, Frontier Tanzania leg. (ZMUC).

\section{Paratypes}

All from TANZANIA, Iringa Region, Iringa District, Udzungwa Mts, New Dabaga/Ulangambi FR, all collected by Frontier Tanzania, all in ZMUC: $27 \partial^{\lambda} \partial^{\prime}, 08^{\circ} 04^{\prime} 05.7^{\prime \prime} \mathrm{S}, 35^{\circ} 54^{\prime} 18.8^{\prime \prime}$ E, montane, 1930-

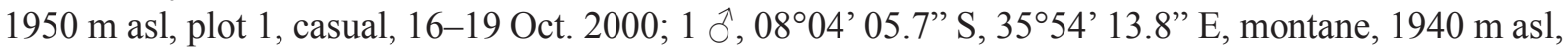
plot 1, sample 3 of 3, 19 Oct. 2000.

\section{Type locality}

TANZANIA: Iringa Region, Iringa District, Udzungwa Mts, New Dabaga/Ulangambi FR, 0804'05.7” S, 35 54' $18.8^{\prime \prime}$ E, montane, 1930-1950 m asl.

\section{Description (male)}

DiAMETER. $1.9-2.2 \mathrm{~mm}, 45-47$ podous rings.

CoLour. After 12 years in alcohol yellowish, with dark spots at ozopores and paramedian dark dorsal bands flanking a mid-dorsal light stripe; paramedian dark colouration sometimes extending down flanks on metazonites, giving the body a ringed appearance; body rings 6 and 7 darker than the others.

AnAl valves (Fig. 6D). Entirely without dorsal and ventral spines; marginal rim not raised, setae not on tubercles.

LimBus (Fig. 4H). With low, broad, rounded lobes, separated by parabolic sinuses; each lobe $c a .4$ times broader than long, margin densely and finely serrate, lobes indistinctly striate on external surface.

\section{TARSAL SETATION. Normal.}

Gonopod COXA (Figs 9, 25). About $3 \frac{1}{2} \times$ as long as wide. Lateral margin straight in basal $2 / 3$, then shallowly concave, angle between lateral and apical margins $90^{\circ}$, sharp; cucullus $(\mathrm{cu})$ hence subquadratic. Metaplical flange $(\mathrm{mf})$ smoothly rounded, no angle, no process; metaplical mesal margin straight up to level of arculus. Metaplical shelf $(m s)$ forming subrectangular process just distal to arculus, followed by very deep incision (in) separating cucullus from basal part of metaplica; $m s$ proximally stout, continuing 

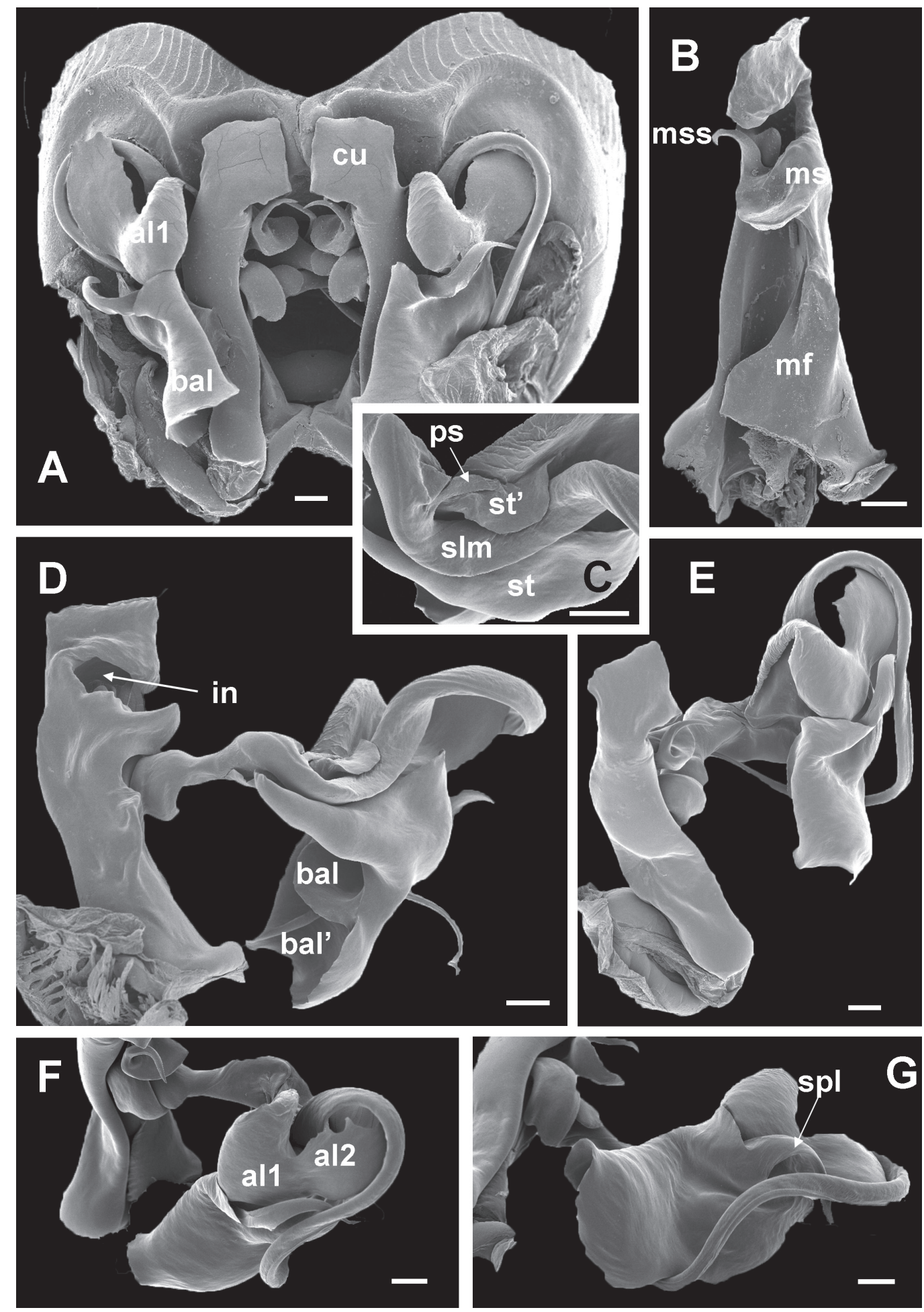

Fig. 25. Chaleponcus teres sp. nov., gonopods. A. Gonopods in situ in seventh body ring, anterior view. B. Left gonopod, mesal view. C. Right gonopod, base of solenomere and telomere, ventral view. D. Right gonopod, posterior view. E. Left gonopod, anterior(-lateral-ventral) view. F. Right telopodite, mesalanterior-ventral view. G. Right telopodite, mesal-anterior view. all, al2 $=$ branches of apical telomeral lamella, $b a l, b a l$ ' = basal lamella of telomere, $c u=$ cucullus, $i n=$ metaplical incision, $m f=$ metaplical flange, $m s=$ metaplical shelf, $m s s=$ metaplical shelf-spine, $p s=$ proximal spine of solenomere, $s l m=$ solenomere, $s p l=$ spine-like lamella of telomere, $s t, s t^{\prime}=$ main stem of telomere. Scales $0.1 \mathrm{~mm}$. 
in metaplical shelf-spine ( $\mathrm{mss}$ ) with no clear demarcation. mss medium long, originating from anteriordistal surface of $m s$, first projecting distad, then curving mesad, and then slightly basad.

GoNOPOD TELOPODite (Fig. 25). Solenomere with a small, inconspicuous, irregular proximal spine ( $p s$ ). Telomere without a separate proximal lobe but posterior margin of proximal part of main stem (st') lying closely against base of solenomere $(\mathrm{slm})$. Telomere distally with three branches:

- A large, roughly rectangular basal lamella (bal) carrying a secondary lamella (bal') on its lateral side,

- A distal spine-like branch, slender and sinuous ( $s p l)$,

- An irregular apical lamella dividing in two branches, proximal branch (all) with smooth margins, the distal branch (al2) with irregularly serrated margin. all and bal in situ curving around opposite coxa (Fig. 25A).

\section{Distribution and habitat}

Known only from Udzungwa Mts, New Dabaga/Ulangambi FR. Altitudinal range: 1930-1950 m asl. Habitat: montane forest.

\section{Coexisting species}

C. termini sp. nov. and C. vilici sp. nov. were found in the same samples as C. teres sp. nov. In addition, C. dabagaensis, $C$. gracilior sp. nov., C. krai sp. nov., C. malleolus sp. nov., C. mwabvui sp. nov., C. nectarinia sp. nov., C. netus sp. nov. and C. vandenspiegeli sp. nov. occur in New Dabaga/ Ulangambi FR.

\section{Notes}

The gonopods somewhat resemble those of C. hamerae sp. nov.

Chaleponcus hamerae sp. nov. urn:1sid:zoobank.org:act:E27E3FB0-22E6-46EF-81CB-447DA44E3090

Figs 9, 26

\section{Diagnosis}

Medium-sized. Characterized by the sub-rectangular outline of the cucullus, resembling C. teres sp. nov. in this character, but differing by having a dorsal spine on each anal valve. Telomeral lamellae largely smooth. Gonopod coxa (Fig. 9) without a lateral process; metaplical shelf-spine long.

\section{Etymology}

The name honours Michelle Hamer in recognition of her work on the taxonomy and conservation of African millipedes.

Material studied (total: 9 ふึふ)

\section{Holotype}

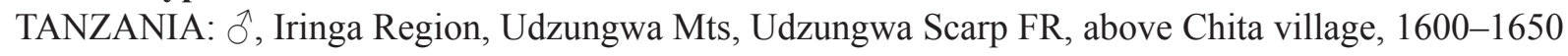
m, 8-13 Nov. 1984, pitfall traps, montane rain forest, N. Scharff leg. (ZMUC).

\section{Paratypes}

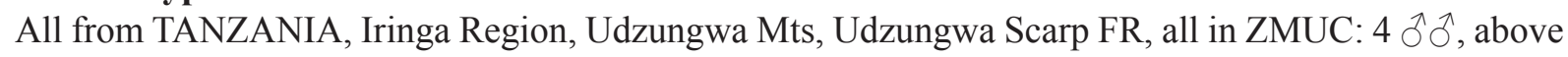

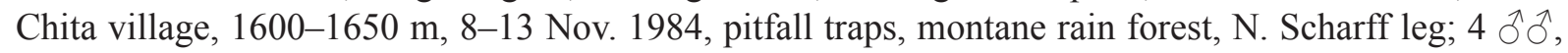
$11 \mathrm{~km}$ SE of Masisiwe village, Kihanga Stream, 1800 m, 08²2’ 05.7’' S, 3558’ 41.6” E, 17-27 May 1997. ZMUC \& SI Exp. 


\section{Type locality}

TANZANIA: Iringa Region, Udzungwa Mts, Udzungwa Scarp FR, above Chita village, 1600-1650 m, rain forest.

\section{Description (male)}

DiAMETER. $2.1-2.3 \mathrm{~mm}, 46-47$ podous rings.

Colour. After 30 years in alcohol (brownish) yellow, traces of broad light dorsal stripe flanked by dorsolateral dark stripes, narrow lateral dark line at ozopore level.

AnAl valves. Each with a small dorsal spine and a very small ventral spine; marginal rim raised, setiferous tubercles on ravelins.

LimBus. With broadly rounded to spatulate, apically finely serrate lobes; lobes as broad as long or slightly broader, separated by rounded incisions much narrower than width of lobes, or by short stretches of straight, finely serrulate margin.

\section{TARSAL SETATION. Normal.}

GonOPOD COXA (Figs 9, 26). About $3 \frac{1}{2}-4 \times$ as long as wide. Lateral margin basally slightly sinuous, basally convex, $c a$. at level of proplical lobe $(p r l)$ concave and then again convex, meeting oblique, straight apical margin under blunt angle; cucullus $(\mathrm{cu})$ hence subrectangular in outline. Metaplical flange $(m f)$ ending in blunt, rounded angle, no process; metaplical mesal margin slightly concave up to level of $\mathrm{prl}$, distally tucked in, on posterior side sinuous: first concave, then convex, then concave again up to level of metaplical shelf $(\mathrm{ms})$. $m s$ very prominently projecting mesad but not notably posteriad. Metaplical shelf-spine ( $\mathrm{mss}$ ) short, originating from anterior-mesal part of $m s$, projecting distad, slightly curved.

Gonopod telopodite (Fig. 26). Solenomere without a proximal spine. Telomere distally with two distal branches, both curving anteriad:

- anterior lamella (al) broad, twisted, mostly with smooth edges but with terminal, subrectangular lobe $\left(a l^{\prime}\right)$ with dentate terminal edge,

- posterior lamella $(p l)$ situated basal to $a l$ and rest of telopodite, large, smoothly curved, with smooth edges and subterminally with long, apical spine $(\mathrm{pls})$.

\section{Distribution and habitat}

Known only from Udzungwa Mts, Udzungwa Scarp FR. Altitudinal range: 1600-1800 m asl. Habitat: montane rain forest.

\section{Coexisting species}

C. nikolajscharffi sp. nov. was found in the same samples as $C$. hamerae sp. nov. In addition, $C$. circumvallatus sp. nov. was found in Udzungwa Scarp FR.

\section{Notes}

The gonopods quite resemble those of $C$. teres sp. nov. 

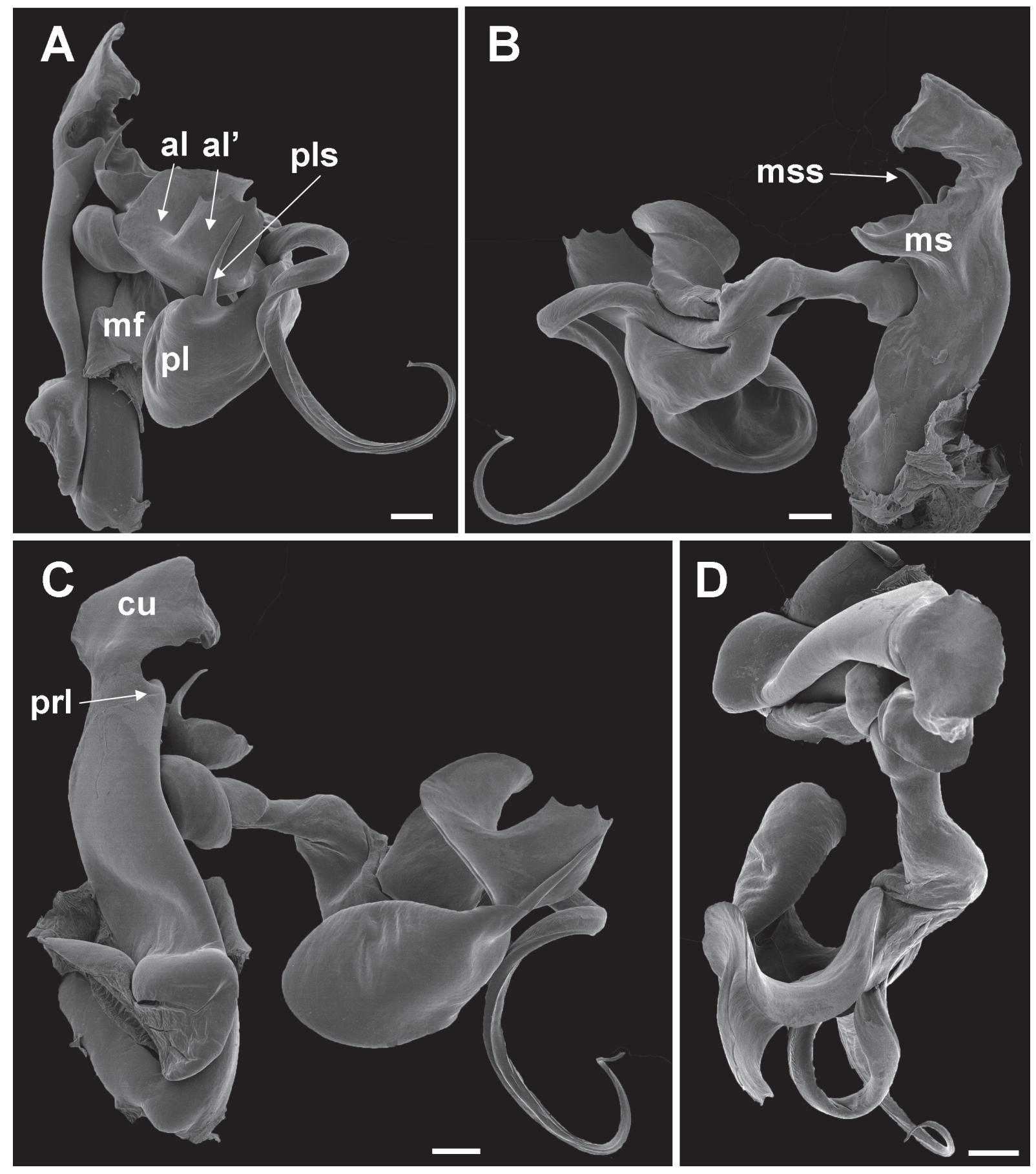

Fig. 26. Chaleponcus hamerae sp. nov., left gonopod. A. Mesal-anterior view. B. Posterior view. C. Anterior view. D. Ventral view. $a l$, $a l^{\prime}=$ anterior telomeral lamella, $c u=$ cucullus, $m f=$ metaplical flange, $m s=$ metaplical shelf, $m s s=$ metaplical shelf-spine, $p l=$ posterior telomeral lamella, $p r l=$ proplical lobe, $p l s$ $=$ spine on $p l$. Scales $0.1 \mathrm{~mm}$. 


\section{Chaleponcus termini sp. nov. urn:1sid:zoobank.org:act:C7102566-C098-434C-A419-652D26ED1738}

Figs 7-9, 27

\section{Diagnosis}

Medium-sized. Characterized by the two-lobed, strongly serrate anterior telomeral lamella. Gonopod coxa (Fig. 9) without a lateral process; metaplical shelf-spine long.

\section{Etymology}

The name is the genitive case of the Latin noun terminus which means frontier, and the name honours the NGO Frontier Tanzania.

Material studied (total: $28 \precsim \precsim$ )

\section{Holotype}

TANZANIA: $\widehat{\jmath}$, Iringa Region, Iringa District, Udzungwa Mts, New Dabaga/Ulangambi FR, $08^{\circ} 04^{\text {' }}$ 5.7" S, 3554' 18.8" E, montane, 1930-1950 m asl, plot 1, casual, 16-19 Oct. 2000, Frontier Tanzania leg. (ZMUC).

\section{Paratypes}

All from TANZANIA, Iringa Region, Iringa District, Udzungwa Mts, New Dabaga/Ulangambi FR, all

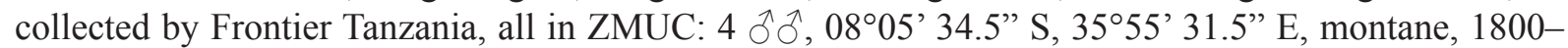

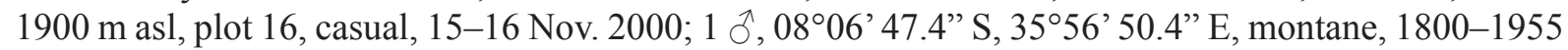
$\mathrm{m}$ asl, plot MS - plot A, 29 Oct. 2000; 10 oे $^{\circ}, 08^{\circ} 05^{\prime} 34.5^{\prime \prime} \mathrm{S}, 35^{\circ} 55^{\prime} 31.8^{\prime \prime} \mathrm{E}$, montane, $1885 \mathrm{~m}$ asl,

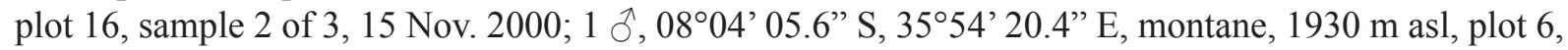

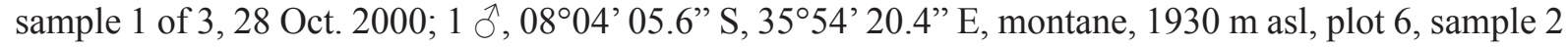

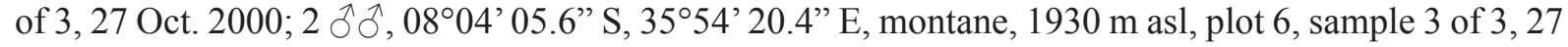

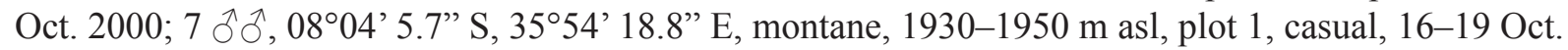

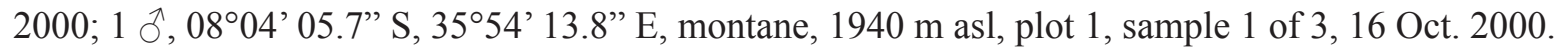

\section{Type locality}

TANZANIA: Iringa Region, Iringa District, Udzungwa Mts, New Dabaga/Ulangambi FR, 0804' 5.7”' S, 35 54' 18.8' E, montane, 1930-1950 m asl.

\section{Description (male)}

DiAMETER. $1.6-1.9 \mathrm{~mm}, 41-43$ podous rings.

Colour. After 12 years in alcohol yellowish, with dark spots at ozopores and paramedian dark dorsal bands flanking a mid-dorsal light stripe.

AnAL VALves. Each with a long, slightly curving dorsal spine and a well-developed, triangular ventral one; marginal rim raised, no setiferous tubercles.

LimBus. With rounded-triangular, longitudinally furrowed denticles separated by parabolic sinuses, lobes $c a$. as long as wide, striate on external surface.

\section{TARSAL SETATION. Normal.}

GonOPOD COXA (Figs 7, 9, 27). Almost $4 \times$ as long as wide. Lateral margin regularly convex from base up to just below level of $\mathrm{prl}$, at this place turning slightly laterad and forming blunt, rounded angle with oblique apical margin; cucullus $(\mathrm{cu})$ hence subtriangular, apically rounded. Metaplical flange $(\mathrm{m} f)$ ending 
in long, triangular process pointing anteriad-mesad-distad; metaplical mesal margin straight up to level of arculus. Metaplical shelf $(\mathrm{ms})$ forming subrectangular-rounded process just distal to arculus, followed by triangular incision separating cucullus from basal part of metaplica. $m s$ simple, proximally stout, continuing in metaplical shelf-spine ( $m s s$ ) with no clear demarcation. mss medium long, originating from anterior-distal surface of $m s$, first projecting distad, then curving mesad, and then slightly basad.

Gonopod telopodite (Figs 8A, 27). Solenomere with a small, irregular proximal spine (ps). Telomere distally with two branches:

- a large anterior lamella dividing into two triangular lobes (all and al2) with strongly laciniate margins; basalmost lobe (al2) folded laterad and in situ visible in front of opposite coxa,

- a large posterior lamella $(p l)$ first directed distad then folding back and delimiting an empty space together with al2.
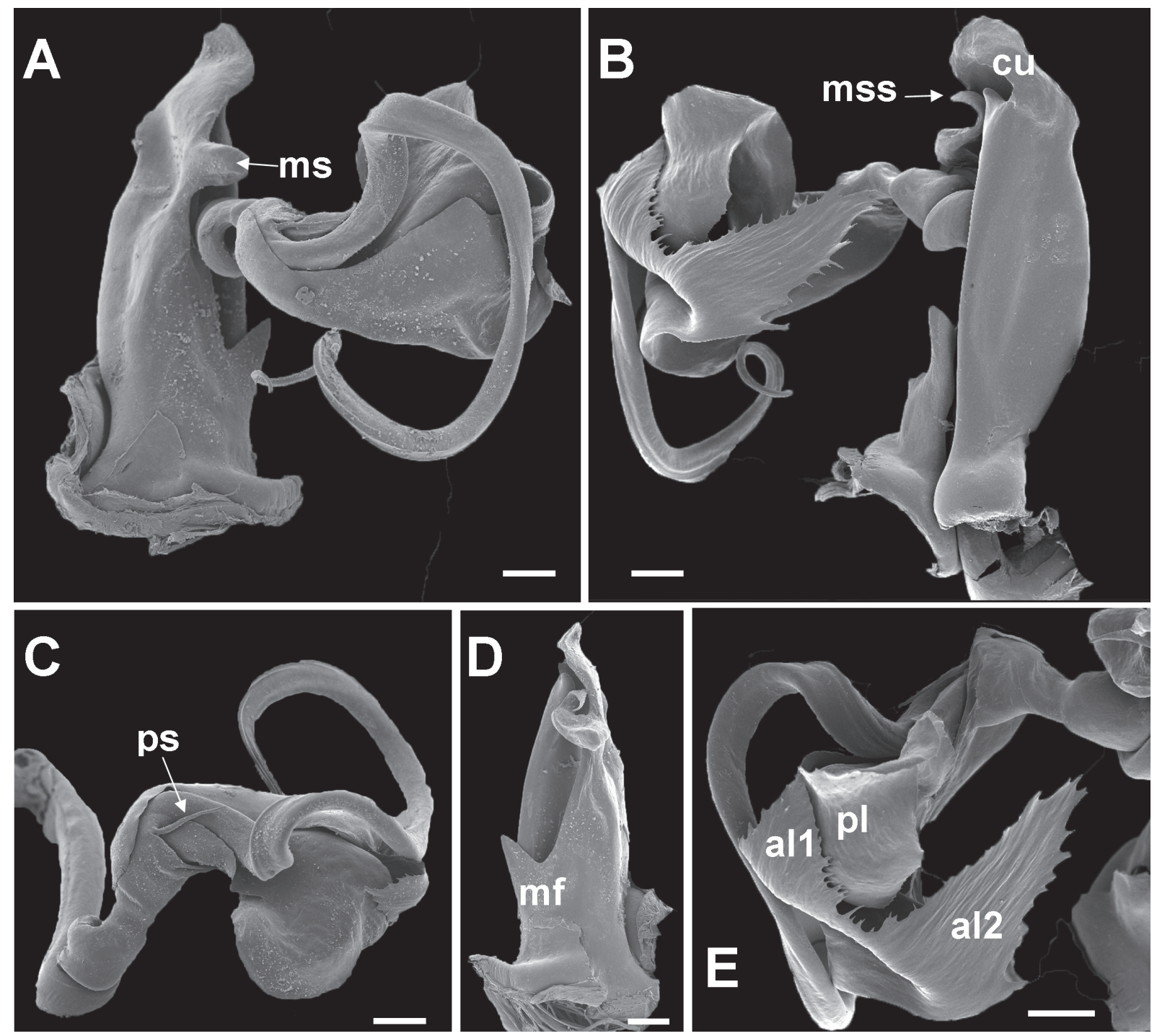

Fig. 27. Chaleponcus termini sp. nov., gonopods. A. Right gonopod, posterior view. B. Right gonopod, anterior view. C. Left telopodite, mesal-ventral view. D. Left coxite, mesal view. E. Right telopodite, anterior-ventral view. all, al2 = anterior telomeral lobe, $c u=$ cucullus, $m f=$ metaplical flange, $m s=$ metaplical shelf, $m s s=$ metaplical shelf-spine, $p l=$ posterior telomeral lamella, $p s=$ proximal spine on solenomere. Scales $0.1 \mathrm{~mm}$. 


\section{Distribution and habitat}

Known only from Udzungwa Mts, New Dabaga/Ulangambi FR. Altitudinal range: 1800-1955 m asl. Habitat: montane forest.

\section{Coexisting species}

C. gracilior sp. nov., C. mwabvui sp. nov., C. nectarinia sp. nov., C. netus sp. nov., C. teres sp. nov. and $C$. vilici sp. nov. were found in the same samples as $C$. termini sp. nov. In addition, $C$. dabagaensis, $C$. krai sp. nov., C. malleolus sp. nov. and C. vandenspiegeli sp. nov. occur in New Dabaga/Ulangambi FR.

\section{Chaleponcus gracilior sp. nov. urn:1sid:zoobank.org:act:85282955-A517-4E67-8848-F2C3C880DEC6}

Figs 4, 9, 28

\section{Diagnosis}

Slender, but with more podous rings than other small species. Easily recognizable by the subrectangular cucullus profile, by the conspicuous 'inflated' distal telomeral process and by the unique 'string-ofbeads'-like appearance of the limbus. Gonopod coxa (Fig. 9) without a lateral process; metaplical shelfspine short.

\section{Etymology}

The name is a Latin adjective meaning "more slender" and refers to the small body diameter in relation to the number of body rings.

Material studied (total: 84 ふぶ)

\section{Holotype}

TANZANIA: $\widehat{\lambda}$, Iringa Region, Iringa District, Udzungwa Mts, New Dabaga/Ulangambi FR, $08^{\circ} 05^{\prime}$ 37.9” S, 3554' 05.6” E, fallow/cultivation, 1900-1920 m asl, plot FP, casual, 26-28 Nov. 2000, Frontier Tanzania leg. (ZMUC).

\section{Paratypes}

All from TANZANIA, Iringa Region, Iringa District, Udzungwa Mts, New Dabaga/Ulangambi FR, all

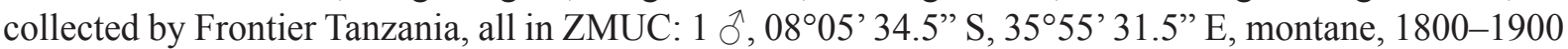

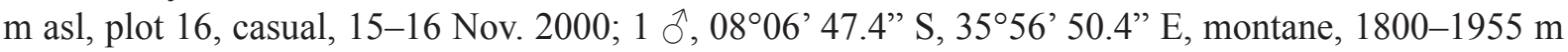

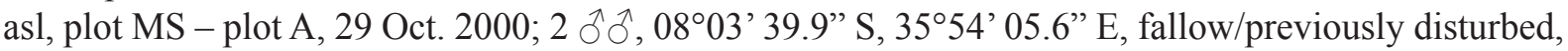

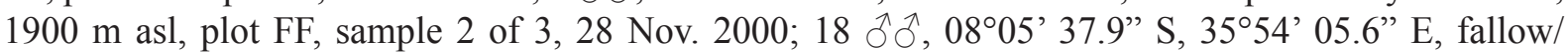

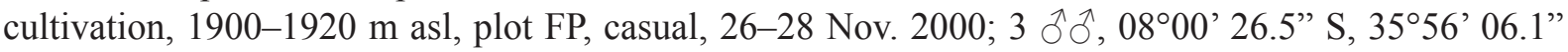

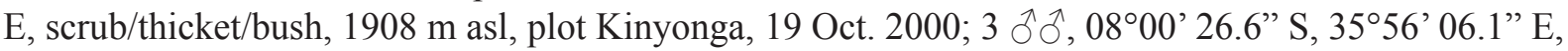

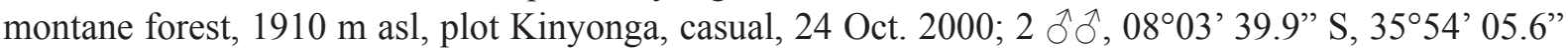
E, fallow/previously disturbed, $1915 \mathrm{~m}$ asl, plot FF, casual, $27 \mathrm{Nov} .2000 ; 1 \mathrm{O}^{\top}, 08^{\circ} 00^{\prime}$ ' $26.6^{\prime \prime} \mathrm{S}, 35^{\circ} 56^{\prime}$ '

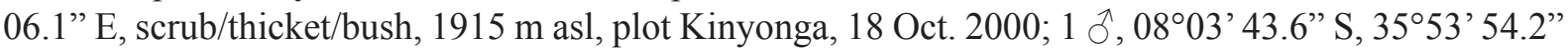
E, plantation, $1980 \mathrm{~m}$ asl, plot pine, sample 1 of 3, 13 Oct. 2000.

\section{Referred non-type material}

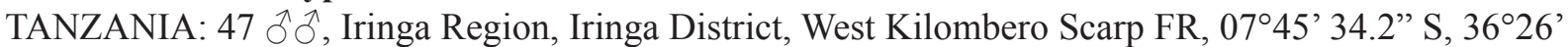
37.4" E, (open) woodland, $1510 \mathrm{~m}$ asl, plot Acacia, casual, 5-8 Dec. 2000, Frontier Tanzania UMPS leg. (ZMUC); 1 đ̊, Udzungwa Mts, 1500 m, Kiranzi-Kitungulu FR, $08^{\circ} 09^{\prime} \mathrm{S}, 35^{\circ} 05^{\prime} \mathrm{E}$, forest, Jan. 1996, M. Andersen, P. Gravlund, A. Jakobsen leg. (ZMUC); 3 $\widehat{\partial}$, Iringa Region, Iringa District, Kalimbazi Mtn, 2000-2100 m asl, $10 \mathrm{~km} \mathrm{~S} \mathrm{of} \mathrm{Mazombe,} \mathrm{forest} \mathrm{floor,} \mathrm{Jan} \mathrm{Kielland} \mathrm{leg.} \mathrm{(VMNH).}$ 

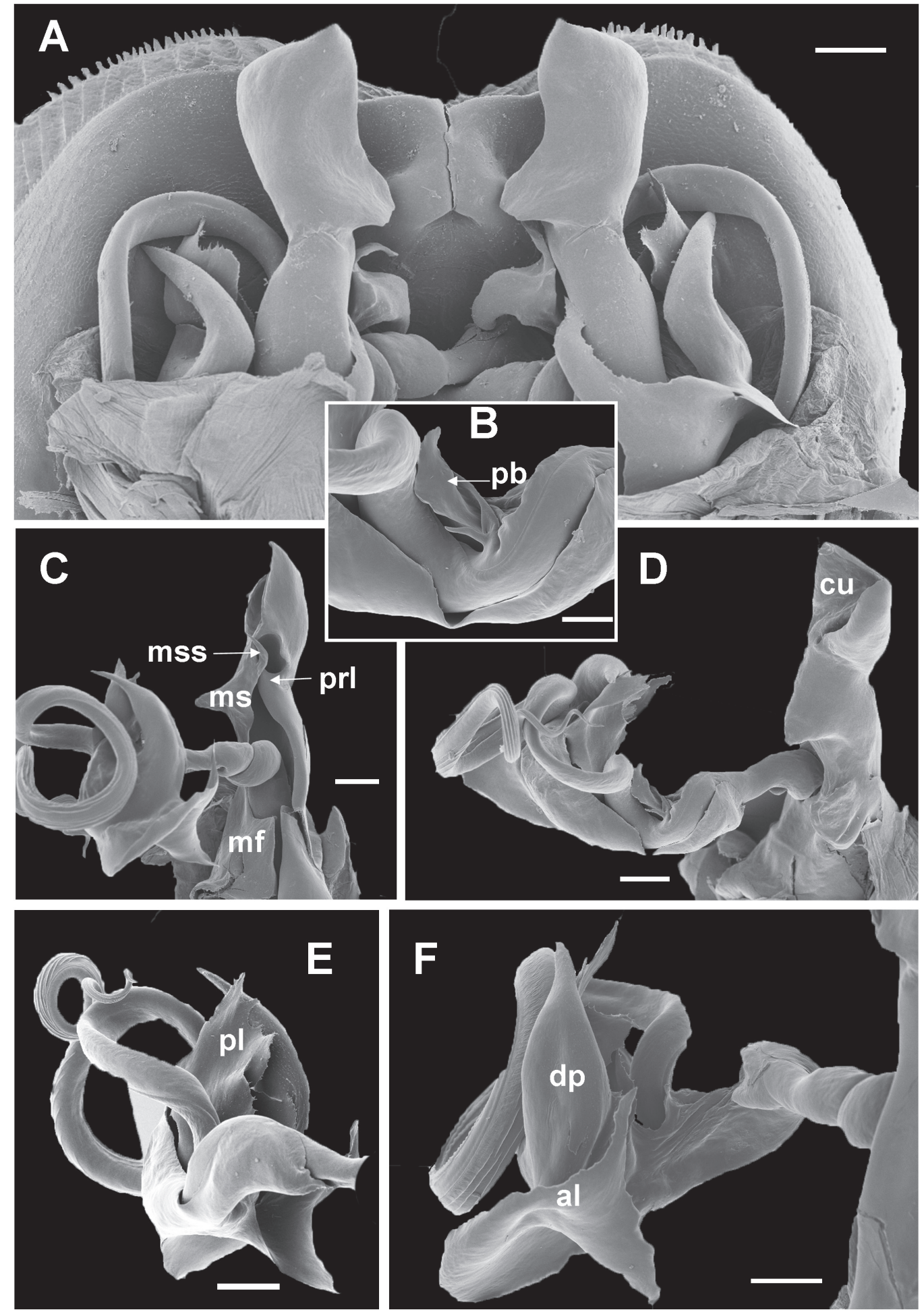

Fig. 28. Chaleponcus gracilior sp. nov., gonopods. A. Gonopods in situ in body ring 7, anterior view. B. Right gonopod, detail of base of solenomere, showing basal side branch consisting of a tiny, spinelike part and a larger, irregularly lamellate one. C. Right gonopod, anterior-mesal view. D. Left gonopod, posterior view. E. Left telopodite, posterior-lateral view. F. Right telopodite, anterior view. $a l=$ anterior telomeral lamella, $c u=$ cucullus, $d p=$ distal telomeral process, $m f=$ metaplical flange, $m s=$ metaplical shelf, $m s s=$ metaplical shelf-spine, $p b=$ proximal side branch of solenomere, $p l=$ posterior telomeral lamella, $p r l=$ proplical lobe. Scales: $0.1 \mathrm{~mm}(\mathrm{~A}, \mathrm{C}-\mathrm{F}), 0.05 \mathrm{~mm}(\mathrm{~B})$. 


\section{Type locality}

TANZANIA: Iringa Region, Iringa District, New Dabaga/Ulangambi FR, 0805' 37.9” S, 3554'05.6” E, fallow/cultivation, $1900-1920 \mathrm{~m}$ asl.

\section{Description (male)}

DiAMETER. $1.5-1.8 \mathrm{~mm}, 45-49$ podous rings.

Colour. After 12 years in alcohol faded, uniform pale brown, no traces of a dorsal stripe.

ANAL VALVES. Each with a long dorsal spine, no ventral spines; marginal rim barely raised, setiferous tubercles inconspicuous.

Limbus (Fig. 4F). Lobes spatulate, about as long as wide, separated by stretches of straight margin $c a$. same length as width of lobe; body ring surface between lobes forming shallow concavity behind straight margin; lobes deeply striate on external surface. The unique limbus gives the body ring posterior margins a characteristic 'string-of-beads'-like appearance, visible even on undissected specimens.

\section{TARSAL SETATION. Normal.}

GONOPOD COXA (Figs 9, 28). About $4 \times$ as long as wide. Lateral margin almost straight, slightly indented at level of proplical lobe $(\mathrm{prl})$ and metaplical shelf $(\mathrm{ms})$, forming a $\mathrm{ca} \cdot 100^{\circ}$ angle with straight apical margin; cucullus $(\mathrm{cu})$ subrectangular. Metaplical flange $(\mathrm{mf})$ ending in a rather sharp $90^{\circ}$ angle, no process; metaplical mesal margin shallowly concave up to level of arculus, then abruptly turning mesad at right angles at base of metaplical shelf $(m s)$, then turning apicad at right angles, margin from then on shallowly concave, meeting apical margin under a $c a .80^{\circ}$ angle. Metaplical shelf $(\mathrm{ms})$ regularly rounded, projecting posteriad as well as mesad. Metaplical shelf-spine ( $\mathrm{mss}$ ) originating from anteriormesal end of $m s$, short, directed apicad, slightly and simply curved.

GonOPOD TELOPODITE (Fig. 28). Solenomere with a small proximal side branch $(p b)$ originating on distal surface and consisting of a tiny spine-like part and a larger, irregularly lamellate one. Telomere distally with three branches:

- an anterior, irregularly triangular, twisted lamella $(a l)$ with undulate edges,

- a large, smooth, pointed, slightly curved distal process $(d p)$ with an 'inflated' appearance,

- an irregularly shaped posterior lamella $(p l)$.

\section{Distribution and habitat}

Known from four areas in the Udzungwa Mts: New Dabaga/Ulangambi FR, West Kilombero Scarp FR, Kiranzi-Kitungulu FR and Kalimbazi Mtn. Altitudinal range: 1500-2100 m asl. Habitat: montane forest, fallow/previously disturbed/cultivation, scrub/thicket/bush, plantation, (open) woodland. This species seems much more euryoecious than any other species in the $C$. dabagaensis group.

\section{Coexisting species}

In line with its comparatively wide distribution, $C$. gracilior sp. nov. co-occurs with many other species of the $C$. dabagaensis group. Thus, $C$. dabagaensis was found in the same sample as $C$. gracilior sp. nov. in Kiranzi-Kitungulu FR, and C. dabagaensis, $C$. krai sp. nov., C. malleolus sp. nov., C. mwabvui sp. nov., $C$. netus sp. nov., $C$. termini sp. nov. and $C$. vilici sp. nov. were found in the same samples as $C$. gracilior sp. nov. in New Dabaga/Ulangambi FR. In addition, C. krai sp. nov. also occurs on Kalimbazi Mtn, C. nectarinia sp. nov., C. teres sp. nov., and C. vandenspiegeli sp. nov. also occur in New Dabaga/ Ulangambi FR., and C. basiliscus sp. nov., C. circumvallatus sp. nov., C. ibis sp. nov., C. netus sp. nov., and C. tintin sp. nov. also occur in West Kilombero FR. 
ENGHOFF H., Chaleponcus millipedes from Udzungwa Mountains

\section{Chaleponcus mwabvui sp. nov. urn:1sid:zoobank.org:act:C1BCEEF3-3247-47D9-BA27-663385735829}

Figs 6, 9, 29

\section{Diagnosis}

Medium-sized. Gonopod coxa (Fig. 9) without a lateral process; cucullus small. Distinguished from other species, i.a., by the characteristically shaped posterior telomeral lamella (Fig. 29).

\section{Etymology}

The name honours Tarombera Mwabvu in recognition of his work on the taxonomy of African millipedes.

Material studied (total: $11 \hat{\diamond} \widehat{)})$

\section{Holotype}

TANZANIA: $\hat{\partial}$, Iringa Region, Iringa District, Udzungwa Mts, New Dabaga/Ulangambi FR, $08^{\circ} 06^{\prime}$ 47.4" S, 35 56' 50.4" E, montane, 1800-1955 m asl, plot MS - plot A, 29 Oct. 2000, Frontier Tanzania leg. (ZMUC).

\section{Paratypes}

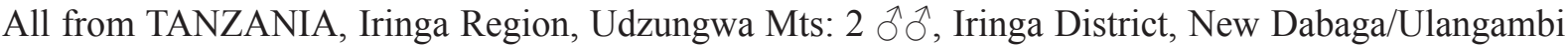
FR, 0806' 47.4” S, 35 56' 50.4” E, montane, 1800-1855 m asl, plot MS - plot A, sample 3 of 3, 11 Nov. 2000, Frontier Tanzania leg. (ZMUC); $5 \partial^{\widehat{\partial}}$, Iringa District, New Dabaga/Ulangambi FR, $08^{\circ} 06^{\prime}$ 47.4" S, 35 56' 50.4" E, montane, 1800-1955 m asl, plot MS - plot A, 29 Oct. 2000, Frontier Tanzania leg. (ZMUC); 3 ỗ, Mufindi, Kigogo Forest Reserve, 1900 m, 7-15 Oct. 1984, pitfall traps in montane rain forest, N. Scharff leg. (ZMUC).

\section{Type locality}

TANZANIA: Iringa Region, Iringa District, Udzungwa Mts, New Dabaga/Ulangambi FR, $08^{\circ} 06^{\prime} 47.4$ ” S, 35'56’ 50.4” E, montane, 1800-1955 m asl.

\section{Description (male)}

DiAMETER. $1.8-1.9 \mathrm{~mm}, 43-45$ podous rings.

CoLour. After 13 years in alcohol brownish yellow, dorsolaterally dark brown, a broad middorsal pale stripe, a narrow blackish lateral stripe at ozopore level.

AnAL valves (Fig. 6C, F). Each with a long, slightly curving dorsal spine and a small, triangular ventral one; marginal rim raised, setiferous tubercles barely developed, not on 'ravelins'.

LimBus. With long, slender, apically denticulate lobes, separated by wider sinuses.

\section{TARSAL SETATION. Normal.}

GoNOPOD COXA (Figs 9, 29). About $4 \times$ as long as wide; lateral margin evenly convex in distal 2/3; cucullus $(\mathrm{cu})$ small, smoothly rounded, without processes. Metaplical flange $(\mathrm{mf})$ ending in triangular, apicad process; metaplical mesal margin straight, but with triangular process $(\mathrm{mp})$ just below level of arculus. Metaplical shelf $(\mathrm{ms})$ regularly rounded, projecting posteriad as well as mesad, continuing without transition in metaplical shelf-spine ( $m s s$ ). Metaplical shelf-spine ( $m s s$ ) of medium length, curving first mesad, then distad, then pointing mesad again; in specimen prepared for SEM pointing obliquely basad, tip reaching beyond basomere. 


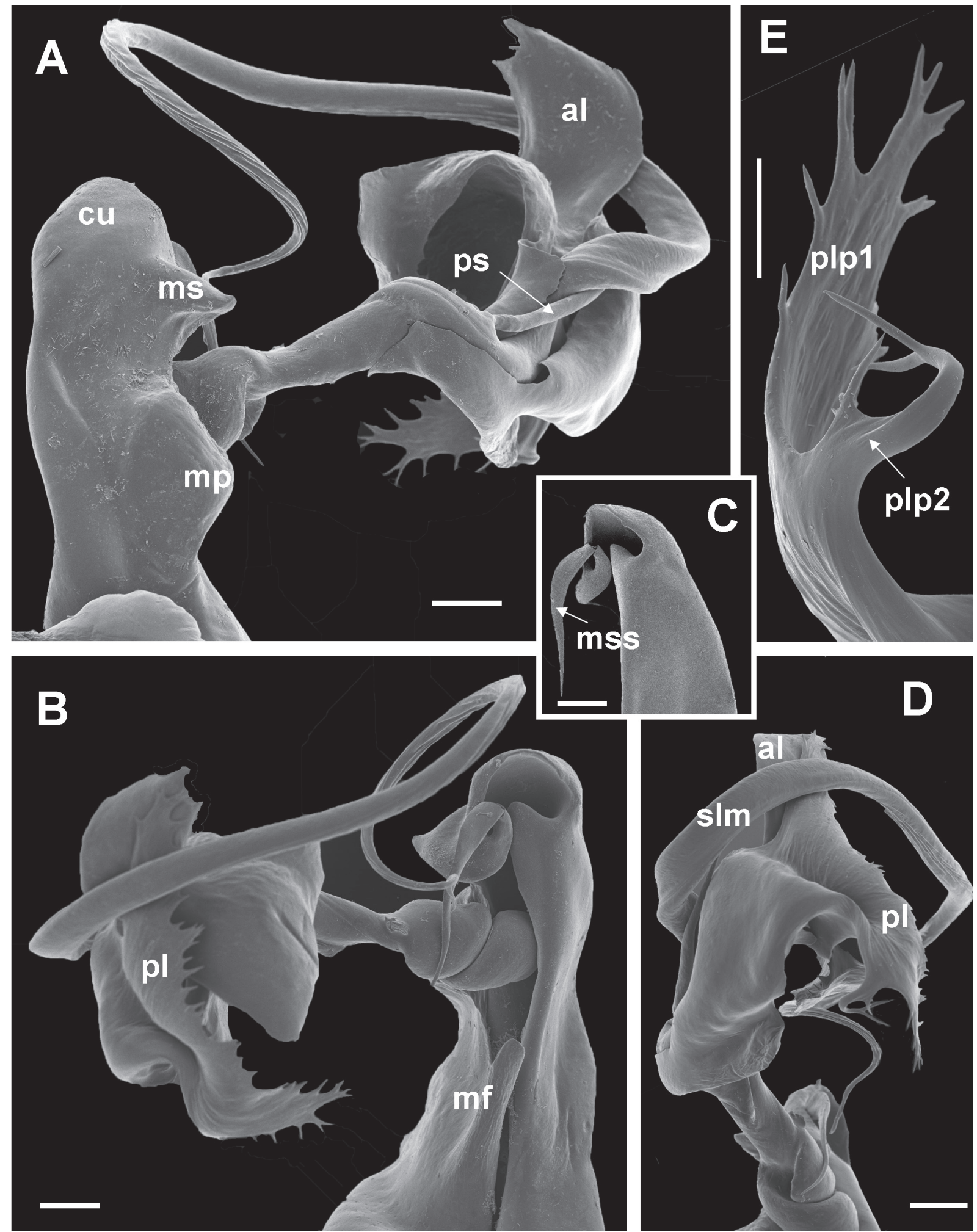

Fig. 29. Chaleponcus mwabvui sp. nov., right gonopod. A. Posterior view. B. Anterior-mesal view. C. Coxa, tip, anterior view. D. Telopodite, apical-dorsal view. E. Process $p l p$ of telomere. $a l=$ anterior telomeral lamella, $c u=$ cucullus, $m f=$ metaplical flange, $m p=$ mesal metaplical process, $m s=$ metaplical shelf, $m s s=$ metaplical shelf-spine, $p l=$ posterior telomeral lamella, $p l p 1, p l p 2$, posterior telomeral lamella processes, $p s=$ proximal spine on solenomere, $s l m=$ solenomere. Scales: $0.1 \mathrm{~mm}$ (A-D), $0.05 \mathrm{~mm}(\mathrm{E})$. 
Gonopod telopodite (Fig. 29). Solenomere with a long, straight, mesad, proximal spine ( $p s$ ). Telomere distally with two branches:

- a large, convoluted anterior lamella (al) with smooth edges except for a few distal denticulations,

- a posterior-distal lamella $(\mathrm{pl})$; distal margin of $\mathrm{pl}$ deeply laciniate in apical part, basally produced in slender process furcating into larger branch ( $p l p l)$ with long-spinose margins and smaller, slender branch ( $p l p 2)$ with large spine at base and terminally bifurcating.

\section{Distribution and habitat}

Known from two forest reserves in the Udzungwa Mts: New Dabaga/Ulangambi FR and Kigogo FR. Altitudinal range: $1800-1955 \mathrm{~m}$ asl. Habitat: montane forest.

\section{Coexisting species}

All four species known from Kigogo FR, i.e., C. quasimodo sp. nov., C. scopus sp. nov., C. howelli sp. nov. and C. mwabvui sp. nov., were found in the same samples. In New Dabaga/Ulangambi FR, C. dabagaensis, $C$. gracilior sp. nov., C. netus sp. nov. and C. termini sp. nov. were found in the same samples as $C$. mwabvui sp. nov. In addition, $C$. krai sp. nov., C. malleolus sp. nov., C. nectarinia sp. nov., C. teres sp. nov., C. vandenspiegeli sp. nov. and C. vilici sp. nov. occur in New Dabaga/Ulangambi FR.

Chaleponcus howelli sp. nov. urn:Isid:zoobank.org:act:F7D97CB8-4791-4584-AD89-F2BCC6589590

Figs 4, 9, 30

\section{Diagnosis}

Medium-sized. Gonopod coxa (Fig. 9) without a lateral process; cucullus small. Distinguished from other species, i.a., by the presence of a spine (sts) on the main stem of the telomere in combination with the large distal spine (als) on the anterior telomeral lamella.

\section{Etymology}

The name honours Kim Howell in recognition of his huge efforts to increase the knowledge of Tanzanian millipedes.

Material studied (total: $100 \AA \widehat{)}$

Holotype

TANZANIA: §̊, Iringa Region, Udzungwa Mts, Mufindi, Kigogo Forest Reserve, 1900 m, 7-15 Oct. 1984, pitfall traps in montane rain forest, N. Scharff leg. (ZMUC).

\section{Paratypes}

TANZANIA: $61 \hat{\jmath} \widehat{\partial}$, Iringa Region, Udzungwa Mts, Mufindi, Kigogo Forest Reserve, 1700 m, 8-10

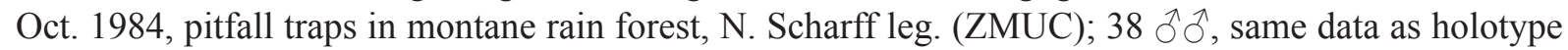
(ZMUC).

\section{Type locality}

TANZANIA: Iringa Region, Udzungwa Mts, Mufindi, Kigogo Forest Reserve, 1900 m, montane rain forest.

Description (male)

DiAMETER. $2.0-2.2 \mathrm{~mm}, 44-47$ podous rings. 

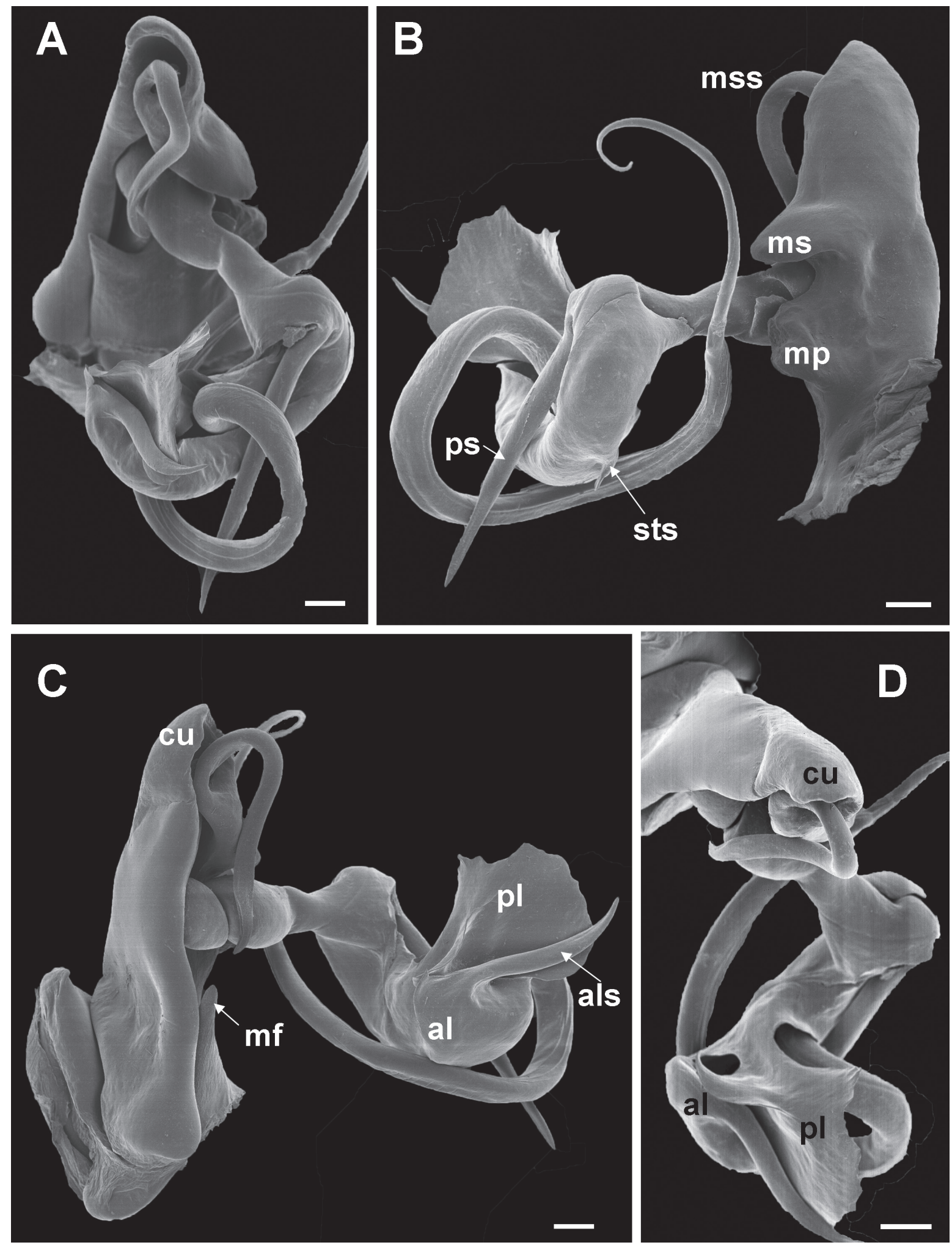

Fig. 30. Chaleponcus howelli sp. nov., left gonopod. A. Mesal-ventral (-anterior) view. B. Posterior view. C. Anterior view. D. Ventral (-anterior) view. $a l=$ anterior telomeral lamella, $a l s=$ spine on $a l$, $c u=$ cucullus, $m f=$ metaplical flange, $m p=$ mesal metaplical process, $m s=$ metaplical shelf, $m s s=$ metaplical shelf-spine, $p l=$ posterior telomeral lamella, $p s=$ proximal spine on solenomere, $s t s=$ spine on telomeral main stem. Scales $0.1 \mathrm{~mm}$. 
Colour. After 30 years in alcohol almost uniform pale brown, with faint traces of a light dorsal stripe, sometimes with a thin dark line in midline.

ANAL VALVES. Each with a long, dorsal spine and a well-developed, but small, triangular ventral one; marginal rim raised, setiferous tubercles well developed, on 'ravelins'.

LimBus (Fig. 4B). With long, slender triangular lobes, separated by rounded sinuses; lobes striate on external surface.

TARSAL SETATION. Normal.

Gonopod coxa (Figs 9, 30). About $3 \frac{1}{2} \times$ as long as wide. Lateral margin almost straight, towards apex gently curving mesad and continuous with apical margin; cucullus $(\mathrm{cu})$ an almost perfect hollow hemisphere. Metaplical flange $(\mathrm{mf})$ ending in blunt, equilateral triangular process; metaplical mesal margin with large rounded process $(m p)$ delimiting semicircular sinus together with base of metaplical shelf. Metaplical shelf $(\mathrm{ms})$ simple, regularly rounded, mostly projecting laterad. Metaplical shelf-spine ( $m s s$ ) of medium length, originating from anterior-mesal part of $m s$, projecting disto-mesad, then basad, reaching beyond telopodital basomere.

GonOPOD TELOPODITE (Fig. 30). Solenomere with a very long, straight, meso-basad, proximal spine ( $p s$ ). Main stem of telomere with a small spine (sts) $c a$. in middle of basal surface. Telomere distally with two branches:

- a rounded anterior lamella $(a l)$ ending in a long, gently sinuous mesad spine (als),

- a large, irregular posterior lamella $(p l)$.

\title{
Distribution and habitat
}

Known only from Udzungwa Mts, Kigogo FR. Altitudinal range: 1700-1900 m. Habitat: montane rain forest.

\section{Coexisting species}

All four species known from Kigogo FR, i.e., C. quasimodo sp. nov., C. scopus sp. nov., C. howelli sp. nov. and C. mwabvui sp. nov., were found in the same samples.

\section{Chaleponcus tintin sp. nov. urn:1sid:zoobank.org:act:E350A221-3166-45FA-B897-F5A36A31A900}

\author{
Figs 9, 31, 34
}

\section{Diagnosis}

Small. Distinguished from all other species in the C. dabagaensis group by the hook-like tip of the gonopod coxa (Fig. 9). Gonopod coxa without a lateral process; metaplical shelf-spine long.

\section{Etymology}

The name is a noun in apposition and refers to a cartoon character developed by the Belgian author Hergé because of the (somewhat remote) resemblance of the shape of the gonopod cucullus to Tintin's hairstyle.

Material studied (total: 1 đ)

\section{Holotype}

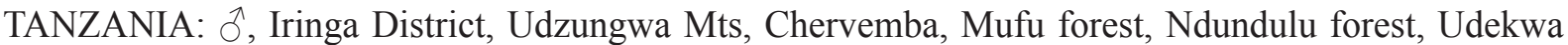
village, 2100 m, montane evergreen forest, in dead wood, 6 Sep. 1991, Louis Hansen leg. (ZMUC). 

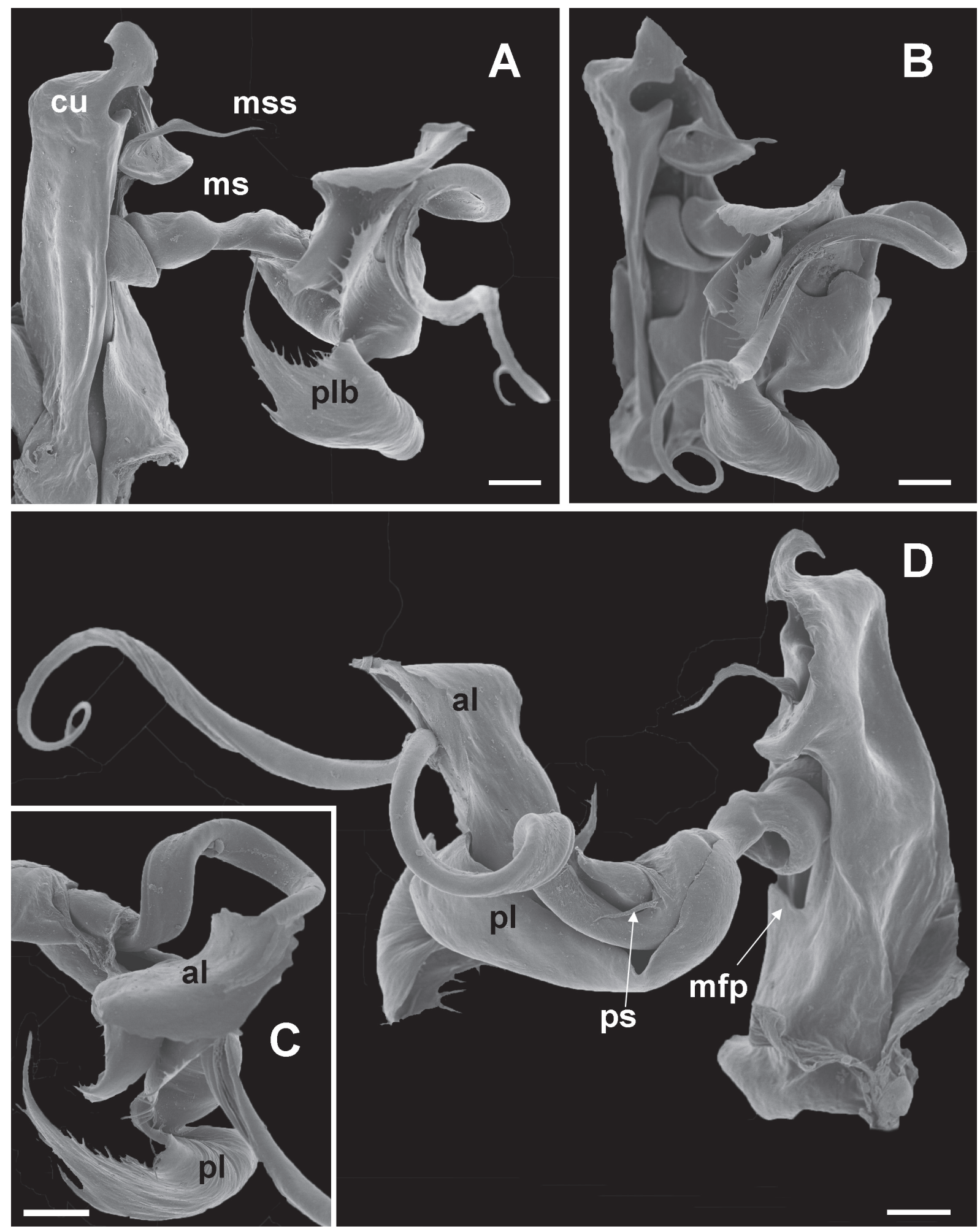

Fig. 31. Chaleponcus tintin sp. nov., left gonopod. A. Anterior view. B. Mesal-anterior view. C. Ventral (-anterior) view. D. Posterior (-mesal) view. $a l=$ anterior telomeral lamella, $c u=$ cucullus, $m f p=$ metaplical flange process, $m s=$ metaplical shelf, $m s s=$ metaplical shelf-spine, $p l=$ posterior telomeral lamella, $p l b=$ basal branch of $p l, p s=$ proximal spine on solenomere. Scales $0.1 \mathrm{~mm}$. 


\section{Type locality}

TANZANIA: Iringa District, Udzungwa Mts, Chervemba, Mufu forest, Ndundulu forest, Udekwa village, $2100 \mathrm{~m}$, montane evergreen forest.

\section{Description (male)}

DiAMETER. $1.6 \mathrm{~mm}, 41$ podous rings.

CoLour. After 23 years in alcohol almost uniform pale brownish, with traces of a pale dorsal band.

ANAL VALVES. Each with a strong dorsal spine and a very small ventral one; marginal rim raised, setiferous tubercles inconspicuous, not on 'ravelins'.

LimBus. With triangular lobes; lobes slightly longer than wide, striate on outer surface.

\section{TARSAL SETATION. Normal}

GonOPOD COXA (Figs 9, 31). About $3 \times$ as high as wide. Lateral margin straight, apically curving mesad at right angles, cucullus $(\mathrm{cu})$ produced in characteristic laterad-curving hook. Metaplical flange ending in triangular process $(\mathrm{mfp})$. Metaplical shelf $(\mathrm{ms})$ small and simple; metaplical shelf-spine ( $\mathrm{mss}$ ) short, thin, sinuous, pointing mesad.

Gonopod telopodite (Fig. 31). Solenomere with a very small proximal spine (ps). Telomere with two branches:

- a relatively small, subrectangular anterior lamella $(a l)$,

- a more elaborate posterior lamella $(p l)$ with strongly spiny margins and with a basal branch $(p l b)$ ending in long spine; $p l$ including $p l b$ curving anteriad and best visible in anterior view.

\section{Distribution and habitat}

The unique holotype was found in Udzungwa Mts, Chervemba, Mufu forest, Ndundulu forest, Udekwa village. Altitude: $2100 \mathrm{~m}$ asl (the highest accurate record of the $C$. dabagaensis group). Habitat: montane evergreen forest, in dead wood.

\section{Coexisting species}

No further species of the $C$. dabagaensis group is known from Ndundulu forest. However, C. basiliscus sp. nov., C. circumvallatus sp. nov., C. gracilior sp. nov., C. ibis sp. nov. and C. netus sp. nov. also occur in West Kilombero FR to which Ndundulu forest belongs.

\section{Key to species of the Chaleponcus dabagaensis group}

The 21 known species of the C. dabagaensis group are almost all quite distinctive in gonopod morphology. A key to the species is given below, but comparison with the gonopod coxa profiles in Fig. 9 will often lead directly to the right species. As new species of the group are likely to be discovered, and as the species in the key may prove to be more variable with regard to number of podous rings and body diameter, any identification should be checked against the detailed gonopod description and illustrations, and the size (no. of podous rings vs. body diameter) should be compared with the diagrams, Figs. 2-3. The limbus (Fig. 4) offers additional diagnostic characters.

The key is based on adult males.

1. Body diameter $>2.5 \mathrm{~mm}$ .2

- Body diameter $<2.5 \mathrm{~mm}$ 
2. Gonopod coxa with two lateral processes basiliscus sp. nov.

- Gonopod coxa without lateral processes

3. Anterior lamella of telomere divided into a horizontal lobe with deeply laciniate edges and a long, straight, distal spine-like part (Fig. 19C). Setation of walking leg tarsi normal (as Fig. 5A) ...krai sp. nov.

- Anterior lamella of telomere different. Setation of walking legs unusual: claws surrounded by

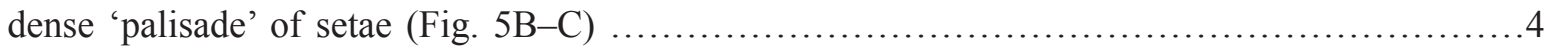

4. Posterior lamella of telomere ending in two long spines. Anterior lamella of telomere with small accessory lamella, otherwise with smooth edges (Fig. 21B) ........circumvallatus sp. nov.

- Posterior lamella of telomere ending in two short processes. Anterior lamella of telomere with a coarsely dentate basal part (Fig. 22C) ibis sp. nov.

5 45-49 podous rings. Body diameter 1.5-1.8 mm (Fig. 2). Cucullus of gonopod coxa subrectangular (Fig. 28). Limbus with spatulate lobes (Fig. 4F) ............................ gracilior sp. nov.

$-<45$ body rings and/or body diameter $\geq 1.9 \mathrm{~mm}$. Cucullus and limbus different ................6

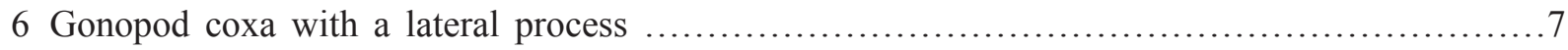

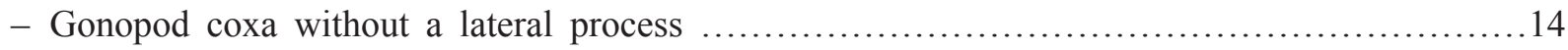

$7<40$ body rings. Body diameter $1.7-1.8 \mathrm{~mm}$. No dorsal spine on anal valves. Lateral process of gonopod coxa a strongly bent hook (Fig. 14) ...........................malleolus sp. nov.

$->40$ body rings. Body diameter $\geq 1.8 \mathrm{~mm}$. Each anal valve with a dorsal spine. Lateral process

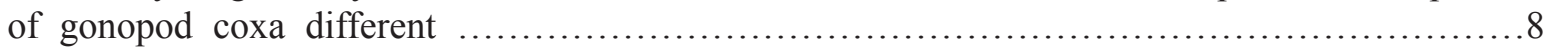

8 Metaplical shelf of gonopod coxa in two levels between which metaplical shelf-spine fits. Lateral process of gonopod coxa small to inconspicuous (Fig. 24) ....................vilici sp. nov.

- Metaplical shelf in one level. Metaplical shelf-spine and lateral process different ...........9

9 Lateral margin of gonopod coxa basal to lateral process pronouncedly 'hunch-backed' (Figs 12-13)

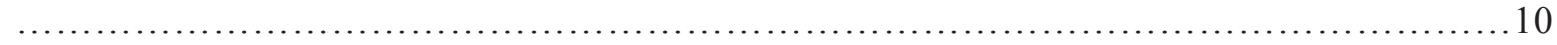

- Lateral margin of gonopod coxa basal to lateral process not pronouncedly 'hunch-backed' ........11

10 Main stem of telomere with thumblike process (Fig. 12D) .......................dabagaensis

- Main stem of telomere without thumblike process (Fig. 13) ...................quasimodo sp. nov.

11 Proximal lobe of telomere with long, fluted spine (Figs 10A, 11E) ..................netus sp. nov.

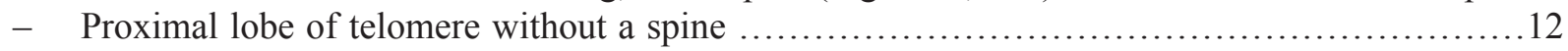

12 Lateral process of gonopod coxa small. Cucullus without a large mesal extension (Fig. 17) .mwanihanensis sp. nov.

- Lateral process of gonopod coxa larger. Cucullus with a large mesal extension (Figs 15-16) ...13

13 Lateral process of gonopod coxa pointed (Figs. 15A) ......................scopus sp. nov.

- Lateral process of gonopod coxa broadly rounded, irregularly dentate (Fig. 16B) .nikolajscharffi sp. nov.

14 Metaplical shelf-spine of gonopod coxa long, projecting \pm mesad (Figs 20A-B, 23A, D) ........15

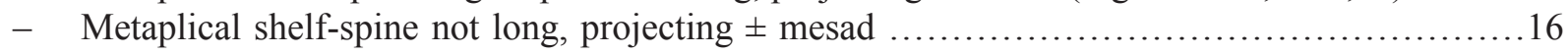

15 Posterior lamella of telomere divided into a horizontal lobe with spinose edges and a long, straight, distal spine-like part (Fig. 20C, E) nectarinia sp. nov. 
- Posterior lamella of telomere with strongly laciniate edges but without a long, straight, spine-like

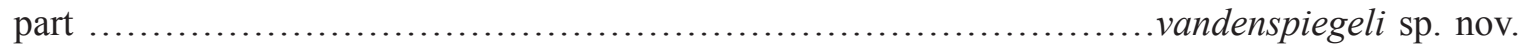

16 Metaplical shelf of gonopod coxa in two levels between which metaplical shelf-spine fits. Gonopod coxa with a small to inconspicuous lateral process (Fig. 24) ...........vilici sp. nov.

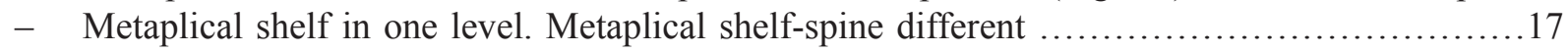

17 Gonopod coxa with distal hook-like extension (Fig. 31A). 41 podous rings, body diameter $1.6 \mathrm{~mm}$ tintin sp. nov.

- Gonopod coxa without distal hook-like extension. Mostly $>41$ podous rings and/or body

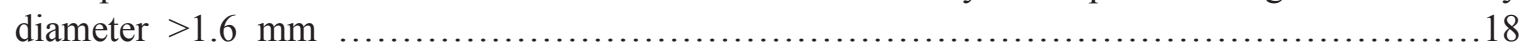

18 Anal valves without dorsal spines (Fig. 6D) .................................teres sp. nov.

- Each anal valve with a dorsal spine ....................................................

19 Cucullus of gonopod coxa subrectangular in outline (Fig. 26B-C) ..........hamerae sp. nov.

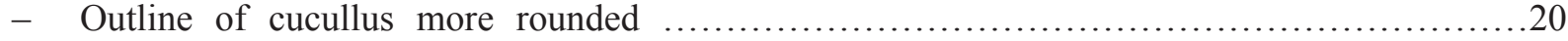

20 Anterior lamella of gonopod telomere with long, smooth spine (Fig. 30C-D) ......howelli sp. nov.

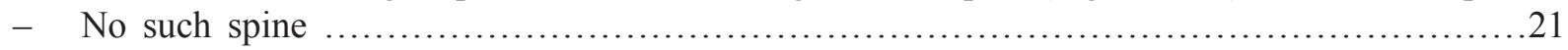

21 Anterior lamella of gonopod telomere divided into two triangular lobes with serrate margins (Fig. 27B, E). Posterior lamella simple ..................................termini sp. nov.

- Anterior lamella of gonopod telomere simple. Posterior lamella with a slender, spinose branch with a long, thin, bifurcate side branch (Fig. 29E) .............................mwabvui sp. nov.

\section{Distribution and habitat}

Fig. 32 shows the distribution of the 21 species of the Chaleponcus dabagaensis group plotted on a semi-diagrammatic map of the Forest Reserves (FR) from which species of the group have been collected. Fifteen of the species have been collected in only one FR, with New Dabaga/Ulangambi FR being the richest (6 exclusive species, 11 species in all).

Five species are shared between two FR, and C. gracilior sp. nov. even occurs in four FR, being clearly the most widespread of the species. The easternmost FR, Mwanihana, does not share any species with any other FR.

As Fig. 1 clearly shows, there are several forested areas in the Udzungwa Mts where the $C$. dabagaensis group has not been collected. This is probably due to a collecting bias, since the very comprehensive millipede material from the Udzungwa Mts kept in ZMUC largely derives from the FRs where the $C$. dabagaensis group is now known to occur. Additional collection effort, especially in the large southerncentral Matundu forest, is likely to reveal several additional species of the group. Even renewed collecting in the forest reserves already sampled is likely to reveal new species, since three (ibis sp. nov., vandenspiegeli sp. nov., tintin sp. nov.) out of the 21 species are singletons and one (circumvallatus sp. nov.) is a doubleton (Fig. 33).

The Chaleponcus dabagaensis group consists of high-altitude species, all material having been collected at 1390-2100 m asl, and with the highest species diversity above $1700 \mathrm{~m}$ (Table 2). The vast majority of specimens was collected in montane forest, but some species were found in disturbed habitats as well, e.g., the relatively widespread C. gracilior sp. nov. Very often several (up to 5) species were represented in a sample, but whether such coexisting species occupy different microhabitats is not known. 


\section{Two notes on general morphology}

\section{Torsion of the gonopod telopodite}

Torsion of the gonopod telopodite is characteristic of the majority of species of Odontopygidae and the related family Spirostreptidae (Kraus 1966, Hoffman 2008) and is important for the function of the gonopod (Barnett \& Telford 1996). In all odontopygids examined by me the torsion always begins with an anteriad bend, i.e., the torsion is clockwise when followed from coxa towards the gonopod tip and viewed from a mesal point of view on the RIGHT gonopod. Published drawings by, e.g., Kraus (1966) and Frederiksen $(2013 a, b)$ confirm the generality of this pattern.

\section{Intercalary cuticular microscutes}

Very small $(c a .1 \mu \mathrm{m})$ circular microstructures were frequently observed between cuticular microscutes on body rings (Fig. 34). Similar structures were reported by Akkari \& Enghoff (2011) from several

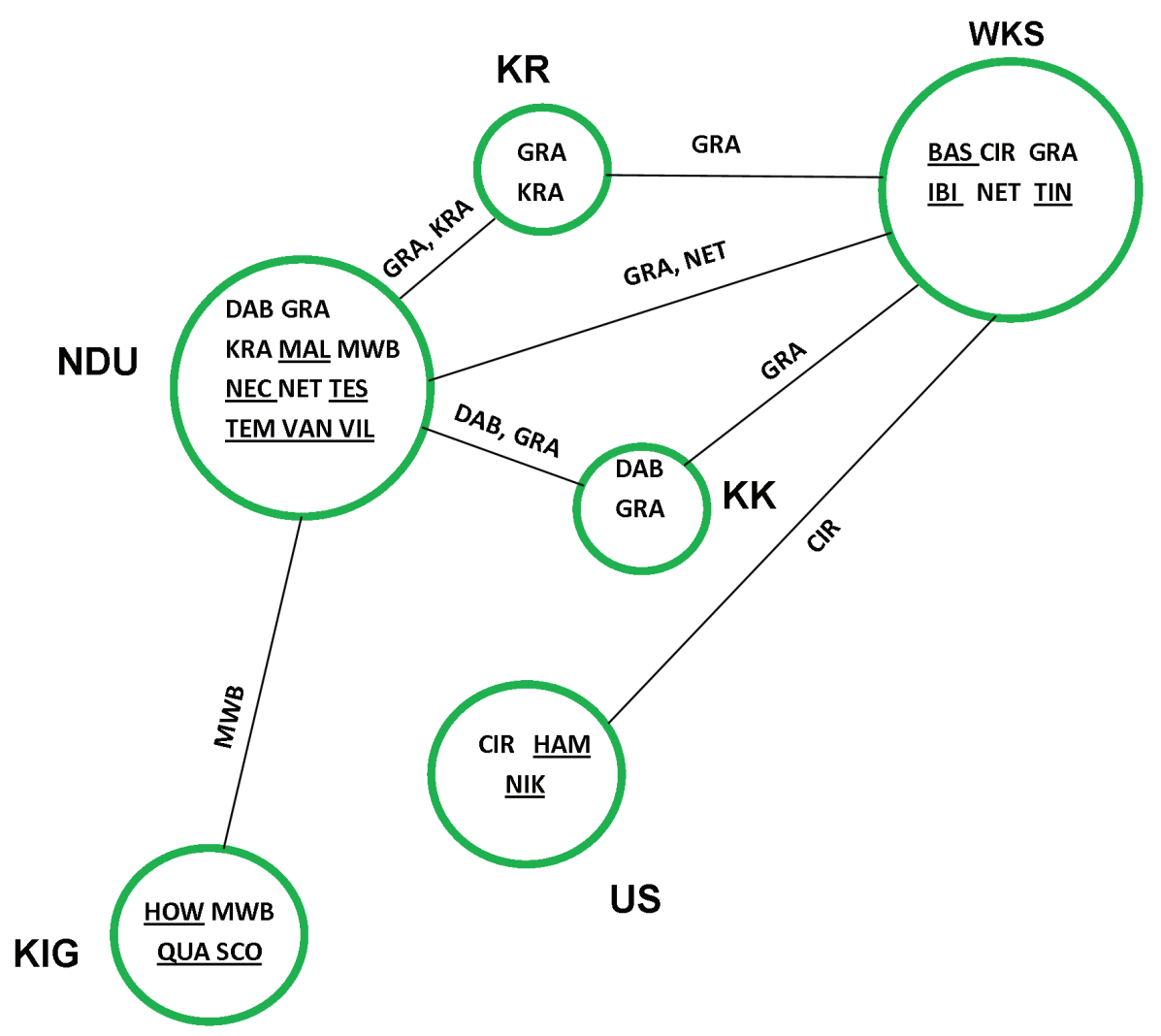

MWA

Fig. 32. Distribution of species of the Chaleponcus dabagaensis group in Forest Reserves of the Udzungwa Mts. The position of the Forest Reserves in relation to each other approximately corresponds to their true relative positions, cf. Fig. 1. Underlined species acronyms denote species known only from one Forest Reserve. Shared species are shown on lines connecting the circles. - Forest Reserve acronyms: $\mathrm{KIG}=$ Kigogo, $\mathrm{KK}=$ Kiranzi/Kitunguli, $\mathrm{KR}=$ Kisinga/Rugaro, MWA = Mwanihana, NDU = New Dabaga/Ulangambi, US = Udzungwa Scarp, WKS = West Kilombero Scarp. - Species acronyms: $\mathrm{BAS}=$ basiliscus, $\mathrm{CIR}=$ circumvallatus, $\mathrm{DAB}=$ dabagaensis, $\mathrm{GRA}=$ gracilior, $\mathrm{HAM}=$ hamerae , $\mathrm{HOW}=$ howelli, $\mathrm{IBI}=i b i s, \mathrm{KRA}=k r a i, \mathrm{MAL}=$ malleolus, $\mathrm{MWB}=m w a b v u i, \mathrm{MWN}=$ mwanihanensis, $\mathrm{NEC}=$ nectarinia, $\mathrm{NET}=$ netus, $\mathrm{NIK}=$ nikolajscharff, $\mathrm{QUA}=$ quasimodo, $\mathrm{SCO}=$ scopus, $\mathrm{TES}=$ teres, $\mathrm{TEM}=$ termini, $\mathrm{TIN}=$ tintin, $\mathrm{VAN}=$ vandenspiegeli, $\mathrm{VIL}=$ vilici . 
ENGHOFF H., Chaleponcus millipedes from Udzungwa Mountains

Table 2. Altitudinal range of species of the Chaleponcus dabagaensis group, based on "maximal ranges", see Material and methods. No altitude data are available for C. basiliscus and C. ibis.

\begin{tabular}{|l|c|c|c|c|c|c|c|c|}
\hline Altitude (m) & $\begin{array}{c}1390- \\
1499\end{array}$ & $\begin{array}{c}1500- \\
1599\end{array}$ & $\begin{array}{c}1600- \\
1699\end{array}$ & $\begin{array}{c}1700- \\
1799\end{array}$ & $\begin{array}{c}1800- \\
1899\end{array}$ & $\begin{array}{c}1900- \\
1999\end{array}$ & $\begin{array}{c}2000- \\
2099\end{array}$ & $\begin{array}{c}2100- \\
2199\end{array}$ \\
\hline netus & $\mathrm{x}$ & & & & $\mathrm{x}$ & $\mathrm{x}$ & & \\
\hline dabagaensis & & & & $\mathrm{x}$ & $\mathrm{x}$ & $\mathrm{x}$ & $\mathrm{x}$ & \\
\hline quasimodo & & & & $\mathrm{x}$ & & $\mathrm{x}$ & & \\
\hline malleolus & & & & & & $\mathrm{x}$ & & \\
\hline scopus & & & & $\mathrm{x}$ & & $\mathrm{x}$ & & \\
\hline nikolajscharffi & $\mathrm{x}$ & $\mathrm{x}$ & $\mathrm{x}$ & & $\mathrm{x}$ & & & \\
\hline mwanihanensis & & & & & $\mathrm{x}$ & & & \\
\hline krai & & & & & & $\mathrm{x}$ & $\mathrm{x}$ & \\
\hline nectarinia & & & & & & $\mathrm{x}$ & & \\
\hline circumvallatus & $\mathrm{x}$ & & $\mathrm{x}$ & & & & & \\
\hline vandenspiegeli & & & & & $\mathrm{x}$ & & & \\
\hline vilici & & & & & & $\mathrm{x}$ & & \\
\hline teres & & & & & & $\mathrm{x}$ & & \\
\hline hamerae & & & $\mathrm{x}$ & & $\mathrm{x}$ & & & \\
\hline termini & & & & & $\mathrm{x}$ & $\mathrm{x}$ & & \\
\hline gracilior & & $\mathrm{x}$ & & & $\mathrm{x}$ & $\mathrm{x}$ & $\mathrm{x}$ & \\
\hline mwabvii & & & & & $\mathrm{x}$ & $\mathrm{x}$ & & \\
\hline howelli & & & & $\mathrm{x}$ & & $\mathrm{x}$ & & \\
\hline tintin & & & & & & & & $\mathrm{x}$ \\
\hline
\end{tabular}

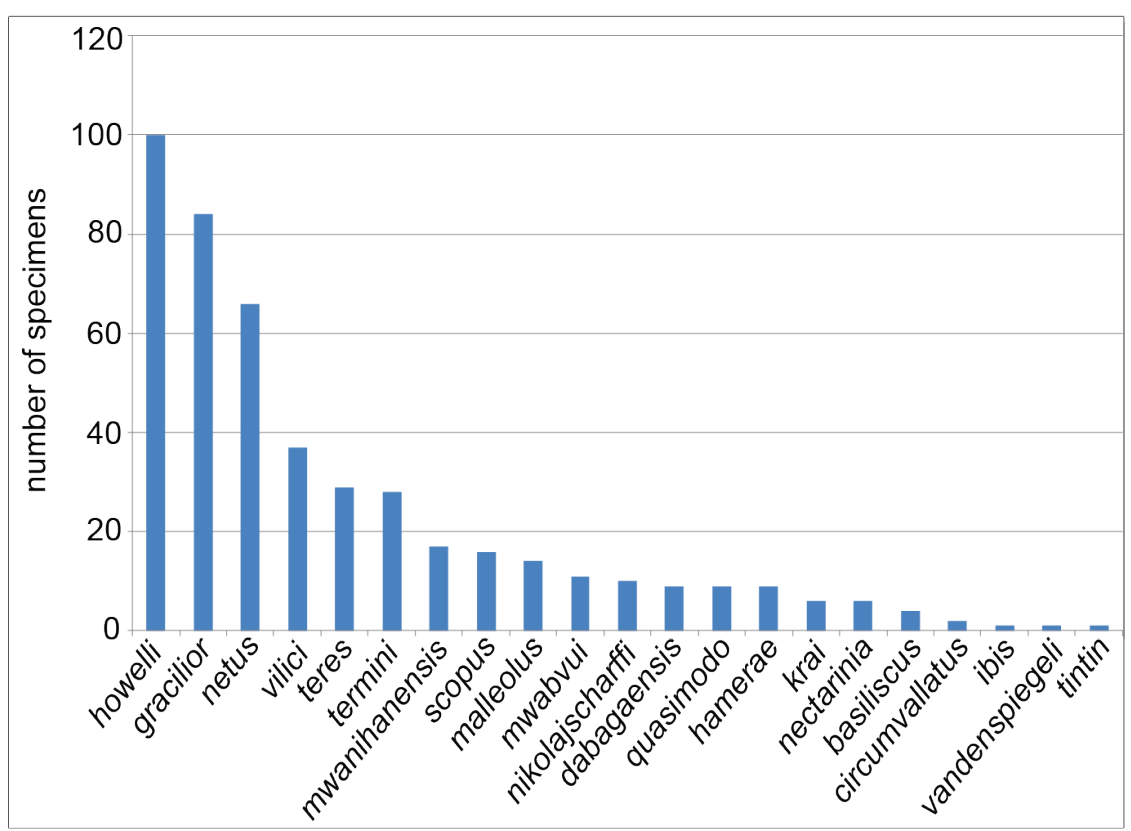

Fig. 33. The number of studied specimens (males) per species. 
families of the order Polydesmida and have also been observed on Lusitanipus alternans (Verhoeff, 1893) (Callipodida: Dorypetalidae) (HE and S. Reboleira unpublished), but have not been recorded from other millipede orders. Such intercalary cuticular microscutes are, however, discernible on fig. 8 of Frederiksen (2013a) (Chaleponcus parensis Frederiksen, 2013), as well as on fig. 1 of Frederiksen (2013b) (Lamelloramus rhombiformis Frederiksen, 2013b). They have also been observed on a species of the genus Aquattuor Frederiksen, 2013, and may be widespread in Odontopygidae. The nature of the microscutes is unknown. In a preparation of $C$. nikolajscharffi sp. nov. some of the microscutes give
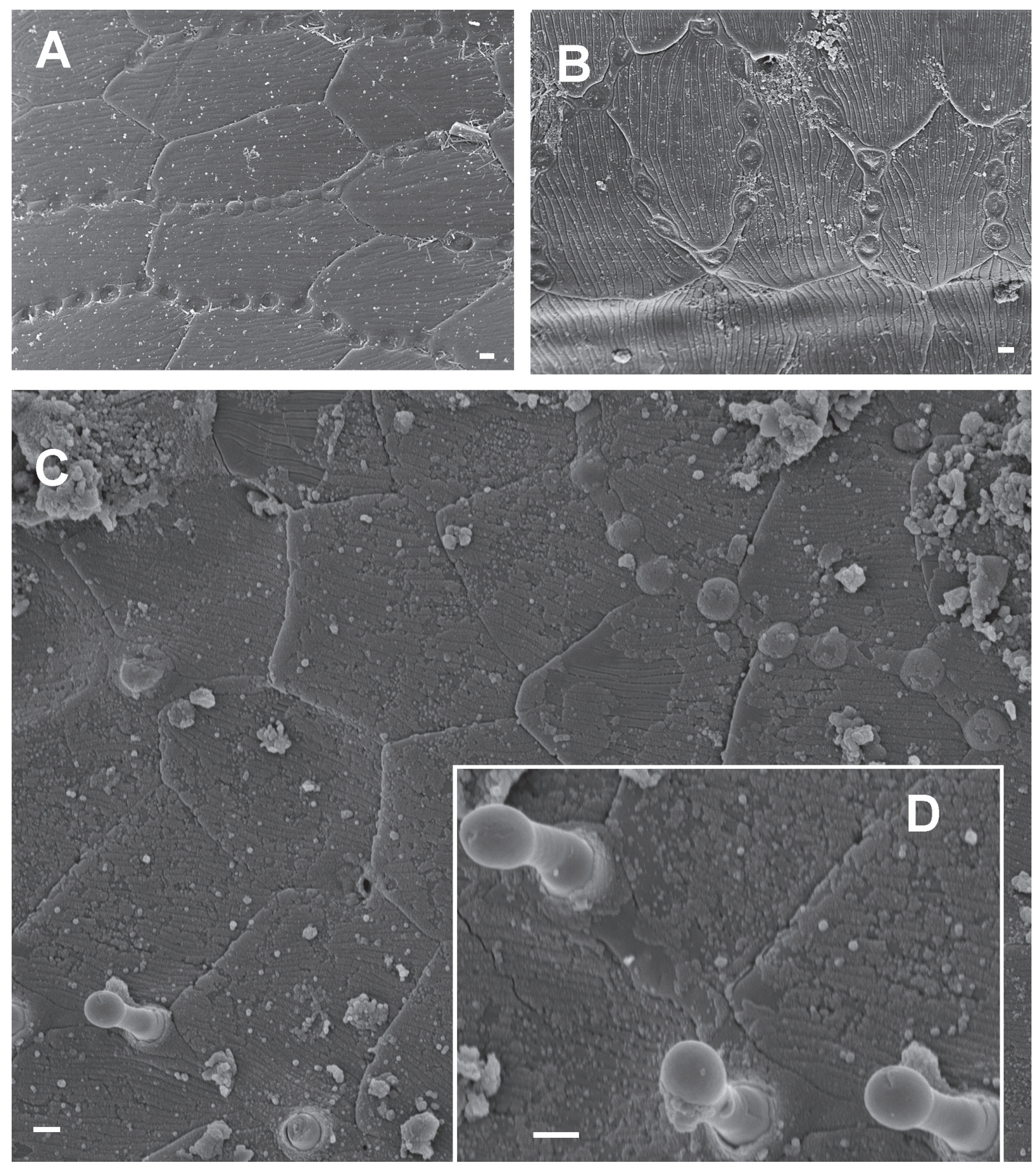

Fig. 34. Intercalary cuticular microscutes in Chaleponcus spp. A. C. netus sp. nov. B. C. tintin sp. nov. C-D. C. nikolajscharffi sp. nov. Fig. D shows fungus-like outgrowths from scutes. Scales $0.001 \mathrm{~mm}$. 
rise to projecting, club-shaped outgrowths of a few $\mu \mathrm{m}$ length (Fig. 34D) which may represent parasitic fungi of a kind?

\section{Discussion}

The high diversity of odontopygids, in casu the genus Chaleponcus, in forests at high elevations in the Udzungwa Mountains is impressive and somewhat unexpected: odotopygids in general "do not seem to be especially abundant at higher elevations" (Hoffman 1993). Collections of odontopygids at hand from other Eastern Arc mountain blocks are much less diverse.

All 21 Udzungwan Chaleponcus species belong to the morphologically well-defined C. dabagaensis group which is most probably monophyletic as suggested by the unique, potentially autapomorphic spine-bearing shelf on the gonopod coxa. No species referable to this group is known from elsewhere, and the $C$. dabagaensis group can therefore be regarded as an endemic high altitude Udzungwan 'species swarm'. To my knowledge, there are no similar examples of taxa which have radiated 'sympatrically' within the Udzungwa Mountains.

Too little microhabitat information is available to support a hypothesis of adaptive radiation similar to that observed in certain insular species swarms of millipedes (Enghoff 1983, 2011b; Enghoff \& Báez 1993). However, the frequent occurrence of multiple species in a sample (Table 1), in combination with the considerable inter-specific differences in body size (Figs 2-3), as well as the unusual tarsal setation of a few species (C. circumvallatus sp. nov., C. ibis sp. nov.), indicates that adaptive radiation may indeed have taken place.

\section{Acknowledgements}

This work would not have been possible at all without the impressive collections made by Frontier Tanzania. My sincere thanks are due to this NGO, as well as to Nikolaj Scharff and other colleagues at the Natural History Museum of Denmark who have also collected important material and have provided various advices. Further thanks are due to Judith Marshall and her colleagues in the Virginia Museum of Natural History for taking good care of me during my visit and for arranging loan of specimens from the collection of the late Richard Hoffman, to Luca Bartolozzi for loaning specimens from the Firenze museum, to Andy Marshall for advice, and to Nesrine Akkari and Sergei Golovatch for very useful comments on the manuscript.

\section{References}

Akkari N. \& Enghoff H. 2011. On some surface structures of potential taxonomic importance in families of the suborders Polydesmidea and Dalodesmidea (Polydesmida, Diplopoda). ZooKeys 156: 1-24. http:// dx.doi.org/10.3897/zookeys.156.2134

Barnet M. \& Telford S. 1996. Sperm competition and the evolution of millipede genitalia. Mémoires du Muséum national d'Histoire naturelle 169: 331-339.

Burgess N., Butinsky T.M., Cordeiro N.J., Doggart N.H., Fjeldså J., Howell K.M., Kilahama F.B., Loader S.P., Lovett J.C., Mbilinyi B., Menegon M., Moyer D.C., Nashanda E., Perkin A., Rovero F., Stanley W.T. \& Stuart S.N. 2007. The biological importance of the Eastern Arc Mountains of Tanzania and Kenya. Biological Conservation 134: 209-231. http://dx.doi.org/10.1016/j.biocon.2006.08.015

Enghoff H. 1983. Adaptive radiation of the millipede genus Cylindroiulus on Madeira: habitat, body size, and morphology (Diplopoda, Julida: Julidae). Revue d'Écologie et de Biologie du Sol 20: 403-415.

Enghoff H. 2011a. East African giant millipedes of the tribe Pachybolini (Diplopoda, Spirobolida, Pachybolidae). Zootaxa 2753: 1-41. 
Enghoff H. 2011b. The millipede genera Cylindroiulus and Dolichoiulus as examples of Macaronesian species swarms. In: Serrano A.R.M., Borges P.A.V., Boieiro M. \& Oromí P. (eds) Terrestrial Arthropods of Macaronesia - Biodiversity, Ecology and Evolution: 231-247. Sociedade Portuguesa de Entomologia, Lisboa.

Enghoff H. \& Báez M. 1993. Evolution of distribution and habitat patterns in endemic millipedes of the genus Dolichoiulus (Diplopoda: Julidae) on the Canary Islands. With notes on distribution patterns of other Canarian species swarms. Biological Journal of the Linnean Society 49: 277-301. http://dx.doi. org/10.1111/j.1095-8312.1993.tb00906.x

Enghoff H., Howell K.M. \& Hoffman R.L. in prep. Checklist of the millipedes (Diplopoda) of Tanzania.

Frederiksen S.B. 2013a. East African odontopygid millipedes 2: A new, geographically disjunct species of Chaleponcus (Attems 1914) from the Pare Mts, Tanzania (Diplopoda, Spirostreptida, Odontopygidae). Zootaxa 3636: 597-600. http://dx.doi.org/10.11646/zootaxa.3636.4.7

Frederiksen S.B. 2013b. East African odontopygid millipedes 3: Two new genera; Lamelloramus and Aquattuor proposed to contain three new species (Diplopoda, Spirostreptida, Odontopygidae). Zootaxa 3694: 59-66. http://dx.doi.org/10.11646/zootaxa.3694.1.4

Frederiksen S.B. \& Enghoff H. 2012. East African odontopygid millipedes 1: Five new species of Xystopyge (Attems, 1909) and a proposal for a new gonopod terminology (Diplopoda; Spirostreptida; Odontopygidae). Zootaxa 3485: 69-82.

Hoffman R.L. 1990. Myriapoda 4. Polydesmida: Oxydesmidae. Das Tierreich 107: i-xv + 1-512.

Hoffman R.L. 1991. What is Odontopyge? A solution to a long standing nomenclatorial enigma in the Diplopoda (Spirostreptida Odontopygidae). Tropical Zoology 4: 65-73. http://dx.doi.org/10.1080/0394 6975.1991.10539475

Hoffman R.L. 1993. Biogeography of East African montane forest millipedes. In: Lovett J. \& Wasser S.K. (eds) Biogeography and Ecology of the Rain Forests of Eastern Africa: 103-114. Cambridge University Press, Cambridge.

Hoffman R.L. 2005a. Monograph of the Gomphodesmidae, a Family of African Polydesmoid Millipeds. Verlag des Naturhistorischen Museums, Vienna.

Hoffman R.L. 2005b. Two new prepodesmine millipeds, genus Callistocilla, from Tanzania (Polydesmida: Chelodesmidae). Myriapodologica 8: 49-58.

Hoffman R.L. 2008. Two new genera of spirostreptid millipeds from central Africa, with a new terminology for male genitalia in the family Spirostreptidae (Diplopoda Spirostreptida). Tropical Zoology 21: 167-186.

Hoffman R.L. \& Howell K.M. 1985. A new Tanzanian genus and species of paradoxosomatid millipeds with medusiform gonopods (Diplopoda: Paradoxosomatidae). Revue de Zoologie africaine 99: 57-61.

Hoffman R.L. \& Howell K.M. 1996. Synopsis of Macrolenostreptini, a new tribe of Tanzanian spirostreptid millipeds (Diplopoda Spirostreptida). Tropical Zoology 9: 441-453. http://dx.doi.org/10.1 $\underline{080 / 03946975.1996 .10539322}$

Jolivet P. 1986. Le millepatte de Santo Antao (Iles du Cap Vert) ou comment une espèce inoffensive peut devenir un ravageur! L'Entomologiste 42: 45-56.

Kraus O. 1958. Myriapoden von Ostafrika (Tanganyika Territory). Veröffentlichungen des Überseemuseums in Bremen, Reihe A 3(1): 1-16.

Kraus O. 1960. Äthiopische Diplopoden I. Monographie der Odontopygidae-Odontopyginae (Diplopoda, Spirostreptoidea). Annalen van het Koninklijk Museum van Belgisch-Congo 82: 1-207. 
Kraus O. 1966. Phylogenie, Chorologie und Systematik der Odontopygoideen (Diplopoda, Spirostreptomorpha). Abhandlungen der Senckenbergischen naturforschenden Gesellschaft 512: 1-143.

Marshall A.R., Brink H. \& Topp-Jørgensen J.E. 2001a. Millipede diversity and distribution - West Kilombero Scarp Forest Reserve. In: Doody K.Z., Howell K.M., \& Fanning E. (eds) West Kilombero Scarp Forest Reserve - Zoological Report: 124-132. Report for the Udzungwa Mountains Forest Management and Biodiversity Conservation Project, MEMA, Iringa, Tanzania.

Marshall A.R., Brink H. \& Topp-Jørgensen J.E. 2001b. Millipede diversity and distribution in New Dabaga/Ulangambi Forest Reserve. In: Doody K.Z., Howell K.M., \& Fanning E. (eds) New Dabaga/ Ulangambi Forest Reserve - Zoological Report: 108-116. Report for the Udzungwa Mountains Forest Management and Biodiversity Conservation Project, MEMA, Iringa, Tanzania.

Marshall A.R., Jørgensbye H.I.O., Rovero F., Platts P.L., White P.C.L. \& Lovett J.C. 2010. The speciesarea relationship and confounding variables in a threatened monkey community. American Journal of Primatology 72: 325-336. http://dx.doi.org/10.1002/ajp.20787

Myers N., Mittermeier R.A., Mittermeier C.G., da Fonseca G.A.B. \& Kent J. 2000. Biodiversity hotspots for conservation priorities. Nature 403: 853-858. http://dx.doi.org/10.1038/35002501

Nascimento B. 2012. Applied research on millipede Bandeirenica caboverdus (Diplopoda, Odontopygidae) and the end of quarantine restrictions. Acta Horticulturae 934: 417-420.

Vohland K. \& Hamer M. 2013. A review of the millipedes (Diplopoda) of Namibia, with identification keys and descriptions of two new genera and five new species. African Invertebrates 54: 251-304.

Manuscript received: 11 August 2014

Manuscript accepted: 24 September 2014

Published on: 24 October 2014

Topic editor: Rudy Jocqué

Desk editor: Kristiaan Hoedemakers

Printed versions of all papers are also deposited in the libraries of the institutes that are members of the EJT consortium: Muséum National d'Histoire Naturelle, Paris, France; Botanic Garden Meise, Belgium; Royal Museum for Central Africa, Tervuren, Belgium; Natural History Museum, London, United Kingdom; Royal Belgian Institute of Natural Sciences, Brussels, Belgium; Natural History Museum of Denmark, Copenhagen, Denmark. 